\title{
AVALIAÇÃO DA PREVALÊNCIA DA DISFUNÇÃO TEMPOROMANDIBULAR (DTM) EM PACIENTES TRATADOS DAS MÁS OCLUSÕES DE CLASSE III, SUBMETIDOS A TRATAMENTO ORTODÔNTICO E ORTO-CIRÚRGICO
}

KARYNA MARTINS DO VALLE-COROTTI

EDIÇÃO REVISADA

Tese apresentada à Faculdade de Odontologia de Bauru, da Universidade de São Paulo, como parte dos requisitos para obtenção do título de Doutor em Odontologia, área de Ortodontia. 


\section{AVALIAÇÃO DA PREVALÊNCIA DA DISFUNÇÃO TEMPOROMANDIBULAR (DTM) EM PACIENTES TRATADOS DAS MĀS OCLUSÕES DE CLASSE III, SUBMETIDOS A TRATAMENTO ORTODÔNTICO E ORTO-CIRÚRGICO}

KARYNA MARTINS DO VALLE-COROTTI

EDIÇÃO REVISADA

Tese apresentada à Faculdade de Odontologia de Bauru, da Universidade de São Paulo, como parte dos requisitos para obtenção do título de Doutor em Odontologia, área de Ortodontia.

Orientador: Prof. Dr. Arnaldo Pinzan

BAURU

2004 
Valle-Corotti, Karyna Martins do

V242a Avaliação da Prevalência da Disfunção Temporomandibular (DTM) em Pacientes Tratados das Más Oclusões de Classe III, submetidos a Tratamento Ortodôntico e Orto-Cirúrgico / Karyna Martins do ValleCorotti, 2004.

139p.: il.; $30 \mathrm{~cm}$

Tese. (Doutorado) - Faculdade de Odontologia de Bauru. USP.

Orientador: Prof. Dr. Arnaldo Pinzan

Autorizo, exclusivamente para fins acadêmico e científico, a reprodução total ou parcial desta dissertação, por processos fotocopiadores e/ou meios eletrônicos.

Assinatura do autor (a):

Data:

Comitê de Ética da FOB: Projeto de pesquisa aprovado em 24 de setembro de 2003.

$N^{\circ}$ do Protocolo: Processo No $098 / 2003$ 


\section{KARYNA MARTINS DO VALLE-COROTTI}

17 de agosto de $1974 \quad$ Nascimento - Bauru, SP.

$1993-1996$

Faculdade de Odontologia de Bauru, USP.

$1997-1998$

Curso de Aperfeiçoamento em Oclusão e Disfunção Craniomandibular.

$1998-2000$

Curso de Pós-Graduação em Ortodontia, ao nível de Mestrado, na Faculdade de Odontologia de Bauru, USP.

2001-2004

Curso de Pós-Graduação em Ortodontia, ao nível de Doutorado, na Faculdade de Odontologia de Bauru, USP. 
Ao Senhor da minha vida, Santo e Eterno Deus, merecedor de toda a honra e glória, que está à frente dos mens caminhos, minha paz e fortaleza, sempre fiel, derramando Sua graça e amor, a ti dedico o meu louvor pelas infinitas bênçãos. 
Ao Mauro, por todo amor a mim dedicado, que tornou suaves as minhas dificuldades e transformou em realidade os meus sonhos.

Aos meus pais, Accacío e Tânía, que com amor, carinho e muita dedicação, me incentivaram, com sábias orientações, a enfrentar mais esta etapa, sendo constantemente exemplos de vida.

Aos meus irmãos, Caío e Larissa, que com alegria e amizade fiel me apoiaram em todos os momentos.

Dedico este trabalho. 


\section{AGRADECIMENTOS ESPECIAIS}

À toda minha família que sempre me dedicaram amor e atenção. Aos meus avós Accácio, Nilda e João que nunca esqueceram de mim em suas orações.

À Ana Aida pela atenção e carinho a mim dedicado durante toda a minha vida.

A todos os meus amigos e irmãos em Cristo, que me sustentaram em oração durante a execução deste trabalho. 
Aos professores

\section{Doutor Arnaldo Pinzan}

Agradeço por ter me orientado com paciência e respeito, pelo exemplo de conduta profissional, sempre demonstrando humanidade e carinho, que serviram-me de estímulo durante estes anos de convivência.

\section{Doutor Paulo César Rodrigues Conti}

Agradeço a atenção, carinho e disposição em esclarecer minhas dúvidas. Obrigada pelo incentivo e pela amizade, mostrando-se sempre pronto a me ajudar.

\section{Doutor Laurindo Zanco Furquim}

Por todo carinho e colaboração que possibilitaram a execução deste trabalho. 


\section{AGRADECIMENTOS}

À Professora Doutora Maria Fidela de Lima Navarro, diretora desta Faculdade, pelo incentivo transmitido.

Ao Professor Doutor José Carlos Pereira, Presidente da Comissão de Pós-Graduação da FOB-USP, pela compreensão e amizade.

Aos Professores Doutores da Disciplina de Ortodontia da Faculdade de Odontologia de Bauru,

Prof. Dr. DÉCIO RODRIGUES MARTINS, Prof. Dr. RENATO RODRIGUES DE ALMEIDA, Prof. Dr. JOSÉ FERNANDO CASTANHA HENRIQUES, Prof. Dr. MARCOS ROBERTO DE FREITAS, Prof. Dr. GUILHERME DOS REIS PEREIRA JANSON, e às suas respectivas famílias, pelos ensinamentos e experiências transmitidos, pelo incentivo e apoio constantes, e pela confiança e carinho a mim dispensados. 


\section{Aos Professores Doutores desta Faculdade, pela}

orientação e motivação transmitidos durante toda a minha formação acadêmica.

Aos amigos do Curso de Doutorado,

\section{Adriano Lia Mondelli}

Ana Carla Raphaelli Nahás

Daniela Gamba Garib Carrera

Danilo Furquim Siqueira

Fausto Bramante

Karina Santana Cruz

Paulo Eduarde Guedes Carvalho

Renata Almeida Pedrin

por todos os momentos que passamos juntos, pelo carinho, amizade e respeito durante estes anos. Vocês foram fundamentais para a conclusão deste curso. 
Aos funcionários da Disciplina de Ortodontia, por toda a amizade e atenção durante o nosso convívio, desde o curso de Mestrado.

Aos funcionários da Pós-Graduação, pela ajuda e dedicação com que sempre me atenderam.

Aos funcionários da Biblioteca pela atenção e amizade sempre prontos a me ajudarem.

Aos funcionários desta Faculdade pela dedicação a mim transmitidos.

Aos pacientes da Graduação e Pós-Graduação pela colaboração para minha formação.

À Capes pela concessão da bolsa de estudos que viabilizou a execução desta pesquisa. 


\section{SUMÁRIO}

LISTA DE FIGURAS Xii

LISTA DE TABELAS Xiii

LISTA DE ABREVIATURAS Xiv

RESUMO XV XV

1 - INTRODUÇÃO

2 - REVISÃO DA LITERATURA $\quad 8$

2.1 - Disfunção Temporomandibular $\quad 9$

$\begin{array}{ll}2.2 \text { - Oclusão } & 17\end{array}$

2.3 - Má Oclusão e Tratamento Ortodôntico 32

2.4 - Deformidade Dentofacial e Cirurgia Ortognática 46

3 - PROPOSIÇÃO

4 - MATERIAL E MÉTODOS

5 - RESULTADOS 66

5.1 - Resultados Descritivos $\quad 67$

$\begin{array}{ll}5.2 \text { - Resultados Analíticos } & 77\end{array}$

6 - DISCUSSÃO

6.1 - Dados Gerais e Prevalência de DTM 90

6.2 - Movimentos Mandibulares 93

6.3 - Palpação Articular e Muscular 94

6.4 - Oclusão Morfológica 995 
6.5 - Aspectos Oclusais $\quad 99$

6.6 - Tipo de Tratamento 104

6.7 - Considerações Gerais 108

7- CONCLUSÕES 111

$\begin{array}{ll}\text { ANEXOS } & 113\end{array}$

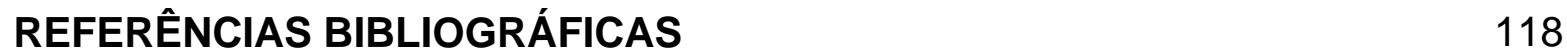

$\begin{array}{lr}\text { ABSTRACT } & 137\end{array}$

$\begin{array}{ll}\text { APÊNDICE } & 139\end{array}$ 


\section{LISTA DE FIGURAS}

Figura 5.1 Gráfico da distribuição da amostra, dividida por grupos, em relação ao índice de DTM

Figura 5.2 Gráfico da relação entre a presença de RC coincidente com MIH e o grau de DTM

Figura 5.3 Gráfico da relação entre os contatos oclusais em não-trabalho e o grau de DTM

Figura 5.4 Gráfico da relação entre o tipo de extração e o grau de DTM 85

Figura 5.5 Gráfico da relação entre as bases ósseas e o grau de DTM 86

Figura 5.6 Gráfico da relação entre o tipo de contenção e o grau de DTM 


\section{LISTA DE TABELAS}

Tabela 5.1 Freqüência percentual das respostas do questionário anamnésico pelo grupo I (Classe III com tratamento ortodôntico)

68

Tabela 5.2 Freqüência percentual das respostas do questionário anamnésico pelo Grupo II (Classe III tratados com cirurgia ortognática)

68

Tabela 5.3 Distribuição da amostra, dividida por grupos, em relação ao índice de DTM

Tabela 5.4 Relação entre a mordida aberta anterior (MAA) e o grau de DTM

Tabela 5.5 Relação entre a mordida cruzada posterior (MCP) e o grau de

DTM

Tabela 5.6 Relação sagital e grau de DTM

Tabela 5.7 Relação entre a discrepância de RC para MIH e o grau de DTM

80

Tabela 5.8 Relação presença de RC coincidente com MIH e o grau de DTM

Tabela 5.9 Relação entre o guia lateral e o grau de DTM

Tabela 5.10 Relação entre a guia anterior e o grau de DTM

Tabela 5.11 Relação entre as interferências oclusais em não-trabalho e o grau de DTM

Tabela 5.12 Relação entre tipo de aparelho e o grau de DTM

Tabela 5.13 Relação entre o tipo de extração e o grau de DTM

Tabela 5.14 Relação entre as bases ósseas e o grau de DTM

Tabela 5.15 Relação entre o tipo de contenção e o grau de DTM 


\section{LISTA DE ABREVIATURAS}

ATM - Articulação Temporomandibular.

DTM - Disfunção Temporomandibular.

IO - Interferência Oclusal.

LDP - Limiar de Dor à Pressão.

MIH - Máxima Intercuspidação Habitual.

MAA - Mordida aberta anterior.

MCP - Mordida cruzada posterior.

OOR - Osteotomia Oblíqua do Ramo.

ORC - Oclusão de Relação Cêntrica.

OSR - Osteotomia Sagital do Ramo.

RC - Relação Cêntrica.

PI - Posição de Intercuspidação.

PR - Posição Retruída. 
RESUMO 


\section{RESUMO}

O objetivo deste estudo foi avaliar a prevalência de Disfunção Temporomandibular (DTM) em indivíduos tratados das más oclusões iniciais de Classe III. Os 50 casos avaliados foram divididos em dois grupos, sendo o grupo I composto de 25 pacientes tratados ortodonticamente e o grupo II de 25 pacientes submetidos a tratamento ortodôntico seguido de cirurgia ortognática. Um questionário relativo aos principais sintomas de DTM, permitiu a classificação da amostra de acordo com a presença e a severidade de DTM. Foi realizado exame físico para avaliação articular, muscular e oclusal. Baseado no questionário anamnésico encontrou-se a prevalência de $42 \%$ com DTM leve, 10\% com DTM moderada e $48 \%$ apresentavam-se com ausência de DTM. Os testes estatísticos aplicados nesta pesquisa foram o "t" de Student para os dados paramétricos, o Mann-Witney para os dados não paramétricos e o Qui-quadrado que analisou a associação entre o índice de DTM e as demais variáveis. Os resultados indicaram que os grupos estudados não apresentaram diferenças significativas quanto ao índice de DTM. Por outro lado observou-se associação entre a severidade de DTM e a presença de interferências em lado de não-trabalho. Concluiu-se, com base na amostra estudada, que os tratamentos das más oclusões de Classe III não se relacionam com a presença e severidade de DTM. 
INTRODUÇÃO 


\section{1 - INTRODUÇÃO}

Disfunção Temporomandibular (DTM) é um termo que compreende alterações clínicas caracterizadas por sinais e sintomas nos músculos da mastigação, na articulação temporomandibular (ATM) ou em ambos ${ }^{91}$.

A Disfunção Temporomandibular tem sido estudada desde o início do século passado tornando-se conhecida, na literatura mundial, quando COSTEN ${ }^{19}$, em 1934 publicou um trabalho descrevendo um conjunto de sintomas conhecido como Síndrome de Costen. Desde então, muitos pesquisadores $8,16,19,23,28,30,37,38,4248,49,50,68,95,96,107,11,117,121$ investigam as características desta doença, sua etiologia, seu tratamento e sua relação com as diferentes especialidades odontológicas. A influência da hiperatividade muscular consagrou o termo Síndrome Dor-Disfunção Miofascial ${ }^{68}$. Porém, MCNEILL ${ }^{80,81}$ propôs: Desordens Craniomandibulares, conhecidas pela sigla DCM, associada ao termo dor orofacial. BELL ${ }^{7}$ sugeriu o termo Desordem Temporomandibular, também conhecido como Disfunção Temporomandibular (DTM).

O grande impulso na área dos estudos epidemiológicos das DTM se concretizou com $\mathrm{HELKIMO}^{47,}{ }^{48}$, que elaborou um índice clínico e um índice anamnésico que mede quantitativamente a severidade dos sintomas da Disfunção Temporomandibular. Em 1992, FONSECA ${ }^{35}$ verificou um índice de confiabilidade de 95\% de um questionário anamnésico, quando comparado ao índice clínico modificado de $\mathrm{HELKIMO}^{47,}{ }^{48}$, devido à alta correlação entre respostas do questionário e achados clínicos, indicando o seu uso em pesquisas epidemiológicas. 
Com a efetividade comprovada do método de avaliação utilizado em pesquisas epidemiológicas, procurou-se estabelecer a prevalência da DTM na população. Em 1996, CONTI et al ${ }^{17}$ observaram em uma amostra de 310 jovens com média de idade de 18,8 anos, uma prevalência de 49,35\% de DTM leve, 10,32\% moderada e $0,97 \%$ severa. Concluíram que embora a prevalência seja relativamente alta, a necessidade de tratamento (DTM moderada e severa) para o grupo estudado foi de $11,29 \%$. Resultados semelhantes foram encontrados por VALLE-COROTTI ${ }^{121}$, ao avaliar uma população de 200 pacientes com más oclusões de Classes I e II, com e sem tratamento ortodôntico, que encontrou níveis de DTM ausente em 62,5\% da amostra; DTM leve em 34\%; DTM moderada em 3,5\%, o que demonstra uma pequena parcela da população precisando de tratamento para a disfunção.

A partir dos anos 80, muitas foram as pesquisas realizadas envolvendo a ortodontia enquanto causa ou cura da Disfunção Temporomandibular, pois se acreditava que a má oclusão era um fator de risco para os sinais e sintomas da disfunção ${ }^{51}$, tornando-a um possível tratamento para os mesmos ${ }^{30}$. Por outro lado, suspeitava-se quanto à possibilidade do envolvimento do tratamento ortodôntico enquanto causa ou fator de risco da Disfunção Temporomandibular. Desde então muitos pesquisadores têm se empenhado em descobrir qual a relação entre as alterações do sistema mastigatório, má oclusão funcional, má oclusão morfológica e o tratamento ortodôntico.

Entre as alterações oclusais funcionais encontram-se: o desvio entre a posição de relação cêntrica $(R C)$ e a máxima intercuspidação habitual $(M I H)$, contatos em lado de trabalho e não-trabalho, ausência de guias laterais ou protrusiva e interferências nas guias de desoclusão. Embora, muitos autores tenham 
demonstrado que não se pode afirmar que as alterações oclusais sejam responsáveis pela DTM ${ }^{3,95}$, desvinculando a relação entre a oclusão funcional e a DTM, BELL et $\mathrm{al}^{8}$, em um estudo recente, sugeriram que as interferências oclusais podem ser consideradas como fator etiológico.

As más oclusões classificadas como: Classes I, II, e III de Angle, mordida aberta, mordida cruzada, e alterações de overjet e overbite, que podem envolver o componente ósseo e/ou dentário, são consideradas alterações morfológicas que comumente necessitam de tratamento ortodôntico. Embora muitas

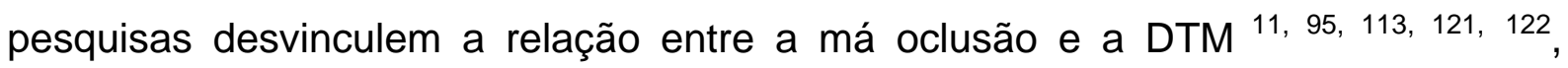
algumas alterações ainda são associadas aos sinais e sintomas da disfunção como: distância entre as posições de RC para MIH maior que $4 \mathrm{~mm}$, ausência de guia anterior e overjet maior que $6 \mathrm{~mm}$ podendo ser consideradas como fatores de risco ${ }^{51}$. Entretanto, a literatura não esclarece uma relação entre a má oclusão de Classe III, seu tratamento e a Disfunção Temporomandibular.

Sabe-se que a má oclusão de Classe III envolve, em sua maior parte, o componente esquelético, caracterizado principalmente pelo prognatismo mandibular e freqüentemente acompanhado de assimetria ${ }^{45}$. Existem relatos na literatura ${ }^{22,64,94}$ que relacionam a Disfunção Temporomandibular e as deformidades dentofaciais, entretanto a prevalência de DTM nestes pacientes ainda representa uma controvérsia.

DAHLBERG et $\mathrm{al}^{22}$ demonstraram alta incidência de DTM em pacientes com deformidades dentofaciais, enquanto PANULA et al $^{94}$ relataram que não existe associação entre a disfunção e algum tipo específico ou magnitude de deformidade dentofacial. As discrepâncias ósseas que caracterizam as 
deformidades dentofaciais muitas vezes necessitam de intervenção cirúrgica para a sua correção e de acordo com LASKIN; RYAN; GREENE ${ }^{69}$, grande parte da população que necessita de cirurgia ortognática é saudável quanto a Disfunção Temporomandibular.

KOBAYASHI et al ${ }^{64}$ observaram a presença de sinais e sintomas de disfunção articular em 35\% de uma amostra composta por pacientes com prognatismo mandibular, e que entre os pacientes com assimetria associada ao prognatismo, 58\% apresentavam deslocamento de disco. Estes autores concluíram que a morfologia esquelética pode apresentar um papel no desenvolvimento da DTM, mas o seu mecanismo foi considerado obscuro. Os aspectos morfológicos da Classe III esquelética também foram considerados como possível fator de risco para o desenvolvimento do deslocamento de disco por MUTO et $\mathrm{al}^{87}$. De encontro com estes achados está o resultado do estudo realizado por SANROMÁN; GONZÁLES; HOYO $^{108}$ que observaram uma incidência de degeneração interna da ATM inferior a 10\% em um grupo de má oclusão de Classe III.

HARAGUCHI; TAKADA; YASUDA ${ }^{45}$ consideraram que as alterações na Articulação Temporomandibular (ATM), em uma população com má oclusão de Classe III, podem ser a causa da assimetria esquelética presente nesta má oclusão. Considerando que a assimetria facial está comumente associada ao prognatismo mandibular e que os sinais e sintomas da DTM estão presentes em pacientes com esta deformidade dentofacial, parece justo afirmar que a má oclusão de Classe III está relacionada com a presença de sinais e sintomas da DTM. Entretanto não existem relatos científicos que dêem base para esta afirmação. 
A má oclusão de Classe III pode ter envolvimento dentoalveolar e/ou esquelético e para cada caso existe um protocolo de tratamento diferente. $\mathrm{O}$ tratamento pode ser ortodôntico, ortopédico (quando ainda existe potencial de crescimento), ou ortodôntico seguido de cirurgia ortognática, quando existe envolvimento esquelético no paciente adulto.

As pesquisas têm demonstrado a não associação entre o tratamento ortodôntico e a DTM, afirmando que a intervenção ortodôntica não pode ser considerada como causa, cura ou prevenção da disfunção ${ }^{16,52,121}$. Entretanto, na sua grande maioria, as amostras são predominantemente de pacientes com más oclusões de Classe I e II.

Outra questão que envolve a relação com a DTM é a cirurgia ortognática, pois o paciente adulto portador da má oclusão de Classe III com envolvimento esquelético, comumente necessita de tratamento ortodôntico associado à cirurgia ortognática. Como vimos anteriormente, existe uma possível relação entre a alteração esquelética, considerada como deformidade dentofacial, e a DTM, embora não comprovada cientificamente. Estes casos necessitam de tratamento orto-cirúrgico devido ao envolvimento esquelético e este fato aproxima a cirurgia ortognática de uma possível inter-relação com a DTM.

O tratamento orto-cirúrgico da má oclusão de Classe III esquelética pode apresentar efeitos favoráveis na ATM e na função da mandíbula ${ }^{88,94}$. Esta melhora na condição da ATM pode estar relacionada com o tipo de osteotomia realizada ${ }^{55}$ ou com o tipo de fixação utilizada ${ }^{34}$. A reabsorção condilar também foi observada após a cirurgia ortognática realizada com osteotomia sagital bilateral na mandíbula ${ }^{54}$. 
Os resultados presentes na literatura são contraditórios quanto à relação entre a má oclusão de Classe III, a cirurgia ortognática e a Disfunção Temporomandibular e oferecem suporte para a realização deste estudo que pretende avaliar a prevalência da DTM e as condições oclusais em uma amostra de pacientes com má oclusão de Classe III tratados ortodôntica e cirurgicamente. 
REVISÃO DA LITERATURA 


\section{2 - REVISÃO DA LITERATURA}

\section{1 - DISFUNÇÃO TEMPOROMANDIBULAR}

A preocupação com os problemas do sistema mastigatório não é um produto dos tempos modernos, pois os distúrbios funcionais e as sintomatologias que afligem o sistema estomatognático possuem registros bastante remotos.

Apesar de alguns artigos pioneiros no assunto, a literatura torna clássico o trabalho do otorrinolaringologista James B. COSTEN ${ }^{19}$, em 1934, considerado a primeira descrição detalhada da origem e sintomas dos problemas articulares. Seu estudo baseou-se na descrição dos sintomas de 11 pacientes onde incluíam dor ao redor dos ouvidos, zumbidos, dores de cabeça, secura na boca e garganta e ruídos articulares. Este conjunto de sintomas foi caracterizado como síndrome de Costen. O autor acreditava ainda que a perda dos dentes posteriores causava sobremordida, resultando em aumento da pressão dos côndilos nas estruturas retrocondilares e que a compressão destas estruturas, principalmente dos vasos e nervos auriculotemporais e do meato acústico externo, resultava nesta sintomatologia.

SCHWARTZ ${ }^{111}$, em 1955, sugeriu o termo síndrome dor-disfunção da ATM e afirmou que sua causa era principalmente a disfunção dos músculos mastigatórios, considerando as anormalidades oclusais apenas fatores contribuintes e os fatores psicogênicos como primários.

Em 1969, LASKIN ${ }^{68}$ propôs uma revisão da síndrome dor-disfunção da ATM de SCHWARTZ ${ }^{111}$ e observou que o espasmo dos músculos mastigatórios 
seria o fator primário responsável pelos sintomas, passando a utilizar o termo síndrome dor-disfunção miofascial. As causas dessa fadiga muscular seriam hábitos bucais crônicos, que agiriam como mecanismos involuntários de alívio de tensão. Assim, considerou-se a síndrome dor-disfunção como uma doença psicológica, com alterações orgânicas que mais tarde poderiam ser notadas nos dentes e ATMs como um fenômeno secundário. Os fatores como desarmonias oclusais e artrite degenerativa agiriam como perpetuantes do processo.

AGERBERG; CARLSSON ${ }^{1}$, em 1972, estudaram a freqüência das desordens funcionais do sistema mastigatório pela avaliação das respostas de um questionário, que abrangeu uma amostra de 1.106 pessoas com média de 35 anos. Dores faciais e de cabeça foram relatadas por $24 \%$ dos indivíduos, enquanto a restrição do movimento mandibular constou da resposta de $7 \%$ da amostra, sendo mais freqüente nas mulheres, assim como o ruído articular, presente em 39\% dos entrevistados. Os autores concluíram que os dentistas devem se interessar mais pelo diagnóstico e tratamento destas desordens funcionais, devido aos altos índices de disfunção.

Dando continuidade à pesquisa anterior, AGERBERG; CARLSSON², no ano seguinte, formularam um índice baseado nas respostas do trabalho inicial. Os resultados encontrados mostraram maiores valores para mulheres, porém, com diferenças numericamente pequenas. A presença de um único sintoma de disfunção foi encontrado em $57 \%$ e a combinação de dois ou mais, em $30 \%$ da amostra. Concluíram que sintomas de disfunção mastigatória são comuns e de etiologia heterogênea. 
GOSS $^{41}$, em 1974, revisou os conceitos relativos à etiologia e diagnóstico da dor-disfunção miofascial. Observou dois grupos envolvidos com esta síndrome: o primeiro composto por indivíduos dentados dos 17 aos 25 anos e o segundo, composto por adultos desdentados (com mais de 30 anos). $\mathrm{O}$ autor afirmou que as mulheres são afetadas quatro vezes mais que os homens e que a síndrome surge a partir de espasmos dos músculos da mastigação ocorridos devido à tensão emocional e a má oclusão. O autor concluiu que existe uma variedade enorme de manifestações clínicas da síndrome, mas as quatro mais importantes, consideradas sinais cardinais, são: a dor, o espasmo muscular, a crepitação auricular e a disfunção muscular.

O grande impulso na área dos estudos epidemiológicos se deu com HELKIMO $^{47,48}$, que em 1974, publicou uma série de trabalhos sobre a função e a disfunção do sistema mastigatório e elaborou um índice anamnésico e um índice clínico de disfunção que mede, quantitativamente, a severidade dos sintomas em três níveis (sem sintomas, médio, severo) e o índice clínico, em quatro níveis (sem sinais, leve, moderado, severo).

HELKIMO ${ }^{49}$ observou que nos indivíduos onde o índice anamnésico mostrava-se severo, $75 \%$ apresentavam pelo menos um sinal clínico severo e $44 \%$ possuíam dois ou mais. Nos pacientes livres de sintomas, apenas 18\% estavam totalmente assintomáticos clinicamente. Concluiu que o índice realmente mede o que é proposto, sendo de grande valia na identificação das disfunções do sistema mastigatório.

Em relação à idade, $\mathrm{HELKIMO}^{50}$ relatou grande diversificação da prevalência dependendo do sintoma estudado, sendo que pacientes entre 15 e 24 
anos apresentavam menor freqüência de sintomas. Já em relação ao gênero, houve a mesma prevalência entre homens e mulheres. $\mathrm{O}$ autor concluiu que estes dados em relação ao gênero e idade diferem dos artigos prévios e não são representativos para a população em geral.

Em 1979, WIGDOROWICZ - MAKOWEROWA et $\mathrm{al}^{128}$. realizaram um estudo epidemiológico sobre a prevalência e etiologia dos distúrbios do sistema mastigatório. Cinco populações de diferentes idades e ocupações receberam exame clínico e análise psicológica subjetiva. O aumento da tensão psicoemocional, má oclusão e fatores iatrogênicos foram avaliados como fatores etiológicos. Os autores concluíram que tais distúrbios são causados por fatores locais que interferem com a oclusão normal e também pelo aumento da tensão psicoemocional. Afirmaram ainda, que fatores traumáticos como bruxismo e má oclusão aumentam a freqüência de disfunção da ATM, independente da idade ou ambiente, e que os fatores ambientais e condições de vida exercem importante papel na freqüência dos distúrbios, relatando que o estresse mental e a responsabilidade no trabalho são importantes.

MAGNUSSON; EGERMARK-ERIKSSON; CARLSSON ${ }^{78}$, em 1986, realizaram um estudo longitudinal dos sinais e sintomas de disfunções mandibulares em 135 adolescentes. Os pacientes foram examinados aos 15 anos e posteriormente aos 20 . Os autores utilizaram o índice de HELKIMO ${ }^{47,48}$ e obtiveram como resultado um aumento na ocorrência dos sintomas subjetivos, porém o índice clínico de disfunção não se mostrou alterado com o aumento da idade da amostra. Relataram ainda, que em ambas as épocas, os ruídos articulares foram os achados mais freqüentes, enquanto aos 20 anos houve aumento nos hábitos parafuncionais. 
Na década seguinte, FONSÊCA ${ }^{35}$ (1992) propôs-se a verificar a confiabilidade de um questionário anamnésico, comparado ao índice clínico modificado de HELKIMO ${ }^{47}$, ${ }^{48}$, avaliando 120 pacientes com DTM. Foi obtido um índice de confiabilidade de $95 \%$ devido à alta correlação entre respostas do questionário e achados clínicos, levando à sugestão da adoção desse índice anamnésico, devido as suas vantagens de menor custo e rapidez, para pesquisas epidemiológicas e em serviços públicos.

CONTI et al. ${ }^{17}$ (1996) avaliaram a prevalência e a necessidade de tratamento de DTM em estudantes de cursos pré-universitários da cidade de BauruSP, analisando os fatores psicológicos e oclusais como agentes etiológicos. Avaliaram 310 estudantes por questionário anamnésico, exame oclusal, palpação muscular e das ATMs. A análise estatística mostrou uma relação entre a presença e o grau de DTM e os aspectos oclusais, psicológicos e sensibilidade à palpação. Concluíram que: a) a prevalência de DTM foi de 49,35\% leve, 10,32\% moderada e 0,97\% severa; b) as mulheres apresentaram uma prevalência de DTM maior que os homens; c) não houve diferença estatística significativa entre os grupos estudados; d) a oclusão não apresentou participação na severidade da DTM; e e) a palpação muscular mostrou-se efetiva para se detectar a DTM. Apesar da prevalência ser relativamente alta, a necessidade de tratamento (DTM moderada e severa) para o grupo estudado foi de $11,21 \%$.

Em 1997, HESSE; VAN LOON; NAEIJE ${ }^{53}$ compararam: (1) o relato subjetivo de dor e o resultado de testes estáticos e dinâmicos para dor, e (2) o resultado de alguns testes ortopédicos em pacientes assintomáticos e com sinais e sintomas de DTM com dor recente. Foram selecionados 32 pacientes com sinais e 
sintomas compatíveis com DTM após responderem a um questionário de relato de sintomas, que apresentavam dor na região dos músculos mastigatórios ou na ATM e 22 indivíduos fizeram parte do grupo controle. Alta correlação foi encontrada entre os pacientes que relataram dor na articulação ou dor muscular através do questionário e a classificação obtida como paciente articular ou paciente muscular, baseado no resultado dos testes dinâmicos e estáticos $(p=0,0003)$.

CARLSON et al. ${ }^{12}, 1998$, identificaram variáveis psicológicas e fisiológicas que diferenciam pacientes com dor nos músculos da mastigação de indivíduos assintomáticos. Para esse propósito, foram selecionados 35 pacientes com dor facial (média de 30,17 anos), sendo que 33 eram mulheres e 35 indivíduos (média de 30,14 anos), sem dor, com a mesma proporção homem/mulher para o grupo controle. Toda a amostra respondeu uma série de questionários e se submeteu a uma avaliação laboratorial da quantificação do estresse e de estimulação através de pressão em determinados pontos do corpo (masséter, temporal e dedo médio). Durante a avaliação, a condição emocional e fisiológica dos indivíduos (pressão arterial, respiração, temperatura da pele, atividade muscular) foi monitorada. Os resultados mostraram que pessoas com dor muscular reportaram maior fadiga, distúrbios do sono, depressão, ansiedade, sintomas menstruais e menor auto-estima em comparação com os indivíduos do grupo controle.

No ano seguinte, LIST et al. ${ }^{72}$ fizeram um estudo a fim de determinar a prevalência de dor relacionada à DTM, às diferenças entre os gêneros, e à necessidade de tratamento em crianças e adolescentes. Responderam a um questionário 862 crianças e adolescentes, com idade entre 12 e 18 anos. Além disso, em cada indivíduo, foi tomado o grau de abertura bucal. Os indivíduos que 
reportaram dor 1 vez por semana ou mais no sistema mastigatório receberam um exame mais detalhado e formaram o grupo 1. O grupo 2 foi composto por aqueles que reportaram dor com freqüência menor que 1 vez por semana. Do total da amostra, $7 \%$ foi diagnosticado como pacientes de DTM. A prevalência de dor encontrada se mostrou na seguinte proporção: $21 \%$ na cabeça; $12 \%$ na região da têmpora; e 3\% na face, na ATM ou nos maxilares. A prevalência de dor relacionada com DTM foi significativamente maior nas meninas que nos meninos. Quanto à intensidade não foram encontradas diferenças entre os gêneros no grupo 1. Os autores concluíram que a dor relacionada com DTM é mais prevalente em meninas do que em meninos.

Em 2000, FREDRIKSSON; ALSTERGREN; KOPP ${ }^{36}$ compararam os níveis entre o limiar de dor à pressão (LDP) em pontos testes (masseter, temporal anterior e aspecto lateral da ATM) e em pontos de referência (protuberância mental, metacarpo e $1 \mathrm{~cm}$ acima da glabela), utilizando um algômetro. A amostra estudada constou de 12 homens (média de idade de 29 anos) e 12 mulheres (média de idade de 35 anos), sendo todos livres de sinais e sintomas de DTM. Realizaram 5 exames consecutivos, com intervalos de 2 minutos, em cada paciente, e outro após 6 meses, com um algômetro. O limiar de dor diminuiu entre os 5 testes iniciais e aumentou entre o primeiro e o segundo exame. Os homens apresentaram limiares significativamente maiores em relação às mulheres. Os autores concluíram que os LDP em indivíduos saudáveis variaram durante as tomadas consecutivas e após 6 meses.

CONTI et al ${ }^{18}$, em 2003, investigaram a prevalência das cefaléias primárias, das DTMs e da ocorrência simultânea destas patologias em 286 pessoas 
com média de idade de 36,44 anos, por questionários para auto-entrevista, com perguntas e opções de resposta acerca das patologias citadas. Os resultados indicaram 34\% de prevalência para cefaléias e 60\% para a DTM e cerca de 54\% dos portadores de DTM têm cefaléia primária. O gênero feminino e a tensão emocional também se mostraram estatisticamente associadas com tais patologias. Os autores concluíram ainda que a tensão emocional é um fator importante que está relacionado a estas patologias.

Ainda em 2003, SANTOS SILVA ${ }^{110}$, determinou um intervalo de pressão capaz de estimular resposta dolorosa em um grupo de 77 pacientes com DTM, quando comparado a um grupo controle de 75 indivíduos livres de qualquer queixa dolorosa compatível com DTM. Os exames de palpação foram realizados por um único examinador nos seguintes pontos: corpo do masseter, temporal anterior, temporal médio e temporal posterior. O grupo com DTM apresentou limiar de dor à pressão (LDP) significantemente menor em comparação ao grupo controle. O masseter apresentou menor LDP, seguido pelo temporal anterior, médio e posterior e o lado direito apresentou LDP menor que o lado esquerdo. O autor verificou que o intervalo de pressão mais confiável para o masséter foi de $1,02-1,5 \mathrm{Kg} / \mathrm{cm}^{2}$, para 0 temporal anterior e médio foi de $1,51-2 \mathrm{Kg} / \mathrm{cm}^{2}$ e para o temporal posterior 2,01$3 \mathrm{~kg} / \mathrm{cm}^{2}$. Concluiu que a palpação mostrou ser um exame confiável para se detectar sensibilidade muscular em pacientes com DTM. 


\section{2. - OCLUSÃO}

Acreditando na relação da musculatura mastigatória com a interferência oclusal, DAWSON ${ }^{23}$, em 1973, relatou que, ao existir uma interferência oclusal, diversos músculos do sistema mastigatório podem ser envolvidos, principalmente o músculo pterigóideo lateral, apresentando-se com espasmo e sensível à palpação. O autor relatou que o diagnóstico diferencial deve constar da manipulação da mandíbula em relação cêntrica, palpação do músculo pterigóideo lateral e da confecção de "front plateau" (dispositivo que impede o contato entre os dentes), usado por 24 horas. Quando constatada a interferência em relação cêntrica e cessada a sintomatologia dolorosa do músculo após o uso do "front plateau", concluiu-se que as interferências eram as causadoras da sintomatologia apresentada. Neste caso, o autor sugeriu o ajuste oclusal como tratamento para a remissão dos sintomas.

Com o objetivo de investigar as prováveis relações entre as interferências oclusais e a ocorrência do desconforto na ATM e estruturas adjacentes, GEERING ${ }^{38}$, em 1974, avaliou 251 pacientes, obtendo histórico e análise oclusal, verificando uma possível relação entre o deslize de RC para MIH e os sintomas relacionados à ATM em 70 dos pacientes. Contudo, não estabeleceu uma relação entre a magnitude dos deslizes mandibulares e a ocorrência de dor ou outros sintomas. Numa segunda etapa do estudo, verificou a associação entre o deslize e as interferências em não-trabalho e sua relação como a causa principal dos distúrbios do sistema mastigatório. O autor relatou que $40 \%$ dos pacientes 
apresentaram interferências oclusais não associadas ao deslize e que estes não demonstraram sinais ou sintomas de disfunção.

MOLIN et al. ${ }^{86}$, em 1976, analisaram a freqüência dos sintomas de DTM em 253 adultos jovens do gênero masculino, com média de idade de 19 anos, utilizando um questionário, palpação muscular e das ATM e exame clínico intrabucal. Observaram que pacientes com sintomas de disfunção tinham maior freqüência de sinais musculares, ruídos nas ATM e distúrbios oclusais (contatos em não-trabalho) do que aqueles sem sintomatologia. Concluíram que o contato em não-trabalho foi o único fator oclusal significativamente correlacionado com DTM, devido à dor durante o movimento mandibular e sensibilidade à palpação.

SOLERG; WOO; HOUSTON ${ }^{118}$, em 1979, avaliaram a prevalência de sinais e sintomas de DTM, em 739 jovens, pertencentes à Universidade da Califórnia, em Los Angeles, com aplicação de um questionário anamnésico e exame físico. Os autores observaram que os sinais subclínicos de disfunção são comuns (76\%) e constataram que $16,8 \%$ apresentavam algum sintoma, $9 \%$ tinham dois ou mais sintomas e apenas quatro indivíduos apresentavam cinco sintomas. Os ruídos articulares acometiam 28,3\% dos jovens, sendo $16,6 \%$ estalidos e $11,5 \%$ de crepitação. Não houve diferença estatística significativa entre os gêneros com relação aos sintomas, contudo, as mulheres apresentaram maior prevalência de sinais. Relataram ainda, que os deslizes de RC para MIH podem estar associados aos sinais de disfunção.

Em outro estudo, MOHLIN; INGERVALL; THILANDER ${ }^{85}$, em 1980, avaliaram 389 pacientes do gênero masculino, com média de idade de 32 anos, com a finalidade de estabelecer a prevalência de sintomas de DTM e revelar a correlação 
entre os diferentes tipos de interferência oclusal. Os dados foram obtidos através de anamnese e exame físico, que incluiu a análise de: movimentos mandibulares; dor durante a função; ruídos articulares; sensibilidade muscular à palpação; sensibilidade articular à palpação; interferências oclusais. Os tipos de interferências oclusais foram: (a) contato dentário unilateral ou contato dentário anterior em RC; (b) contato em movimento lateral em RC e MIH; (c) contato em que o desvio de RC para MIH foi maior que $2 \mathrm{~mm}$; (d) contato simples no lado de trabalho e de não-trabalho e contato unilateral em RC. Os resultados mostraram correlações positivas entre os sintomas subjetivos de DTM e a presença de interferências oclusais no lado de nãotrabalho, bem como contatos simples no lado de trabalho. A presença de contatos simples no lado de trabalho também foi relacionada com a presença de ruídos articulares causados por luxação ou fechamento da mandíbula. As interferências oclusais unilaterais em RC foram correlacionadas com sensibilidade muscular e ruídos articulares.

Ao examinar pacientes com contatos em lado de não-trabalho, sem sinais e sintomas de Disfunção Temporomandibular, INGERVALL; CARLSSON ${ }^{57}$ (1982) avaliaram a atividade muscular, comparando com um grupo controle. O estudo não demonstrou influência das interferências oclusais nos músculos analisados, e estas interferências não representam um obstáculo ao funcionamento normal dos músculos mastigatórios, ou ainda que os pacientes estavam bem adaptados à situação oclusal e concluíram que o sistema mastigatório apresenta uma capacidade adaptativa.

NILNER ${ }^{90}$, em 1983, pesquisou a relação entre hábitos parafucionais e distúrbios funcionais do sistema estomatognático em 309 jovens de 15 a 18 anos, 
utilizando entrevista e exame clínico. Os resultados demonstraram correlação entre interferências oclusais em relação cêntrica e a presença de estalidos articulares. As interferências oclusais também se apresentaram relacionadas com a sensibilidade à palpação muscular e articular, e a sobremordida profunda relacionou-se ao apertamento e desgaste dentário na região anterior.

No mesmo ano, De BOEVER; ADRIAENS ${ }^{24}$ avaliaram a possível relação entre a severidade dos sintomas de DTM e as características oclusais, particularmente com relação à presença de interferências oclusais. A análise de 135 pacientes, que buscaram tratamento para dor ou DTM, foi feita em três etapas: na primeira visita, após duas semanas e três semanas após a instalação da placa. Concluíram que a ocorrência de contatos prematuros no lado de não-trabalho causava maiores mudanças no padrão de contração muscular, refletindo em mudanças no movimento mandibular. No entanto, verificaram que a etiologia da dor ou DTM é complexa e que um simples fator oclusal parece não ser o responsável pelo problema, já que a perda dos molares e ocorrência de contatos prematuros não parece influenciar na severidade da dor e/ou disfunção, mas podem ter um papel importante na resolução do tratamento.

DROUKAS; LINDÉE; CARLSSON ${ }^{26}$, em 1984, estudaram a possível influência de alguns fatores oclusais, especialmente o padrão oclusal, no desenvolvimento de sinais e sintomas de DTM em adultos assintomáticos. Foram estudados 48 indivíduos com média de idade de 25 anos de ambos os gêneros e realizados registros dos sintomas subjetivos através de questionário e exame clínico para classificar os pacientes de acordo com o índice de disfunção de HELKIMO ${ }^{47,}{ }^{48}$. As variáveis oclusais registradas foram: contatos oclusais em $\mathrm{MlH}$, contato em 
posição de RC, contatos em movimentos laterais e desgastes oclusais. As interferências oclusais foram registradas nas seguintes posições: contato unilateral em RC, deslize de RC igual ou maior que $2 \mathrm{~mm}$ no sentido vertical e horizontal, interferência no lado de não-trabalho direito e esquerdo que impediram o contato no lado de trabalho e contato unilateral na protrusiva. Os resultados mostraram uma pequena freqüência dos sintomas subjetivos, sendo o ruído articular o mais comum deles (19\%). Os achados clínicos mostraram que 40\% dos indivíduos apresentaram dor muscular à palpação e 35\% danos na articulação, principalmente estalidos. Houve uma grande variação dos contatos oclusais nas várias posições de oclusão. A distância entre RC e MIH foi geralmente pequena com 12 registros de $2 \mathrm{~mm}$ ou mais no sentido vertical. O desgaste dentário, na sua maioria, ficou confinado ao esmalte na maioria dos dentes, no entanto $40 \%$ dos indivíduos apresentaram lesões na dentina. Nenhum tipo específico de padrão oclusal teve influência significativa nos sinais e sintomas de DTM neste grupo. Os autores concluíram que esses resultados suportam o conceito de etiologia multifatorial para as DTM, sendo o fator oclusal o de menor importância.

MAGNUSSON; ENBOM ${ }^{76}$, ainda em 1984, estudaram, durante duas semanas, os efeitos de interferências oclusais no lado de não-trabalho, em 24 indivíduos saudáveis. No grupo experimental, foram instaladas interferências bilaterais no lado de não-trabalho, enquanto o grupo controle recebeu uma simulação de interferência. Os resultados mostraram que, no grupo experimental, 10 indivíduos relataram sintomas subjetivos e 7 apresentaram sinais clínicos de DTM, enquanto no grupo controle, 3 indivíduos apresentaram sinais clínicos de DTM. Os autores concluíram que não existe relação entre a interferência oclusal e DTM, já 
que as DTMs podem ser desenvolvidas sem a existência de interferências oclusais. Segundo os autores, a resposta fisiológica de cada indivíduo aos fatores oclusais locais é o fator mais importante para se desenvolver DTM.

$\mathrm{BUSH}^{11}$, em 1985, procurou evidenciar alguma relação entre a sensibilidade dos músculos mastigatórios e da ATM, a vários tipos de contatos oclusais, em 298 estudantes de odontologia, sendo 242 do gênero masculino e 56, do feminino, com média de idade de 24 anos. A avaliação da amostra foi realizada por palpação muscular e da ATM, exame clínico e dos modelos de estudo montados em articulador semi-ajustável. Não se verificou correlação entre os sintomas de DTM e as más oclusões Classes I, II e III e nem entre qualquer tipo específico de contato oclusal, com a sensibilidade à palpação das estruturas consideradas. Verificou ainda, que os estudantes com relação de Classe I, sem sensibilidade à palpação, apresentaram maiores deslizes entre RC e MIH.

Com o objetivo de avaliar a influência da função em grupo, desoclusão pelo canino, interferências no lado de trabalho e no lado de nãotrabalho, na atividade eletromiográfica dos músculos elevadores da mandíbula, BELSER; HANNAM ${ }^{9}$, em 1985, examinaram 12 pacientes. Os dados foram coletados durante atividades funcionais e hábitos parafuncionais, ocorrendo uma diminuição da atividade muscular quando foi introduzido um guia canino onde originalmente havia função em grupo. A introdução de interferência do lado de nãotrabalho alterou a atividade do músculo temporal numa condição de apertamento lateral. Como conclusão do trabalho os autores sugerem que uma condição de desoclusão pelo canino não altera a atividade muscular em atividades funcionais, porém reduzem-na durante o apertamento parafuncional. 
EGERMARK-ERIKSSON; CARLSSON; MAGNUSSON ${ }^{31}$, em 1987, verificaram a relação entre fatores oclusais e DTM em um estudo longitudinal. Foram avaliadas 402 crianças nas faixas etárias de 7, 11, 15 anos. Um questionário anamnésico foi aplicado em conjunto com um exame clínico para detectar sinais e sintomas de DTM e as condições oclusais, especialmente interferências oclusais (IO) e desgastes dentários. Os resultados mostraram a presença de diversos tipos de IO, mais da metade dos indivíduos com 11 e 15 anos tinham pelo menos um contato unilateral em RC ou durante o desvio lateral da mandíbula entre RC e MIH. Entre 15 e 30\% não possuíam interferência no lado de não-trabalho quando se registravam movimentos excursivos laterais. Com relação às 10 , não houve nenhuma diferença entre meninos e meninas e quanto ao desgaste dentário, não houve aumento significativo de sua severidade durante o período de acompanhamento em todos os grupos de idade e em todas as regiões. Com relação aos sinais de DTM houve um ligeiro aumento na freqüência e na severidade, com o aumento da idade. Os ruídos articulares foram positivamente correlacionados com o desvio lateral da mandíbula e contato em RC e MIH em todas as idades. Finalmente, a interpretação dos resultados sugere a heterogeneidade e a natureza multifatorial dos distúrbios funcionais do sistema mastigatório.

PULLINGER; SELIGMAN; SOLBERG ${ }^{97}$, em 1988, estudaram a freqüência de sintomas de DTM e sua relação com as variáveis oclusais em 222 estudantes, com média de idade de 23,9 anos. Os fatores oclusais como a magnitude do desvio entre $\mathrm{RC}$ e $\mathrm{MIH}$, bem como os contatos dentários foram registrados em $\mathrm{RC}$ através de manipulação passiva, para serem posteriormente relacionados com dor e DTM. Eles observaram que $29 \%$ dos pacientes 
apresentaram ruídos na articulação e 32\% apresentaram dor muscular severa nos músculos temporal anterior e posterior. A amostra apresentou deslize de RC e MIH em $71 \%$, sendo que apenas $10 \%$ apresentaram deslizes maiores ou iguais a $1 \mathrm{~mm}$.

PULLINGER; SELIGMAN; SOLBERG ${ }^{98}$, no mesmo ano, associaram os fatores oclusais à sensibilidade na ATM e à disfunção em 222 adultos jovens com média de idade de 23,9 anos. Os autores concluíram que é vaga a influência da oclusão no desenvolvimento das disfunções da ATM e parece que a diferença entre RC e MIH demonstra uma função protetora para o sistema, pois a carga é anterior à posição limite posterior.

SELIGMAN; PULLINGER; SOLBERG ${ }^{114}$, ainda em 1988, com a mesma amostra das pesquisas anteriores, avaliaram a presença de dor nos músculos da mastigação ou disfunção através de um questionário exame clínico e de modelos com o objetivo de determinar a relação entre a sensibilidade muscular e os aspectos oclusais com os sinais de DTM. Os resultados indicaram que os fatores oclusais não se relacionaram com a sensibilidade muscular, porém esta, esteve relacionada aos sinais de patologias intracapsulares, como crepitação, estalido e sensibilidade à palpação da ATM.

KIRVESKARI; ALANEN; JÄMSA ${ }^{63}$, em 1989, avaliaram a influência de interferências oclusais nos sinais de Disfunções Temporomandibulares. O estudo longitudinal, realizado durante 3 anos, avaliou 53 crianças que receberam ajuste oclusal para eliminar as interferências e 46 que receberam tratamento placebo. Os resultados não demonstraram correlação entre as interferências e os sinais de DTM nos dois primeiros anos, no entanto no $3^{\circ}$ ano do estudo, observaram associação estatisticamente significativa entre a presença de interferências e os sinais de DTM. 
Os autores afirmaram que é necessário analisar e definir cuidadosamente o conceito de interferência para que se tornem viáveis novas pesquisas, a fim de discutí-las como agentes etiológicos das DTMs, pois um programa de estudo inadequado resulta em resultados falso-negativos.

Em 1990, WÄNMAN; AGERBERG ${ }^{125}$ avaliaram alguns fatores oclusais e psicológicos em jovens de 19 anos de idade e os relacionaram como etiológicos de DTM. Os dados foram coletados por meio de um questionário e avaliação clínica, incluindo exame da ATM, dos músculos, mobilidade mandibular e oclusão. O número de contatos oclusais em $\mathrm{MIH}$, durante ligeira pressão foi o fator oclusal mais diretamente relacionado ao número de sinais e sintomas de DTM. O risco de DTM foi três vezes maior no grupo com poucos contatos em MIH e entre 3,4 a 8,5 vezes no grupo que se considerou tenso.

Em uma revisão sobre a influência da oclusão nos sintomas temporomandibulares, LIPP ${ }^{71}$, em 1990, relatou a falta de evidências científicas que comprovem tal interferência e que o sucesso de tratamentos placebos constitui uma delas. O autor concluiu que a capacidade de remodelação da articulação temporomandibular demonstra que a mesma pode acomodar-se e adaptar-se às várias condições oclusais.

SELIGMAN; PULLINGER ${ }^{112}$, em 1991, revisaram a influência dos contatos nos lados de trabalho e não-trabalho, grau de deslize entre a posição retruída (P.R.) e posição de intercuspidação (P.I.), padrão de guias oclusais, parafunção e atrição dentária, na Disfunção Temporomandibular. Os autores concluíram que os estudos falham em demonstrar relação direta entre interferências oclusais e DTM e que o deslize entre a P.R. e a P.I. pode ser um fator de risco para 
certos pacientes. Afirmaram também que os padrões das guias oclusais influenciam os níveis de atividade muscular, mas não parecem provocar DTM. Em relação a parafunção e atrição dentária severa, parecem estar mais presentes em homens.

KARLSON; CHO; CARLSSON ${ }^{59}$, em 1992, estudaram as mudanças no padrão do movimento mastigatório através da inserção de interferências oclusais experimentais no lado de não-trabalho. Afirmaram que houve variações na amplitude de abertura e velocidade do movimento. No entanto, a influência das interferências oclusais nos músculos analisados não representou um obstáculo ao funcionamento normal dos músculos mastigatórios, ou ainda que os pacientes estavam bem adaptados à situação oclusal. Eles concluíram que o sistema mastigatório apresenta uma alta capacidade adaptativa através do sistema neuromuscular, frente às interferências oclusais, logo após uma semana.

Em 1993, KVINNSLAND; KVINNSLAND; KRISTIANSEN ${ }^{67}$ estudaram o efeito das interferências oclusais nas articulações temporomandibulares de ratos com a finalidade de observar o efeito da oclusão traumática na vascularização da articulação. Foram utilizadas interferências de $1 \mathrm{~mm}$ de altura nos primeiros molares direitos de 30 ratos. Antes de serem sacrificados, 1, 5, 10, 15 e 20 dias após a instalação das interferências, as cobaias receberam uma injeção de microesferas fluorescentes na ATM. Os resultados mostraram que, após 15 a 20 dias de interferências oclusais, houve um aumento na vascularização da ATM do mesmo lado da interferência. Quando comparados com o grupo controle, houve também um aumento da vascularização em ambos os lados em todos os animais experimentais. Eles interpretaram esses resultados como uma demonstração de que 
as interferências oclusais são capazes de alterar as cargas recebidas pelas articulações.

Um estudo sobre os sinais clínicos da Disfunção Temporomandibular foi realizado por MAGNUSSON; CARLSSON; EGERMARKERIKSSON $^{77}$, em 1994, em uma amostra, composta de 84 pacientes, acompanhados longitudinalmente dos 15 aos 25 anos de idade. Não observaram diferenças em nenhum sinal clínico e nenhum paciente apresentou índice severo de disfunção. O sinal mais comum foi a sensibilidade muscular à palpação. Encontraram ainda um aumento de interferências em RC em 74\% e em lado de nãotrabalho em $32 \%$ dos casos.

WESTLING ${ }^{127}$, em 1995, avaliou 193 adolescentes assintomáticos para verificar se interferências oclusais unilaterais em RC eram mais freqüentes em meninas que em meninos. Verificaram, também, se as 10 eram freqüentes em indivíduos com e sem estabilidade articular. O registro dos ruídos articulares foi realizado pela auscultação e palpação manual durante os movimentos de abertura e fechamento. Os estalidos foram classificados em: estalido recíproco, estalido não recíproco e estalido tardio. Os resultados mostraram que: (1) 48\% dos indivíduos apresentavam contatos unilaterais em RC; (2) os contatos unilaterais em RC foram significativamente mais freqüentes nas meninas que nos meninos; (3) $67 \%$ dos indivíduos com hipermobilidade articular tiveram contatos unilaterais em RC; (4) os ruídos articulares foram clinicamente observados em 33\% dos adolescentes e (5) os ruídos articulares tiveram pequena correlação com distância vertical maior ou igual a $1 \mathrm{~mm}$. Os resultados mostraram que somente o ruído articular não recíproco foi relacionado com os contatos verticais maior ou igual a $1 \mathrm{~mm}$. Respostas afirmativas 
para as questões sobre dor no movimento foram relacionadas com a presença de contatos unilaterais em RC. Nenhuma diferença ocorreu entre os gêneros na distribuição de estalidos recíprocos e não recíprocos e a distância vertical de RC para $\mathrm{MIH}$. O autor concluiu que contatos unilaterais em RC podem ser considerados um fator predisponente para distúrbios articulares e que fatores adversos podem interferir na medida vertical entre $\mathrm{RC}$ e $\mathrm{MIH}$.

Em 1996, DONEGAN; CHRISTENSEN; MC KAY ${ }^{25}$ examinaram a presença e a ausência de guia canino, comparando-as com sons articulares da ATM em 46 pacientes com Disfunção Temporomandibular e 46 como grupo controle sem sinais e sintomas de disfunção. Os autores observaram uma prevalência baixa de guia em ambos os grupos (22\% em pacientes e $30 \%$ no grupo controle) e não encontraram relação entre a presença de sons articulares e o guia canino. Concluíram que não é possível distinguir o potencial de pacientes ou não pacientes de DTM, com base na guia de desoclusão pelo canino.

A relação central também pode ser denominada de relação cêntrica ou posição de contato retruído e, mais recentemente, de posição de estabilidade ortopédica. OKESON ${ }^{91}$ (1998) definiu esta posição como a relação maxilomandibular onde os côndilos estão apoiados sobre as vertentes posteriores das eminências articulares, com os discos articulares devidamente interpostos. O autor verificou que a RC é uma posição estritamente relacionada à posição condilar, não apresentando nenhuma relação com a posição ou contatos dentários.

WATANABE et al. ${ }^{126}$, em 1998, avaliaram o relacionamento entre sinais e sintomas de DTM e o padrão de contato oclusal bilateral em 143 pacientes com DTM. O exame físico foi composto de palpação muscular e avaliação do padrão 
de contato oclusal de cada paciente, através de movimentos excursivos laterais em ambas as direções. Quando presentes, os contatos oclusais foram classificados em: (1) contato no lado de trabalho, (2) contato no lado de não-trabalho e (3) contato bilateral (trabalho e não-trabalho). Os resultados mostraram que as queixas mais freqüentes de DTM foram: (1) dor muscular $(74,8 \%)$, (2) dificuldade de abertura (46,8\%), (3) ruído articular (40,5\%), (4) dificuldade na mastigação $(4,9 \%)$ e (5) outros $(8,4 \%)$. O padrão de contato oclusal mais comum foi o contato no lado de trabalho (75,9\%), seguido de contatos bilaterais $(18,5 \%)$ e contatos do lado de não-trabalho (5,6\%). Concluiram que existe uma pequena relação entre a sintomatologia de DTM e o padrão de contatos oclusais durante os movimentos excursivos laterais, mas também foi sugerido que poucos sinais e sintomas de DTM podem estar associados com contatos oclusais particulares.

CLARK et al. ${ }^{13}$, em 1999, realizaram uma revisão da literatura sobre interferências oclusais experimentais em dezoito estudos realizados em humanos e dez em animais. Observaram que a presença de interferências oclusais pode causar dor dentária localizada, alteração nos níveis de tensão dos músculos posturais, mudanças nos movimentos mastigatórios e, algumas vezes, a indução de estalidos articulares. No entanto, por esses resultados estarem presentes em pacientes assintomáticos, afirmaram que não se pode provar a relação entre interferências oclusais e dor muscular crônica ou alterações disfuncionais na ATM.

PULLINGER; SELIGMAN ${ }^{96}$, em 2000, avaliaram o potencial que as variáveis oclusais como discrepância entre $\mathrm{RC}$ e $\mathrm{MIH}$, mordida cruzada posterior, overjet, overbite e desvio de linha média, podem apresentar para diferenciar pacientes com DTM de indivíduos normais assintomáticos, em 381 pacientes do 
gênero feminino, comparando com um grupo controle de 98 pacientes do mesmo gênero. Observaram que a oclusão pode ser um co-fator na identificação de pacientes com DTM e que algumas variações representam uma conseqüência da disfunção.

CLARK et al. ${ }^{14}$, em 2001 realizaram uma revisão da literatura com o intuito de descrever as características que são realmente necessárias para uma oclusão ideal. Concluíram que uma oclusão ideal deve apresentar contatos bilaterais em relação central, deslize de RC para M I H inferior a 1mm, ausência de contatos no lado de não-trabalho e guia de desoclusão lateral pelo canino.

BELL et al. ${ }^{8}$, em 2002, estudaram o papel das interferências oclusais como fator etiológico das DTM em 52 mulheres, divididas em dois grupos, com idade variando de 19 a 42 anos. Um grupo era formado por 31 estudantes (19 controle e 12 com IO) com boa saúde geral, ausência de DTM e dentes normais corrigidos por ajuste oclusal para eliminar interferências oclusais. O outro grupo era formado por 21 pacientes (11 controle e 10 com IO), com história de DTM, já anteriormente tratado. As interferências oclusais foram colocadas bilateralmente nas cúspides palatinas do segundo molar superior do lado de não-trabalho, na posição de RC, nos dois grupos. O estudo revelou que nos indivíduos sem DTM, independente se controle ou experimental, não houve diferença estatisticamente significativa no número de sinais e sintomas. Os indivíduos com história de DTM apresentaram sinais e sintomas mais severos nos grupos com interferência, quando comparados com o grupo placebo. Todos os indivíduos com interferência mostraram um aumento dos sinais clínicos em relação aos seus respectivos grupos controle. $O$ tamanho reduzido das interferências pode explicar porque indivíduos sem história de DTM relataram 
somente um pequeno desconforto. Os indivíduos com história de DTM tiveram mais sítios doloridos à palpação do que aqueles sem história de DTM. É possível que a DTM ou o seu tratamento possam afetar indivíduos sensíveis e conscientes da oclusão, já que os indivíduos do grupo assintomáticos não tiveram variação da sensibilidade muscular. Esse estudo concluiu que indivíduos sem história de DTM apresentaram uma melhor adaptação às interferências experimentais. No entanto, os pacientes que apresentaram DTM tiveram variabilidade de sintomatologia. A diferença entre os grupos com e sem DTM sugerem que as interferências oclusais são um fator etiológico das DTM.

FUJII $^{37}$, em 2003, avaliou 71 pacientes sintomáticos divididos em dois grupos, com a finalidade de verificar a associação entre o lado de ocorrência do sintoma de dor ou ruído e o lado da interferência oclusal. O grupo 1 era constituído de 31 pacientes com dor muscular ou articular, e o grupo 2 era constituído de 40 pacientes com algum tipo de ruído articular. A análise da sintomatologia dolorosa, do ruído articular e da oclusão foi realizada na primeira consulta e após o tratamento para a remissão dos sintomas. Os resultados mostraram que não há associação entre o lado em que ocorre a sintomatologia e o lado em que ocorre a interferência oclusal. Esses dados sugerem que dor muscular ou ruído articular não se desenvolvem no lado das interferências oclusais.

MENDONÇA NETO ${ }^{83}$ (2003) verificou a relação entre a magnitude da interferência oclusal com a presença de sinais e sintomas de DTM e de trauma oclusal. Foram avaliados 43 pacientes, observando os registros da posição da borda incisal do incisivo superior na face vestibular do incisivo inferior nas posições de MIH e RC. A diferença em milímetros desta posição determinou a magnitude da 
interferência oclusal. Os resultados mostraram que as evidências de interferência oclusal estão presentes nos pacientes com e sem DTM e sinais clínicos de trauma oclusal. Concluiu que não houve associação entre a magnitude das interferências com a DTM e o trauma oclusal.

No mesmo ano, VALLE-COROTTI et al. ${ }^{121}$ avaliaram a oclusão como fator etiológico da DTM em indivíduos tratados e não tratados ortodonticamente. A amostra constou de 200 pacientes divididos igualmente em 4 grupos com más oclusões de Classes I e II, tratados e não tratados ortodonticamente. O exame da oclusão resultou da avaliação do número de contatos em $\mathrm{MIH}$, discrepância entre as posições de $\mathrm{RC}$ e $\mathrm{MIH}$, contatos em lado de nãotrabalho, tipos de guia lateral, guia anterior, mordida aberta anterior, mordida cruzada posterior, overjet e overbite, ajuste oclusal e presença de facetas de desgaste. Os sinais e sintomas de DTM foram avaliados com um questionário anamnésico e pelo exame de palpação muscular e articular, além da detecção de ruídos articulares e análise da movimentação mandibular. Os resultados demonstraram associação entre o grau de DTM e a ausência de guia anterior, entretanto não foi possível afirmar que a oclusão pode ser considerada, isoladamente, como fator etiológico da Disfunção Temporomandibular.

\section{3 - MÁ OCLUSÃO E TRATAMENTO ORTODÔNTICO}

Um dos primeiros ortodontistas a verificar a presença de oclusão traumática em casos tratados ortodonticamente, foi ARNOLD $^{6}$ (1927), atribuindo esta condição ao fato de que interferências oclusais, tanto em relação cêntrica como 
em movimentos funcionais, provocavam problemas periodontais. O ajuste oclusal, que já havia se revelado como terapêutica para estes problemas, foi indicado como complemento ao tratamento ortodôntico, em todos os casos.

Com o intuito de avaliar a função da ATM e a oclusão funcional, SADOWSKY; BEGOLE ${ }^{106}$ realizaram um estudo, em 1980, utilizando 75 pacientes entre 25 e 55 anos de idade, após no mínimo 10 anos do tratamento ortodôntico corretivo. Como grupo controle utilizaram indivíduos adultos, com má oclusão, não tratados ortodonticamente. Após a avaliação do questionário anamnésico e de um detalhado exame clínico, os resultados demonstraram que a prevalência de sinais e sintomas de DTM e de contatos oclusais não funcionais foi similar entre os dois grupos. A prevalência de deslocamento mandibular entre $\mathrm{RC}$ e $\mathrm{MIH}$ foi evidente em ambos os grupos e significativamente maior no grupo controle.

A relação entre má oclusão, sintomas de Disfunção Temporomandibular e interferências oclusais foi estudada em 1980, por MOHLIN; INGERVALL; THILANDER ${ }^{85}$, que examinaram 389 pacientes do gênero masculino de 21 a 54 anos de idade. A má oclusão de Classe III, a mordida cruzada anterior, apinhamento dentário superior e a mordida aberta anterior apresentaram uma correlação positiva aos sintomas de Disfunção Temporomandibular e às interferências oclusais. Concluíram que a etiologia da DTM é multifatorial, não sendo possível predizer o risco desta em um indivíduo com má oclusão.

MOHLIN ${ }^{84}$, em 1983, relacionou a má oclusão à prevalência de Disfunção Temporomandibular num grupo de 272 mulheres na Suécia, que foram examinadas clinicamente e responderam a um questionário. Os resultados demonstraram uma correlação entre a severidade da disfunção e a necessidade de 
tratamento ortodôntico e entre esta e a sensibilidade à palpação muscular. O autor concluiu que a etiologia da disfunção é, de forma evidente, multifatorial.

SADOWSKY; POLSON ${ }^{107}$, em 1984, realizaram dois estudos longitudinais a fim de investigar as Disfunções Temporomandibulares e a oclusão funcional após o tratamento ortodôntico. Um, em Illinois, utilizando 96 pacientes que receberam tratamento ortodôntico há pelo menos dez anos previamente ao estudo, sendo 66\% deles Classe II e 34\% Classe I. O outro em Eastman, formado por 111 pacientes, sendo 64\% Classe I, 30\% Classe II e 6\% Classe III. Os dois grupos receberam tratamento ortodôntico com aparelho fixo, sendo que 30\% do grupo de Illinois e $36 \%$ de Eastman foram submetidos a extrações como parte da terapia ortodôntica. Os grupos utilizados como controle eram formados de 103 indivíduos de Illinois e 111 de Eastman, adultos com má oclusão, não submetidos a tratamento ortodôntico. Quanto à oclusão funcional, verificou-se uma alta incidência, em todos os grupos, de contatos em lado de não-trabalho e de contatos posteriores durante o movimento protrusivo, não havendo diferença estatística entre eles. Os achados encontrados nos dois grupos foram similares e sugeriram que o tratamento ortodôntico realizado durante a adolescência geralmente não aumenta nem diminui o risco de desenvolver DTM futuramente.

Em um estudo transversal, RIOLO; BRANDT; TENHAVE ${ }^{103}$, em 1987, analisaram a associação entre as características oclusais e os sinais e sintomas de disfunção da ATM em 1.342 jovens de 6 a 17 anos de idade. A amostra foi avaliada quanto à prevalência de (1) tipos específicos de oclusão e (2) sintomas subjetivos e sinais clínicos de disfunção da ATM. Em relação às condições oclusais e os sinais clínicos, os resultados demonstraram que a mudança funcional não 
estava associada à dor muscular e na ATM, o overjet excessivo ou negativo estava mais associado à dor na ATM. A mordida aberta apresentou associação com a dor muscular e na ATM, e os indivíduos mais velhos com mordida de topo ou uma relação molar de Classe II estavam mais relacionados com dor muscular e articular e abertura bucal restrita. Os indivíduos mais velhos com mordida cruzada apresentaram maior prevalência de sons articulares. Quanto à oclusão e os sintomas subjetivos, indicaram que a relação de molar Classe II estava associada aos ruídos articulares nos grupos de 6 a 8 e 15 a 17 anos. Pacientes com overjet negativo foram os que mais relataram ruídos articulares. Os autores concluíram que existem associações estatísticas entre certas características da oclusão e sinais e sintomas da ATM e estas são maiores nos grupos mais velhos.

DAHL et al. ${ }^{21}$ (1988) compararam os sinais e sintomas de Disfunção Temporomandibular entre 51 pacientes tratados ortodonticamente e 47 não tratados, todos aos 19 anos de idade e num período médio de cinco anos após o término do tratamento. Os pacientes foram avaliados com base nos índices de HELKIMO ${ }^{47,48}$. Os indivíduos que não receberam tratamento ortodôntico relataram mais sintomas que o grupo tratado ortodonticamente, entretanto esta diferença não foi significativa e nenhum paciente relatou a presença de sintomas severos. Quanto ao índice clínico de disfunção, observaram 43,1\% de disfunção leve para o grupo tratado e 40\% para o grupo controle. Os pesquisadores não encontraram diferenças substanciais entre os dois grupos.

GREENE $^{42}$, em 1988, reavaliou a relação entre a ortodontia e a Disfunção Temporomandibular nos seguintes aspectos: 1) A ortodontia representa um risco no desenvolvimento da DTM? 2) O paciente portador de má oclusão com 
DTM necessita de tratamento ortodôntico para alívio dos sinais e sintomas da DTM? 3) Um tratamento ortodôntico terminado de forma inadequada aumenta o risco de DTM? 4) Qual deve ser a conduta do ortodontista diante de um paciente com sinais e sintomas de DTM antes ou durante o tratamento? O autor sugere que a relação DTM / ortodontia está envolvida por mitos e baseada em dados subjetivos. Conclui que a DTM é uma disfunção ortopédica-médica bastante complexa e o seu diagnóstico depende do conhecimento multidisciplinar do profissional e do seu domínio sobre o sistema estomatognático.

JANSON; MARTINS ${ }^{58}$ (1990) avaliaram algumas características funcionais da oclusão, presentes de seis meses a um ano após o término do tratamento ortodôntico e analisaram os efeitos do ajuste oclusal sobre as variáveis estudadas. A amostra continha 20 pacientes, sendo 11 do gênero masculino e nove, do feminino, com média de idade de 14 anos e 10 meses. Os autores observaram a ausência de coincidência entre as posições de RC e MIH em 85\% dos pacientes, presença de guia anterior em 90\% e excursão em lateralidade em 50\% da amostra. Observaram ainda uma alta incidência de interferências oclusais durante os movimentos funcionais, e presença de DTM em 10\% dos pacientes estudados. Finalmente, verificaram que o ajuste oclusal permitiu a obtenção da oclusão de relação cêntrica e o aumento do número de contatos nesta posição, a melhora do padrão de desoclusão, a eliminação das interferências durante os movimentos funcionais e a remissão dos sintomas nos pacientes com Disfunção Temporomandibular. Entretanto este procedimento não permitiu o estabelecimento imediato da guia anterior, quando não estabelecida por meio do tratamento ortodôntico. 
HEIKINHEIMO et al. ${ }^{46}$, em 1990, avaliaram, em um estudo longitudinal, a presença de interferências oclusais e sinais de Disfunção Temporomandibular, em 167 pacientes entre 12 e 15 anos, avaliando sua importância no diagnóstico ortodôntico. Os sintomas de DTM são comuns, mas inconsistentes no diagnóstico para o tratamento ortodôntico. A abertura bucal aumentou com a idade, bem como o número de interferências oclusais durante os três anos de estudo. Diante destes resultados, os autores concluíram que nenhum sinal ou sintoma de DTM, ou uma combinação deles pode ser utilizada como determinante para o tratamento ortodôntico.

No mesmo ano, EGERMARK-ERIKSSON, et al. ${ }^{33}$ examinaram um grupo de crianças e adolescentes com 7, 11 e 15 anos, verificando a má oclusão morfológica e sinais e sintomas de DTM. Verificaram que as más oclusões como a mordida aberta anterior, a mordida cruzada, as relações de Classes II e III de Angle podem ser um fator de risco no desenvolvimento da DTM, mas a associação entre os diferentes tipos de má oclusão e a DTM foi baixa. Alguns destes indivíduos foram tratados, porém quando comparados aos não tratados, não apresentaram diferenças quanto a sinais e sintomas de DTM e interferências oclusais.

Com o objetivo de investigar se pacientes tratados ortodonticamente apresentavam um funcionamento do sistema mastigatório semelhante aos pacientes não tratados, KEB; BAKOPULOS; WITT ${ }^{60}$, em 1991, avaliaram 54 pacientes tratados ortodonticamente e 52, não tratados, com idades de 20 a 30 anos. Os autores realizaram avaliação clínica (palpação muscular e da ATM, presença de sons articulares e dor durante o movimento mandibular), avaliação oclusal (número e natureza dos contatos em RC, MIH, guia anterior e lateral) e avaliação instrumental 
(posição e movimento condilar). Os resultados foram transferidos para um programa de computador que determinava automaticamente os índices de HELKIMO ${ }^{47,48}$. Os achados deste estudo não indicaram o tratamento ortodôntico como causa das desordens do sistema estomatognático, pois os pacientes tratados apresentaram a oclusão e o funcionamento da ATM melhor que o grupo controle. Diante destes resultados os autores concluíram que os sintomas de Disfunção Temporomandibular podem ocorrer em casos individuais, mas não parece haver relação entre os distúrbios funcionais e o tratamento ortodôntico bem realizado.

PULLINGER; SELIGMAN ${ }^{95}$ (1991) estudaram o overjet e o overbite como variáveis em relação a grupos portadores de Disfunção Temporomandibular, comparando-os a um grupo controle livre de sintomas. Os pacientes foram divididos em grupo controle (sem sinais e sintomas de DTM), grupo com deslocamento de disco sem redução, grupo com deslocamento de disco com redução, grupo com osteoartrose articular sem história de degeneração da ATM, grupo com osteoartrose e história degenerativa e um grupo apenas com mialgia. Os resultados demonstraram que a mordida aberta ocorreu apenas nos grupos com osteoartrose e em alguns casos com mialgia, mas foi ausente no grupo controle. O overbite não foi comum em nenhum dos grupos e o overjet, observado com maior freqüência no grupo com osteoartrose, mas não se caracterizou como um grupo determinante no diagnóstico de DTM. Com base nos resultados, concluíram que a mordida aberta está associada à osteoartrose e que o overbite, o overjet e mesmo a mordida aberta não podem ser consideradas isoladamente como causa da DTM. Os valores de $1 \mathrm{a}$ $4 \mathrm{~mm}$ para overbite e 1 a $3 \mathrm{~mm}$ para overjet são considerados como objetivo final no tratamento ortodôntico, contudo, não se pode afirmar que o aumento desses valores 
em pacientes tratados ortodonticamente possa ser considerado responsável pelo aparecimento de Disfunção Temporomandibular.

Em 1991, SELIGMAN; PULLINGER ${ }^{112}$ publicaram uma revisão a respeito da influência das relações oclusais (mordida aberta, mordida cruzada, overjet, overbite) com a Disfunção Temporomandibular. Os autores afirmaram que a mordida aberta esquelética e overjet acentuado estão associados com osteoartrite da ATM; não encontraram evidências quanto a relação entre overjet e overbite com as disfunções não artróticas e que a mordida cruzada não provoca sintomas de DTM.

KREMNAK et al. ${ }^{66}$ (1992) analisaram o tratamento ortodôntico como um fator de risco para a Disfunção Temporomandibular. Em um estudo longitudinal os autores avaliaram 109 pacientes, antes e em intervalos durante e após o tratamento ortodôntico. Os autores concluíram que, segundo a metodologia utilizada, o tratamento ortodôntico não representa um importante fator etiológico da Disfunção Temporomandibular.

EGERMARK-ERIKSSON; THILANDER ${ }^{30}$, em 1992 reexaminaram um grupo de crianças e adolescentes com sinais e sintomas de Disfunção Temporomandibular e avaliaram as diferenças entre os pacientes que receberam tratamento ortodôntico e os não tratados. Foram avaliadas nesta pesquisa 402 pacientes divididos, por idade, em três grupos $(7,11,15$ anos), que participaram de um estudo prévio e foram reexaminados dez anos após o estudo inicial. Os pacientes responderam a um questionário e foram examinados clinicamente. Os resultados demonstraram que os pacientes tratados ortodonticamente apresentaram menor prevalência de sintomas e menor índice clínico de disfunção. 
Com a finalidade de identificar pacientes ortodônticos com Disfunção Temporomandibular, HANS et al. ${ }^{44}$, em 1992, realizaram exame clínico, ressonância magnética e aplicação de um questionário em 51 pacientes. Os autores concluíram que a história e o exame clínico são os testes diagnósticos de escolha para pacientes ortodônticos porque juntos, eles são um teste sensível para todas as formas de disfunções temporomandibulares e que a imagem por ressonância magnética, enquanto específica para desordens de interferência de disco da ATM, não identifica pacientes com DTM resultantes de outras causas.

SADOWSKY ${ }^{105}$, em 1992, revisou a literatura sobre o risco do tratamento ortodôntico no desenvolvimento da Disfunção Temporomandibular. Concluiu que o tratamento ortodôntico realizado em crianças e adolescentes não representa um risco para a DTM, pois sua etiologia é multifatorial e que a mecanoterapia ortodôntica produz mudanças graduais em um ambiente que é, em geral, totalmente adaptativo.

Com o objetivo de determinar a incidência de dor e disfunção em pacientes ortodônticos, RENDELL; NORTON; GAY ${ }^{100}$, em 1992, avaliaram 451 pacientes sem sinais e sintomas de Disfunção Temporomandibular no início do tratamento e 11 com sintomatologia. Os pacientes foram avaliados por uma versão modificada dos índices de disfunção e anamnésico de HELKIMO ${ }^{47,48}$. Aqueles que não apresentaram disfunção no início, não a desenvolveram no decorrer do tratamento e os outros 11 com disfunção não apresentaram alterações consistentes neste período. Baseados nestes resultados não foi possível estabelecer uma relação entre a disfunção e o tratamento ortodôntico. 
OLSSON; LINDQVIST ${ }^{93}$, em 1992, avaliaram 245 pacientes tratados ortodonticamente e 245, como controle, segundo idade, gênero e necessidade de tratamento, utilizando os índices anamnésico e clínico de HELKIMO ${ }^{47,48}$. Os autores observaram que no grupo de pacientes, a freqüência dos sinais e sintomas de DTM foi mais alta nos indivíduos mais velhos e do gênero feminino, e concluíram que os pacientes ortodônticos parecem apresentar maior risco de DTM.

Com a finalidade de comparar os sinais e sintomas de DTM, WADHWA; UTREJA; TEWARI ${ }^{124}$, em 1993, avaliaram, de acordo com os princípios de HELKIMO ${ }^{47,48}$, três grupos de jovens: 30 com oclusão normal, 41 com má oclusão não tratada e 31 pacientes tratados ortodonticamente. Os resultados demonstraram que o grupo com oclusão normal apresentou o maior número de jovens sem disfunção, mas esta diferença não foi estatisticamente significante. O único achado significante foi a diferença do índice clínico de disfunção entre os grupos com oclusão normal e com má oclusão não tratada. Concluíram que a ausência de diferenças substanciais entre os três grupos, indica que o papel do tratamento ortodôntico como preventivo ou precipitador das DTM continua questionável, necessitando de maior atenção para o fator estresse.

KEELING, et al. ${ }^{61}$ avaliaram, em 1994, o relacionamento entre os sons articulares (estalido e crepitação) e as características esqueléticas e dentárias em 3.428 estudantes, com idade de 6 a 12 anos, sem história de tratamento ortodôntico. Os examinadores observaram sons articulares em 10\% da amostra e não encontraram associação entre a prevalência dos sons articulares com a idade, gênero, raça e relação molar e concluíram que pacientes com grande abertura bucal, 
apinhamento anterior e sobremordida profunda têm um risco aumentado de apresentarem estalido ou crepitação na ATM.

VLACHOS ${ }^{123}$, em 1995, analisou os objetivos do tratamento ortodôntico em duas partes: oclusão estática e oclusão funcional. Avaliou ainda o tratamento como causa e cura da Disfunção Temporomandibular. O autor evidenciou que o tratamento ortodôntico não representa um fator de risco para a DTM, como também não foi comprovada sua participação enquanto causa, prevenção ou cura.

Em 1995, EGERMARK-ERIKSSON; RÖNNERMAN ${ }^{29}$ examinaram um grupo de 50 pacientes, tratados ortodonticamente com e sem extrações, analisando sinais e sintomas de DTM, presença de dores de cabeça, bruxismo e interferências oclusais, utilizando questionários e exame clínico, antes, durante e imediatamente após o tratamento. Utilizaram como grupo controle comparativo, 135 pacientes. Concluíram não existir diferenças entre sinais e sintomas de DTM, dores de cabeça e bruxismo nos pacientes tratados ortodonticamente. Verificaram que alguns pacientes apresentavam sinais de disfunção e interferências no lado de nãotrabalho e que durante a fase ativa de tratamento e de contenção estas interferências eram bastante reduzidas. Os pacientes apresentaram menos sinais e sintomas de DTM durante, do que antes do tratamento.

Em uma revisão de literatura MCNAMARA; SELIGMAN; OKESON ${ }^{79}$, em 1995, analisaram a interação das oclusões morfológica e funcional com a Disfunção Temporomandibular, avaliando os seguintes fatores: mordida aberta anterior esquelética, overjet maior que $6 \mathrm{~mm}$, discrepância entre RC e MIH maior que $4 \mathrm{~mm}$, mordida cruzada posterior unilateral e perda de mais de cinco dentes posteriores. Os autores concluíram que os três primeiros fatores estão 
freqüentemente associados a artropatias da ATM e podem ser o resultado de alterações ósseas e ligamentosas dentro da ATM. Analisaram também a relação tratamento ortodôntico e Disfunção Temporomandibular, concluindo: 1) sinais e sintomas de DTM ocorrem em indivíduos normais; 2) sinais e sintomas da DTM aparecem bastante na adolescência, o que significa que não existe relação com o tratamento ortodôntico; 3) o tratamento ortodôntico não causa nem previne a DTM na idade adulta; 4) a extração dentária como parte do tratamento ortodôntico não aumenta o risco de DTM; 5) não existe diferença no tipo de mecânica ortodôntica que possa provocar DTM; 6) embora uma oclusão estável seja a meta do tratamento ortodôntico, quando não conseguida, não é o gatilho para sinais ou sintomas da DTM; 7) o tratamento ortodôntico não é preventivo para DTM e 8) quando sinais e sintomas de DTM estão presentes, uma simples terapêutica de tratamento pode aliviá-los.

Analisando 36 pacientes tratados ortodonticamente pela técnica "edgewise" e 30 indivíduos sem tratamento, HWANG; BEHRENTS ${ }^{56}$, em 1996, estudaram a relação entre tratamento ortodôntico e a discrepância determinada pelos movimentos mandibulares. Foram obtidos modelos de estudos, montados em articulador semi-ajustável, em posição de RC, que permitia também uma análise da $\mathrm{MIH}$, pela comparação entre ambas. Observaram um contato prematuro em $86,7 \%$ dos pacientes não tratados e $58,3 \%$ nos tratados. Analisando os pacientes com mais de dois contatos prematuros, verificaram que os tratados apresentaram um percentual de $41,6 \%$ e os pacientes do grupo controle não apresentaram mais de dois contatos. Observaram que os contatos estavam associados à inclinação vestibular da cúspide palatina dos molares superiores. Encontraram um maior 
número de contatos nos molares para ambos os grupos e que no grupo tratado com extração de primeiros pré-molares, o contato passava para os segundos prémolares. Concluíram com as observações encontradas que o tratamento ortodôntico não resulta em um aumento na discrepância cêntrica.

Em 1998, LUTHER; MORTH ${ }^{75}$, em uma revisão de literatura, estudaram a oclusão funcional (normal), a má oclusão e a Disfunção Temporomandibular, com o objetivo de esclarecer algumas dúvidas: 1) O tratamento ortodôntico deve terminar com uma oclusão funcional?; 2) O tratamento ortodôntico, quando terminado em oclusão funcional pode ser considerado como êxito? E se não for conseguido?; 3) A oclusão funcional quando conseguida, é estável? Concluíram ser necessário outros estudos, com metodologia mais específica para poder relacionar má oclusão e DTM. Embora estes fatores possam estar relacionados entre si, não implica uma relação de causa e efeito, e que a má oclusão e o tratamento ortodôntico não podem ser relatados como causa ou cura da DTM.

EGERMARK-ERIKSSON, MAGNUSSON, CARLSSON ${ }^{32}$ em 2003, analisaram a influência do tratamento ortodôntico nos sinais e sintomas da DTM, e diferentes tipos de má oclusão durante um período de 20 anos. Inicialmente foram examinados clinicamente 402 pacientes com 7, 11 e 15 anos, que também responderam um questionário sobre os sintomas de DTM. A avaliação foi repetida após 5,10 anos e 20 anos, sendo que na fase final 320 pacientes se submeteram novamente à avaliação. Os resultados demonstraram que a correlação entre os sinais e sintomas de DTM e os diferentes tipos de má oclusão foi fraca, entretanto algumas vezes significante. Os autores observaram que indivíduos com má oclusão por longo período apresentaram maior tendência de reportarem mais sinais e 
sintomas de DTM e demonstraram índice mais alto de disfunção, quando comparados com indivíduos sem má oclusão durante o mesmo período, entretanto não houve diferença estatisticamente significativa quanto a prevalência de DTM entre os indivíduos com ou sem tratamento ortodôntico prévio. O acompanhamento durante 20 anos suporta a opinião que não existe um específico fator oclusal com importância no desenvolvimento da DTM, mas a mordida cruzada unilateral pode ser um fator de risco.

Ainda em 2003, CONTI et al. ${ }^{16}$ avaliaram a prevalência de Disfunções Temporomandibulares em indivíduos tratados e não tratados ortodonticamente. A amostra foi composta por 200 jovens divididos em 4 grupos: grupo I com má oclusão de Classe I não tratados, grupo II com má oclusão Classe || não tratado, grupo III com má oclusão Classe I tratado ortodonticamente e grupo IV tratado de má oclusão de Classe II. Foi elaborado um índice anamnésico a partir de um questionário relativo aos principais sintomas de DTM, que permitiu a classificação da amostra de acordo com a presença e a severidade de DTM. Realizaram ainda exames de palpação dos músculos mastigatórios e cervicais, e da ATM, além da deteç̧ão de ruídos articulares e análise da movimentação mandibular. Observaram a prevalência de 34\% com DTM leve, 3,5\% com DTM moderada e 62,5\% apresentavam-se com ausência de DTM. Os índices de DTM leve e moderada foram mais freqüentes no gênero feminino, sendo os ruídos articulares $(15,5 \%)$ e dores de cabeça $(13 \%)$ os mais relatados. Não se observou associação entre a severidade de DTM e realização do tratamento ortodôntico. Concluíram que a realização do tratamento ortodôntico não se relaciona com a presença de sinais e sintomas de DTM, na população estudada. 


\section{4. - DEFORMIDADE DENTOFACIAL E CIRURGIA ORTOGNÁTICA}

Os efeitos do tratamento ortodôntico-cirúrgico no movimento mandibular foi estudado por NAGAMINE et al. ${ }^{88}$ (1993), em 30 pacientes com má oclusão esquelética de Classe III, corrigida com osteotomia sagital do ramo (27), combinação de osteotomia sagital do ramo e ostectomia do corpo (2) e osteotomia sagital combinada com osteotomia alveolar posterior da maxila (1). Após a cirurgia as medidas mínimas e máximas de movimento de protrusão da mandíbula foram respectivamente 4,1 e $6,7 \mathrm{~mm}$. Os resultados demonstraram aumento significativo dos movimentos de excursão lateral da mandíbula após a cirurgia nos lados direito $(4,8$ a $7 \mathrm{~mm})$ e esquerdo $(5,5$ a $7 \mathrm{~mm})$. Os resultados indicaram que a correção ortocirúrgica da Classe III esquelética apresenta efeitos favoráveis na função mandibular.

Em 1994, SEREN, et al. ${ }^{115}$ avaliaram a posição do côndilo na fossa articular em 21 pacientes adultos com má oclusão de Classe III e compararam com 18 adultos com oclusão normal. As estruturas articulares foram analisadas em imagem de corte axial de tomografia computadorizada. Os pesquisadores observaram um aumento significativo na dimensão médio-lateral dos côndilos, um estreitamento na dimensão da fossa e a posição do côndilo mais para anterior no grupo com má oclusão. Segundo os pesquisadores, os resultados sugeriram que a protrusão condilar com o alongamento médio-lateral do côndilo em uma fossa articular diminuída estão correlacionados com o deslocamento anterior da mandíbula na má oclusão esquelética de Classe III. 
FIENERMAN; PIECUCH ${ }^{34}$ examinaram, em 1995, 66 pacientes entre 2 e 9,5 anos após osteotomia sagital bilateral do ramo da mandíbula, sendo que 32 receberam fios de aço para fixação intermaxilar e 34 receberam fixação com miniplacas e parafusos monocorticais com função imediata após a cirurgia. Os autores não observaram diferenças entre os grupos quanto à crepitação, abertura bucal e dor articular, entretanto dores nos músculos da mastigação e estalidos articulares melhoraram com a fixação com mini-placas e parafusos e pioraram no grupo com fios de aço. Os autores concluíram, baseados nesta metodologia, que fixação com mini-placas e parafusos causa menos sinais e sintomas de DTM.

Com objetivo de relatar a prevalência de deslocamento de disco e sintomas articulares em pacientes que necessitavam de cirurgia ortognática, DAHLBERG et al. $^{22}$ (1995) examinaram, clinicamente e com artrografia da ATM, 53 pacientes com diferentes tipos de anomalias craniofaciais. Os resultados demonstraram deslocamento de disco uni ou bilateral em $57 \%$ dos pacientes (46\% das articulações), sendo com redução em 38 articulações e sem redução em 11, 53\% tinham dor muscular ou articular, 30\% das articulações apresentavam estalido e 4\% crepitação. Os autores concluíram que o deslocamento de disco é freqüente em pacientes com anomalia dentofacial, mas não existe relação entre os sintomas articulares e algum tipo específico de anomalia dentofacial.

Devido à deficiência de informação quanto à morfologia da ATM e sua relação com as variações nas relações esqueléticas e dentárias, COHLMIA et al. ${ }^{15}$, em 1996, avaliaram a relação entre côndilo e fossa da ATM em pacientes com diferentes tipos de má oclusão esquelética e dentária. Examinaram 232 pacientes caucasianos (95 do gênero masculino e 137 do feminino), sem tratamento 
ortodôntico ou cirúrgico, com idade entre 9 anos e 4 meses e 52 anos e 6 meses, através da análise de modelos, radiografia cefalométrica lateral, radiografia carpal e tomografia das articulações. A não concentricidade ou uma suave assimetria na relação côndilo-fossa foi comumente observada e os pacientes com má oclusão de Classe III esquelética e dentária demonstraram o côndilo posicionado significativamente para anterior, alteração que não foi observada nos pacientes com má oclusão de Classe I e II, sobremordida ou mordida cruzada.

SANROMÁN; et al. ${ }^{109}$ em 1997, estudaram 24 pacientes, com deformidade dentofacial de Classe III, com média de idade de 23,8 anos, que foram submetidos à cirurgia ortognática sendo que 9 receberam osteotomia apenas da maxila, 15 se submeteram à osteotomia subcondilar da mandíbula combinada a osteotomia maxilar e 10 foram usados como grupo controle por não apresentarem deformidade dentofacial e sinais e sintomas de DTM. As possíveis alterações morfológicas e morfométricas nos diferentes componentes da ATM, após a cirurgia ortognática, foram analisadas com imagens de tomografia computadorizada nos cortes transversal e sagital, por imagem coronal de ressonância magnética, exame clínico e radiográfico em 4 fases diferentes para localizar a posição do côndilo da mandíbula em relação à fossa articular: antes da cirurgia, 3 dias, 8 semanas e 1 ano após a cirurgia. Não houve diferença significativa, no grupo de osteotomia maxilar, entre as 4 fases do estudo. Os pacientes tratados com cirurgia bimaxilar demonstraram movimentos condilares diferentes após a cirurgia e foram observadas alterações na posição nos componentes ósseos da ATM após a cirurgia. Os autores concluíram que, as alterações nas posições dos componentes da ATM dos 
pacientes submetidos à osteotomia bimaxilar, parecem ser transitórias, sem acarretar grandes problemas a longo prazo para os pacientes.

Em 1997, SANROMÁN; GONZÁLEZ; HOYO ${ }^{108}$ investigaram o possível relacionamento entre as características morfológicas da ATM e as observações clínicas da ATM em diferentes tipos de deformidades faciais. Quarenta e oito pacientes com deformidades faciais (96 ATMs) foram avaliados previamente à intervenção cirúrgica e dez pacientes (20 ATMs) sem deformidades faciais foram mantidos como grupo controle. Realizaram avaliações clínicas e radiográficas utilizando tomografia computadorizada e imagem de ressonância magnética para observarem a posição do côndilo e do disco articular nos planos sagital, coronal e horizontal. Mais da metade das articulações $(53,6 \%)$ dos pacientes com deformidade dentofacial de Classe II, apresentava degeneração interna da ATM e deslocamento de disco para a anterior. Nos grupos de Classe I e III a incidência foi mais baixa $(10 \%)$.

MUTO et al. ${ }^{87}$, em 1998, avaliaram a relação entre o deslocamento de disco e as características da morfologia facial em 48 pacientes com má oclusão de Classe III, utilizando exame clínico, radiografia lateral oblíqua da ATM e cefalogramas. O deslocamento de disco foi determinado pela presença de sons articulares (estalido ou crepitação) ou pela restrição da translação condilar durante a máxima abertura bucal. Os autores compararam 32 pacientes que apresentavam sinais de deslocamento de disco, com 16 sem deslocamento de disco. Os resultados mostraram que os pacientes com sinais de deslocamento de disco apresentavam o ângulo goníaco e/ou o ângulo SN-plano mandibular significantemente maior. 
Concluíram que os aspectos morfológicos de pacientes com má oclusão de Classe III podem representar um fator de risco para o deslocamento de disco.

KOBAYASHI et al. ${ }^{64}$ (1999) examinaram 51 pacientes com prognatismo mandibular pela tomografia computadorizada. Observaram a presença de sinais e sintomas de disfunção articular em 35\% (15) da amostra total, no entanto esta incidência foi encontrada em $24 \%$ dos pacientes com prognatismo mandibular e em $58 \%$ dos pacientes com assimetria. Entre os pacientes com assimetria associada ao prognatismo observaram ainda que $58 \%$ apresentavam deslocamento de disco. Os autores concluíram que a morfologia esquelética pode apresentar um papel no desenvolvimento da DTM, mas o seu mecanismo foi considerado obscuro.

Com o intuito de investigar a morfologia da ATM e os sinais clínicos de DTM em pacientes com má oclusão de Classe III, UEKI et al. ${ }^{119}$ (2000), examinaram cefalogramas laterais, frontais e axiais de 44 pacientes divididos em 2 grupos: com e sem assimetria, com imagens obtidas por ressonância magnética. Os resultados indicaram mais deslocamento de disco para anterior e maior presença de sinais como estalido, crepitação e dor no grupo assimétrico. Nos pacientes assimétricos a fossa do lado com desvio se apresentava significativamente maior que a do lado normal. Concluíram que a incidência de degeneração interna da ATM em pacientes com assimetria é maior que em pacientes com prognatismo mandibular simétricos e esta diferença está associada à morfologia diferente dos dois lados no paciente assimétrico.

No mesmo ano, HU, WANG, ZOU ${ }^{55}$ investigaram as alterações na ATM e na posição condilar após o recuo da mandíbula usando diferentes osteotomias do ramo. A amostra constou de 50 pacientes xantodermas adultos com 
prognatismo mandibular, sendo 28 tratados com osteomtomia oblíqua do ramo (OOR) e fixação maxilo-mandibular durante 7 semanas, e 22 com osteotomia sagital do ramo (OSR) e fixação interna com miniplacas e parafusos monocorticais, os quais receberam avaliação clínica de sintomas articulares e radiográfica da ATM para observações morfológicas. O grupo com OOR demonstrou após a cirurgia, um deslocamento significativo do côndilo para anterior, $77 \%$ dos pacientes sintomáticos reportaram diminuição ou ausência de sintomas articulares, e os assintomáticos na fase pré-cirúrgica não desenvolveram sintomas articulares. No grupo com OSR as radiografias articulares demonstraram deslocamento para posterior do côndilo, $60 \%$ dos pacientes sintomáticos antes da cirurgia não apresentaram melhora na função articular após a cirurgia e 8\% dos pacientes assintomáticos desenvolveram sintomas articulares pós-cirurgia. Os autores concluíram que a osteotomia oblíqua do ramo, com fixação maxilo-mandibular, parece ser mais favorável para a articulação e está indicada para pacientes com sintomas articulares na fase pré-operatória.

Ainda em 2000, PANULA et al. $^{94}$ buscaram esclarecer a influência da cirurgia ortognática nos sinais e sintomas da DTM e a prevalência de dor de cabeça em 60 pacientes, com média de idade de 33,2 anos, examinados antes e 2 vezes após a cirurgia, pelo índice anamnésico de $\mathrm{HELKIMO}^{47,48}$ e índice de Disfunção. Um grupo de 20 pacientes com deformidade dentofacial não submetidos à cirurgia ortognática serviram como controle. A maioria dos pacientes $(73,3 \%)$ apresentava sinais e sintomas de DTM na fase pré-cirúrgica e ao final da pesquisa a prevalência de DTM reduziu para 60\%. A prevalência de pacientes com dor de cabeça também diminuiu, antes da cirurgia $63 \%$ dos pacientes apresentavam este sintoma, mas na visita final a prevalência caiu para $25 \%$. Os autores concluíram que 
o estado funcional pode ser significativamente melhorado e os níveis de dores de cabeça reduzidos com a cirurgia ortognática, no entanto não observaram associação entre DTM e um tipo específico ou magnitude de deformidade dentofacial.

Em 2002, GIDARAKOU et al. ${ }^{39}$ avaliaram o efeito do deslocamento de disco bilateral com redução no padrão esquelético e dentário. Observaram 12 pacientes do gênero feminino com deslocamento e 46 voluntárias normais. As pacientes tiveram suas ATM avaliadas por cortes no plano sagital e coronal de ressonância magnética. Foram obtidas medidas cefalométricas lineares e angulares de ressonância magnética para a comparação entre os grupos e utilizaram análise de variância para comparação entre os grupos. Os resultados demonstraram as seguintes alterações no grupo com deslocamento de disco: uma diminuição no comprimento da base do crânio anterior e posterior, e as medidas dos ângulos SNA e SNB também estavam menores. Quanto às alterações no padrão dentário encontraram: ângulo interincisivos maior $e$ os incisivos superiores mais verticalizados. Os autores observaram que as alterações esqueléticas podem estar associadas com deslocamento de disco, no entanto, o mecanismo que desenvolve o deslocamento de disco e/ou o mecanismo que causa a alteração esquelética não está claro. Os autores sugeriram que indivíduos com deslocamento de disco bilateral com redução, podem manifestar a morfologia craniofacial alterada e que o clínico deve estar atento para esta possibilidade em duas situações: pacientes em crescimento e em pacientes candidatos à cirurgia ortognática.

No mesmo ano UEKI, et al. ${ }^{120}$, compararam as alterações na morfologia e na sintomatologia clínica da Articulação Temporomandibular após Osteotomia Sagital do Ramo (OSR) e Osteotomia Vertical do Ramo (OVR) com e 
sem osteotomia do tipo Le Fort I. Foram diagnosticados 43 pacientes, 20 submetidos a OVR sem fixação interna rígida e 23 a OSR com fixação interna rígida. A morfologia articular, incluindo a posição do disco, foi obtida antes e após o procedimento cirúrgico por imagem de ressonância magnética e por telerradiografia axial. Os resultados indicaram diferença significativa na rotação condilar na imagem radiográfica. Pouco ou nenhum sintoma de DTM foi relatado após a cirurgia por $88 \%$ dos pacientes submetidos a OVR com ou sem Le Fort I e por $66,7 \%$ dos operados com OSR. Na imagem sagital não foi observada alteração na posição do disco no grupo de OSR, mas houve uma melhora em 44,4\% dos pacientes com deslocamento de disco anterior quando submetidos a OVR. Os autores concluíram que a OVR melhora o deslocamento anterior do disco no período pós-cirúrgico inicial, mas ambos os procedimento estudados podem melhorar os sintomas de DTM à longo prazo.

Recentemente (2003), GIDARAKOU et al. ${ }^{40}$ avaliaram o efeito do deslocamento de disco sem redução unilateral no padrão esquelético e dentário. Observaram 12 pacientes do gênero feminino com deslocamento e 46, voluntárias normais e para a avaliação da amostra utilizaram a mesma metodologia do estudo anterior. Os autores encontraram poucas diferenças esqueléticas, sendo que no grupo com deslocamento de disco observaram: redução nas medidas da base do crânio anterior (S-Na) e total (S-Ba), o ângulo do plano mandibular mais agudo e menor altura do ramo posterior da mandíbula. Na avaliação dentária a única diferença observada foi a infraoclusão do primeiro molar inferior. Concluíram que os resultados sugerem que indivíduos com deslocamento de disco unilateral sem redução podem apresentar morfologia craniofacial alterada, o que deve alertar o 
clínico, especialmente durante o tratamento ortodôntico em crianças e em pacientes cirúrgicos. 
PROPOSIÇÃO 


\section{3 - PROPOSIÇÃO}

Diante dos aspectos discutidos na Revisão da Literatura, e à grande diversidade de opiniões quanto à relação entre a má oclusão de Classe III, seu tratamento e a DTM, o objetivo deste trabalho foi avaliar, em pacientes com tratamento ortodôntico (grupo I) e orto-cirúrgico (grupo II), as diferentes situações:

- presença e severidade Disfunção Temporomandibular nos pacientes submetidos a tratamento ortodôntico da má oclusão de Classe III e a presença e/ou severidade de DTM;

- presença e severidade Disfunção Temporomandibular nos pacientes submetidos a Cirurgia Ortognática no tratamento da má oclusão de Classe III e a presença e/ou severidade de DTM

- a diferença na prevalência de DTM entre os grupos estudados e - influência dos aspectos oclusais na severidade de DTM. 
MATERIAL E MÉTODOS 


\section{4 - MATERIAL E MÉTODOS}

\section{1 - AMOSTRA}

A amostra deste estudo foi obtida no acervo da Disciplina de Ortodontia, da Faculdade de Odontologia de Bauru (FOB) - Universidade de São Paulo e no arquivo da clínica particular do Dr. Laurindo Zanco Furquim, na cidade de Maringá - Paraná. Foram avaliados 50 pacientes, sendo 21 da FOB e 29 da clínica do Dr. Laurindo Zanco Furquim. A amostra foi dividida em 2 grupos:

Grupo I: 25 jovens, submetidos ao Tratamento Ortodôntico para a correção da má oclusão de Classe III.

Grupo II: 25 jovens, submetidos ao Tratamento Orto-Cirúrgico para a correção da má oclusão de Classe III.

Toda a amostra foi avaliada no mínimo 1 ano após a finalização do tratamento ortodôntico.

\section{2 - ANAMNESE}

\subsection{1 - Aplicação do Questionário}

Aos pacientes foi solicitado o preenchimento de uma ficha contendo informações pessoais (nome, idade, gênero, endereço, telefone) e questões sobre sintomas relativos as Disfunções Temporomandibulares (questionário anamnésico). 
Este questionário foi desenvolvido baseado em fichas preexistentes $^{17,35,47,48}$ e aplicado aos pacientes sem interferência do examinador, de modo que não se criasse uma expectativa, podendo desviar os resultados do exame clínico a ser realizado. Os pacientes responderam 13 perguntas relativas a sintomas, sendo que as primeiras dez, permitiram a obtenção de uma classificação do caso em relação ao grau de disfunção, e as outras três foram analisadas separadamente. Esse questionário foi modificado a partir de trabalhos prévios que demonstraram a eficiência da obtenção de um diagnóstico pela anamnese ${ }^{17,35}$.

\section{ANAMNESE}

1. Você sente dificuldade de abrir a boca?

2. Você sente dificuldade de movimentar sua mandíbula para os lados?

3. Você sente desconforto ou dor muscular quando mastiga?

4. Você sente dores de cabeça com freqüência?

5. Você sente dores no pescoço e/ou ombros?

6. Você sente dores de ouvido ou próximo a ele?

7. Você percebe algum ruído na ATM ?

8. Você considera sua mordida "normal" ?

9. Você usa apenas um lado de sua boca para mastigar?

10. Você sente dores na face ao acordar? 
Foram oferecidas as possibilidades das respostas: "sim", "não" ou "às vezes". Cada "sim" recebeu o valor 2, "às vezes" valor 1 e 0 para a resposta "não". As questões 4, 6 e 7 receberam valor 3 quando a resposta "sim" correspondia a sintomas bilaterais ou intensos, 2 se unilaterais ou leves, 1 "às vezes" e zero para "não", A somatória dos valores obtidos, das respostas dos pacientes, permitiu a classificação da amostra em relação à DTM, com base nos seguinte valores, de acordo com CONTI et al. ${ }^{17}$ :

Valores de 0 a 3: $\quad$ não portador de DTM

Valores de 4 a 8: $\quad$ portador de DTM leve

Valores de 9 a 14: portador de DTM moderada

Valores de 15 a 23: portador de DTM severa

Os pacientes responderam ainda duas questões que não participaram da determinação do índice anamnésico de DTM.

11. Você se considera uma pessoa tensa?

12. Você apresenta algum dos seguintes hábitos?

$\begin{array}{lll}\text { Ranger dentes } & \text { Apertar dentes } & \text { Roer unhas } \\ \text { Morder objetos } \quad \text { Mascar chicletes } & \text { Uso contínuo de telefone } \\ \text { Uso contínuo de computador } & \end{array}$

\subsection{2 - Avaliação dos Tipos de Tratamento}

Os grupos foram avaliados em relação ao tipo de aparelhos utilizados durante o tratamento (fixo, expansor, máscara, mentoneira e progênico). Os diferentes tipos de extração foram relacionados da seguinte forma: ausência de 
extrações, extrações de pré-molares superiores, extrações de pré-molares inferiores e extrações de pré-molares superiores e inferiores.

O grupo II (tratado com ortodontia seguida de cirurgia-ortognática) foi avaliado quanto à base óssea evolvida no procedimento cirúrgico (maxila, mandíbula ou ambas) e ao tipo de contenção utilizada após a cirurgia (elásticos ou fio de aço).

\section{3 - EXAME FÍSICO}

Os materiais utilizados para o exame clínico foram :

a) papel celofane;

b) fita detectora de contatos (Accu-Film*)

c) pinça de Miller e

d) espelho clínico.

O exame clínico foi realizado por um examinador treinado, previamente calibrado, para a obtenção dos dados relacionados com a avaliação da ATM, dos músculos e dos dentes e da oclusão. No que se refere à quantidade de força a ser aplicada, o examinador foi treinado com a utilização de um algômetro (aparelho que mede a sensibilidade à dor, causada por pressão). Esta avaliação foi realizada com os pacientes sentados e relaxados.

* Accu Film II (Red-Black-Parkell- N.Y. - USA) 


\subsection{1 - Avaliação da ATM}

Os movimentos mandibulares foram os primeiros itens analisados. Observou-se o grau de abertura bucal ativa (incluindo o overbite), lateralidade direita e esquerda e a protrusão.

\subsubsection{1 - Abertura bucal máxima ativa}

Foi solicitado ao paciente abrir a boca ao máximo e realizava-se a medição, com uma régua milimetrada, da distância interincisivos superior e inferior, tomando como referência a linha mediana. A este valor somou-se a medida do overbite.

\subsubsection{2 - Lateralidade e protrusão}

Realizou-se este procedimento marcando, com grafite $0,5 \mathrm{~mm}$, a linha média no arco inferior, a partir do arco superior. Em seguida o paciente foi solicitado a movimentar a mandíbula para os lados e com uma régua posicionada no plano horizontal, realizava-se a medida da linha média superior até a linha marcada no arco inferior das excursões máximas.

Solicitando-se ao paciente a realização do movimento da mandíbula para frente, mediu-se a protrusão. Para tal usava-se uma régua posicionada no plano horizontal, tocando a face vestibular do incisivo central superior, e com o paciente em posição protrusiva, tomava-se a medida até a face vestibular do incisivo central inferior acrescentando-se o overjet. 


\subsubsection{3 - Análise de ruídos articulares}

Os ruídos articulares (estalido e crepitação) eram observados posicionando-se os dedos indicadores levemente na região correspondente ao pólo lateral dos côndilos, à frente do meato acústico externo, enquanto o paciente realizava movimentos de abertura e fechamento mandibular. Para se considerar o estalido como presente era necessário que este se repetisse por 3 vezes ${ }^{28}$. Durante este exame, a hipermobilidade da articulação temporomandibular era também analisada.

\subsubsection{4 - Palpação da ATM}

A avaliação da presença de sintomatologia dolorosa na ATM foi realizada inicialmente orientando o paciente quanto à diferença entre pressão e desconforto, com a finalidade de não gerar dúvidas durante as respostas. Realizouse palpação digital bilateral com os dedos indicadores 10 a $20 \mathrm{~mm}$ à frente do conduto auditivo externo, instruindo o paciente a realizar o movimento de abertura e fechamento da boca. Desta forma avaliou-se a ATM com a boca fechada (aspecto lateral) e aberta (aspecto posterior).

\subsection{2 - Exame Muscular}

A palpação muscular foi realizada bilateralmente, exercendo pressão firme, porém de maneira suave, com a sensação dolorosa constatada pelo reflexo palpebral e/ou questionamento ao paciente. Procurou-se manter uma pressão constante de acordo com CONTI et $\mathrm{al}^{17}$ em 1996. 
Os músculos palpados foram: temporal (anterior, médio e posterior), masséter superficial (origem, médio e posterior), masséter profundo, esternocleidomastóideo e trapézio (superior).

Com base nos conceitos descritos por DWORKIN, LE RESCHE ${ }^{27}$, foi considerada a presença de dor muscular quando havia sintomatologia dolorosa em pelo menos três pontos.

\subsection{3 - Avaliação Dentária e Oclusal}

Toda a cavidade bucal foi inspecionada, procurando-se verificar a ausência de dentes, facetas de desgaste, overjet e overbite, relações maxilomandibulares $(\mathrm{RC}$ e $\mathrm{MIH})$, presença e tipo de guias lateral e anterior, interferências no lado de não-trabalho, número de contatos dentários em MIH. A mensuração do overjet e do overbite foi realizada com o auxílio de uma régua milimetrada.

Para averiguar as diferenças das posições maxilomandibulares obteve-se a posição de RC com a técnica de manipulação unilateral do paciente e comparou-se à posição de $\mathrm{MIH}$, medindo-se a discrepância vertical entre essas posições.

Realizou-se a avaliação da presença e do tipo de guia lateral e a presença de guia anterior. O número de contatos em MIH foi obtido interpondo-se uma folha de Accu-Film entre os dentes enquanto o paciente abria e fechava a boca. 
Os tipos de má oclusão foram relacionados classificando a relação sagital final em relação de Classe I, até $1 \frac{1}{2}$ Classe III e Classe III. Consideraram-se ainda a presença das mordidas aberta e cruzada (uni e bilateral).

\section{4 - ANÁLISE ESTATÍSTICA}

As freqüências das diversas variáveis analisadas foram expressas em percentual.

Para a obtenção dos resultados foram aplicados os testes:

- Teste "t" de Student, para dados paramétricos, que testou idade, abertura bucal, lateralidade, protrusão, overjet, overbite e número de contatos oclusais em MIH.

- Teste de qui-quadrado, que analisou a associação entre o índice de DTM e as demais condições estudadas nesta pesquisa.

- Teste Mann-Witney, para dados não paramétricos, que analisou as diferenças intergrupos do índice de DTM.

A execução dos testes estatísticos foi realizada com o auxílio do programa de computador Statistica 5.0. 
RESULTADOS 


\section{5 - RESULTADOS}

\section{$5.1-R E S U L T A D O S$ DESCRITIVOS}

\subsection{1 - DADOS GERAIS E PREVALÊNCIA DE DTM}

A amostra estudada apresentou a média de idade de 25,8 anos. Quando os grupos foram avaliados separadamente encontrou-se os valores de 24,7 anos (mínima de19 e máxima de 47 anos) para o grupo I (pacientes tratados ortodonticamente), e 26,9 anos (mínima 18 e máxima de 40 anos) para o grupo II (pacientes tratados com ortodontia seguida de cirurgia ortognática).

A distribuição do gênero na amostra geral foi de 36\% (18) de indivíduos do gênero masculino e 64\% (32) do feminino.

Os resultados do questionário anamnésico, elaborado com o objetivo de se criar um meio diagnóstico em relação à DTM, encontram-se nas Tabelas 5.1 e 5.2, divididos pelos grupos de estudo. 
Tabela 5.1 - Freqüência percentual das respostas do questionário anamnésico pelo grupo I (Classe III com tratamento ortodôntico)

\begin{tabular}{c|ccc}
\hline Resposta & SIM & Às VEZES & NÃO \\
\hline 1 & & & \\
\hline 2 & $4 \%$ & $4 \%$ & $96 \%$ \\
3 & $0 \%$ & $4 \%$ & $92 \%$ \\
4 & $16 \%$ e $4 \% *$ & $8 \%$ & $92 \%$ \\
5 & $24 \%$ & $40 \%$ & $40 \%$ \\
6 & $8 \%$ & $44 \%$ & $32 \%$ \\
7 & $0 \%$ e $4 \%$ ** & $8 \%$ & $84 \%$ \\
8 & $64 \%$ & $24 \%$ & $72 \%$ \\
9 & $12 \%$ & $0 \%$ & $36 \%$ \\
10 & $4 \%$ & $4 \%$ & $84 \%$ \\
\hline
\end{tabular}

*dor intensa

**presença de sinal bilateral

Tabela 5.2 - Freqüência percentual das respostas do questionário anamnésico pelo Grupo II (Classe III tratados com cirurgia ortognática)

\begin{tabular}{c|ccc}
\hline Resposta & SIM & Às VEZES & NÃO \\
\hline 1 & & & \\
\hline 2 & $0 \%$ & 12 & $88 \%$ \\
3 & $0 \%$ & $16 \%$ & $84 \%$ \\
4 & $4 \%$ & $16 \%$ & $80 \%$ \\
5 & $12 \%$ & $24 \%$ & $64 \%$ \\
6 & $12 \%$ & $44 \%$ & $44 \%$ \\
7 & $8 \%$ & $16 \%$ & $76 \%$ \\
8 & $24 \%$ & $28 \%$ & $48 \%$ \\
9 & $16 \%$ & $0 \%$ & $84 \%$ \\
10 & $16 \%$ & $32 \%$ & $52 \%$ \\
\hline
\end{tabular}


Somando-se os escores das respostas do questionário anamnésico (2 para a resposta "sim", 1 para a resposta "às vezes" e 0 para a resposta "não"), chegou-se à classificação do índice anamnésico para toda a amostra:

- $\quad$ DTM ausente - $48 \%$
- $\quad$ DTM leve - $42 \%$
- $\quad$ DTM moderada - $10 \%$
O índice anamnésico para cada grupo foi:

\begin{tabular}{|c|c|c|c|}
\hline & & Grupo I & Grupo II \\
\hline- & DTM ausente & $40 \%$ & $56 \%$ \\
\hline- & DTM leve & $52 \%$ & $36 \%$ \\
\hline - & DTM moderada & $8 \%$ & $12 \%$ \\
\hline
\end{tabular}

Os sintomas mais relatados por toda a amostra foram as dores de cabeça e os ruídos articulares com $48 \%$ e 40\%, respectivamente, observados nas questões 4 e 7 do questionário. 


\subsection{2 - DADOS RELACIONADOS AOS MOVIMENTOS MANDIBULARES}

A abertura bucal (ativa) mostrou uma média de 48,56mm (dp=6,6), sendo 49,12mm (dp=5,9) para o grupo I e 48mm $(d p=6,0)$ para o grupo II.

Os movimentos de lateralidade direita e esquerda apresentaram médias de 7,32mm $(d p=2,5)$ e 7,88mm $(d p=2,42)$ respectivamente. As médias dos movimentos laterais por grupo foram:

- $\quad$ Lateralidade direita - 7,80mm (grupo I) e 6,84mm (grupo II)

- $\quad$ Lateralidade esquerda - 8,20mm (grupo I) e 7,56mm (grupo II)

No movimento protrusivo a média obtida entre os indivíduos analisados foi de 5,6mm (dp=2), sendo 6,08mm para o grupo I e 5,04mm para o grupo II.

\subsection{3 - DADOS RELACIONADOS À PALPAÇÃO ARTICULAR E MUSCULAR}

Durante o exame clínico, foram detectados estalidos articulares em 44\% ( $n=22)$ da amostra, sendo que 24\% ( $n=12)$ pertenciam ao grupo I e $20 \%(n=10)$ ao grupo II. Ruídos compatíveis com crepitação foram detectados somente em 4 indivíduos, representando $8 \%$ da amostra geral, divididos igualmente entre os dois grupos.

Ao considerar a sensibilidade à palpação da ATM em pelo menos um ponto, envolvendo os aspectos lateral e posterior de ambos os lados, $34 \%$ ( $\mathrm{n}=17$ ) apresentaram sensibilidade dolorosa, presente em 11 indivíduos do grupo I e 6 do grupo II. 
A sensibilidade à palpação muscular, considerada quando presente em pelo menos três pontos, foi observada em 42\% (n=21) da amostra geral, sendo 11 indivíduos do grupo I e 10 do grupo II. Os músculos mais afetados por sensibilidade dolorosa à palpação foram o esternocleidomastóideo e o trapézio ambos observados em $28 \%$ da amostra $(n=14)$.

\subsection{4 - DADOS RELACIONADOS COM A OCLUSÃO MORFOLÓGICA}

$\mathrm{Na}$ mordida aberta anterior, $8 \%(\mathrm{n}=4)$ de todos os casos analisados apresentaram esta má oclusão, divididos igualmente entre os dois grupos estudados.

A mordida cruzada posterior foi observada em 4 jovens representando $8 \%$ da amostra e quando avaliada separadamente enquanto uni ou bilateral, o resultado geral para mordida cruzada unilateral foi de $6 \%(n=3)$, sendo 2 indivíduos do grupo I e 1 do grupo II, enquanto para mordida cruzada bilateral apenas 1 indivíduo do grupo I demonstrou esta má oclusão.

O overbite teve uma média geral de $2,16 \mathrm{~mm}(\mathrm{dp}=1,81)$, sendo $1,8 \mathrm{~mm}(\mathrm{dp}=1,8)$ para o grupo I e 2,5mm $(\mathrm{dp}=2,0)$ para o grupo II.

No overjet o valor médio encontrado foi 1,82mm ( $d p=1,22)$ : o grupo I apresentou 1,44mm (dp=1,32) e o grupo II, 2,20mm $(d p=1,0)$.

$\mathrm{Na}$ avaliação da relação sagital obteve-se para a amostra geral $64 \%$ da amostra $(n=32)$ com relação de Classe I, representados por $48 \%(n=12)$ do grupo I e $80 \%(n=20)$ do grupo II; $28 \%(n=14)$ com até $1 / 2$ Classe III, sendo $36 \%$ 
(n=9) do grupo I e $20 \%$ (n=5) do grupo II. Apenas 4 indivíduos, representando $8 \%$ da amostra, todos do grupo I, apresentaram relação sagital maior ou igual à Classe III.

\subsection{5 - DADOS RELACIONADOS COM OS ASPECTOS OCLUSAIS}

\section{O número de contatos na posição de máxima intercuspidação} habitual mostrou uma média geral de 16,9 contatos $(\mathrm{dp}=4,1)$ para a amostra geral. O número de contatos para os 2 grupos separadamente foi de:

$$
\begin{array}{ll}
\text { - } & \text { Grupo I - 17,2 (dp=3,2) } \\
\text { - } & \text { Grupo II - 16,6 (dp=4,8) }
\end{array}
$$

$\mathrm{Na}$ discrepância entre as posições de relação cêntrica (RC) e máxima intercuspidação habitual (MIH), 92\% ( $\mathrm{n=46)}$ dos indivíduos analisados apresentaram discrepância de 0 a $2 \mathrm{~mm}$, sendo representados por $92 \%(n=23)$ do grupo I e 92\% ( $n=23)$ do grupo II. A diferença entre RC e MIH de 2 a $4 \mathrm{~mm}$ foi observada em 8\% (n=2) nos 2 grupos avaliados, representando 8\% da amostra geral $(n=4)$. Os grupos estudados não apresentaram indivíduos com discrepância maior que $4 \mathrm{~mm}$. De toda a amostra estudada 62\% (n=31) apresentavam RC e MIH coincidente, sendo $68 \%(n=17)$ para o grupo I e $56 \%(n=14)$ para o II.

Ao avaliar a guia lateral, independente do lado, os resultados demonstraram que $70 \%$ ( $n=35,14$ do grupo I e 21 do grupo II) dos indivíduos apresentavam algum tipo de desoclusão lateral, sendo pelo canino ou em grupo.

Quanto à guia lateral direita, os resultados indicaram que $66 \%$ $(n=33)$ da amostra apresentava desoclusão pelo canino, 16\% $(n=8)$, desoclusão em grupo e 18\% (n=9) não tinham guia. Considerando os grupos I e II observou-se: 56\% 
$(n=14)$ e $76 \%(n=19)$ com desoclusão pelo canino; $16 \%(n=4)$ nos dois grupos com desoclusão em grupo; e $28 \%(n=7)$ e $8 \%(n=2)$ não realizavam esses tipos de desoclusão lateral direita.

Os resultados da avaliação da guia lateral esquerda, nos grupos I e II foram respectivamente: $48 \%(n=12)$ e $76 \%(n=19)$ com desoclusão pelo canino; $12 \%(n=3)$ e $16 \%(n=4)$ com desoclusão em grupo; e $40 \%(n=10)$ e $8 \%(n=2)$ sem estas guias laterais. Analisando a amostra como um todo obteve-se: $62 \%(n=31)$ com guia pelo canino, $14 \%(n=7)$ com função em grupo e $24 \%(n=12)$ sem esses tipos de guias.

Considerando a amostra como um todo, obtiveram-se $76 \%(\mathrm{n}=38)$ com guia anterior e $24 \%$ entre os indivíduos sem guia. A análise das amostras separadamente demonstrou uma distribuição igual entre os grupos I e II de $76 \%$ $(n=19)$ com guia e $24 \%(n=6)$ sem guia anterior.

A análise dos contatos em lado de não-trabalho direito, mostrou que $78 \%(n=39)$ dos indivíduos não apresentavam contatos, $8 \%(n=4)$ tinham interferência, porém mantinham a desoclusão no lado de trabalho e 14\% $(n=7)$ demonstraram interferência, impedindo a desoclusão. Os valores obtidos por grupo foram:

\begin{tabular}{ccc} 
& \multicolumn{1}{c}{ I } & II \\
\multicolumn{1}{c}{ Ausente } & $64 \%(\mathrm{n}=16)$ & $92 \%(\mathrm{n}=23)$ \\
Presente com guia & $8 \%(\mathrm{n}=2)$ & $8 \%(\mathrm{n}=2)$ \\
Presente sem guia & $28 \%(\mathrm{n}=7)$ & $0 \%(0)$
\end{tabular}


Quanto aos contatos em lado de não trabalho esquerdo, os valores da amostra total foram 78\% $(n=39)$ sem interferência, 6\% $(n=3)$ com guia e 16\% ( $n=8)$ sem guia. Os grupos se comportaram da seguinte maneira:

$\begin{array}{ccc} & \text { I } & \text { II } \\ \text { Ausente } & 68 \%(n=17) & 88 \%(n=22) \\ \text { Presente com guia } & 8 \%(n=2) & 4 \%(n=1) \\ \text { Presente sem guia } & 24 \%(n=6) & 8 \%(n=2)\end{array}$

Avaliando estes resultados, independente dos lados direito ou esquerdo, obteve-se: $72 \%(n=36)$ da amostra sem contatos no lado de não trabalho, 8\% ( $n=4)$ apresentavam estes contatos sem causar alteração na guia de desoclusão e 20\% (n=10) apresentavam da interferência durante a desoclusão lateral. Ao realizar a avaliação determinando apenas a presença de interferência (contato em lado de não-trabalho que impede a desoclusão lateral), observa-se $80 \%$ da amostra não apresentava este tipo de contato. Considerando amostra divida por grupos obteve-se os seguintes valores:

$\begin{array}{ccc} & \text { I } & \text { II } \\ \text { Ausente } & 60 \%(15) & 88 \%(21) \\ \text { Presente com guia } & 8 \%(2) & 4 \%(2) \\ \text { Presente sem guia } & 32 \%(8) & 8 \%(2)\end{array}$




\subsection{6 - DADOS RELACIONADOS COM O TIPO DE TRATAMENTO}

Os grupos foram avaliados quanto ao tipo de aparelho utilizado durante o tratamento e os resultados indicaram que, no grupo I, $20 \%(n=5)$ foram tratados apenas com aparelho fixo, os demais indivíduos usaram outros aparelhos associados:

Aparelho fixo + expansor: $40 \%(n=10)$

Aparelho fixo + expansor + máscara: $12 \%(n=3)$

Aparelho fixo + expansor + máscara+ progênico: 20\% $(n=5)$

Aparelho fixo + expansor +máscara + mentoneira: $8 \%(n=2)$

No grupo de pacientes tratados com cirurgia ortognática $72 \%(n=18)$ usou apenas aparelho fixo, enquanto 16\% (n=4) realizaram expansão, $8 \%(n=2)$ se submeteu a expansão e tração reversa da maxila e apenas 4\% ( $n=1)$ usou mentoneira antes do preparo ortodôntico.

Considerando que na amostra geral, todos os pacientes usaram aparelho fixo e que $46 \%(n=23)$ usou apenas este, a freqüência de uso dos demais aparelhos foi:

Expansor: $28 \%(n=14)$

Expansor + máscara: 10\% $(n=5)$

Expansor + máscara + progênico: 10\% $(n=5)$

Expansor +máscara + mentoneira: 4\% $(n=2)$

Mentoneira: $2 \%(n=1)$

A realização de extrações de pré-molares como parte do tratamento ortodôntico foi avaliada e considerando a amostra geral, em $58 \%(n=29)$ 
dos indivíduos tratados a extração não fez parte do tratamento, em 12\% (n=6) foram extraídos os pré-molares superiores, os pré-molares inferiores foram extraídos em $14 \%(n=7)$ e a extração em ambos os arcos foi realizada em 16\% (n=8) da amostra.

O grupo II, de pacientes submetidos à cirurgia ortognática foi avaliado quanto às bases ósseas envolvidas na cirurgia, onde $12 \%$ foram operados apenas na maxila, $12 \%$ na mandíbula e $76 \%(n=19)$ em ambas as bases.

O tipo de contenção pós-cirúrgica foi avaliado e os resultados demonstraram que 56\% ( $n=14)$ utilizaram elásticos e $44 \%(n=11)$ utilizaram fio de aço. 


\section{2 - RESULTADOS ANALÍTICOS}

As variáveis abertura bucal, lateralidade, protrusão, overjet, overbite e número de contatos em MIH foram submetidas ao teste "t" de Student para avaliar a diferença entre os grupos estudados. O teste " $\mathrm{t}$ " demonstrou diferença estatisticamente significativa apenas para overjet $(p<0,03)$.

O índice anamnésico foi aplicado também em cada grupo estudado, em relação à presença e/ou severidade de DTM (tabela 5.3).

Tabela 5.3 - Distribuição da amostra, dividida por grupos, em relação ao índice de DTM

\begin{tabular}{c|cccc}
\hline GRUPOS & AUSENTE & LEVE & MODERADA & TOTAL \\
\hline I & $40 \%(10)$ & $52 \%(13)$ & $8 \%(2)$ & $100 \%(25)$ \\
II & $56 \%(14)$ & $32 \%(8)$ & $12 \%(3)$ & $100 \%(25)$ \\
\hline
\end{tabular}

( ) número de indivíduos

Quando aplicado o teste de Mann-Whitney, não se obteve diferença estatisticamente significativa $(p=0,40)$ entre os grupos avaliados. A figura 5.1 apresenta a distribuição dos indivíduos nos dois grupos nas classificações de DTM. Nenhum indivíduo foi classificado como portador de "DTM severa", pelo questionário anamnésico. 


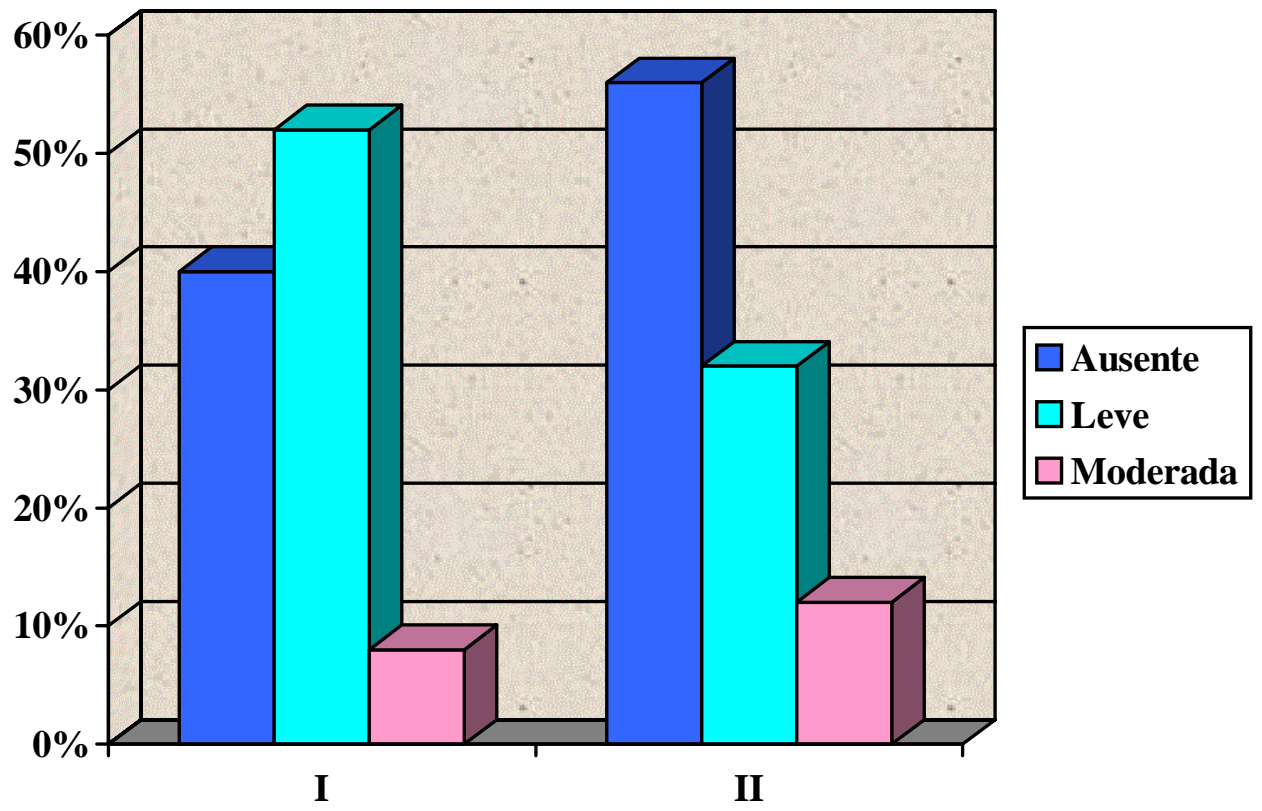

Figura 5.1 - Gráfico da distribuição da amostra, dividida por grupos, em relação ao índice de DTM

As diferentes variáveis foram comparadas, individualmente, aos índices de DTM (ausente, leve e moderada), com o objetivo de elucidar a relação existente entre eles.

Ao aplicar o teste qui-quadrado para se estabelecer a associação entre o gênero e o índice de DTM, não se constatou resultado significativo ( $p>0,3)$. A presença de hábitos também não demonstrou associação significativa com o índice de DTM $(p>0,3)$.

Os dados referentes aos ruídos articulares foram submetidos ao teste qui-quadrado e tanto o estalido $(p>0,1)$ como a crepitação $(p=0,7)$ não demonstraram associação significativa com o índice de DTM pelo teste quiquadrado. 
Os valores obtidos da associação entre a mordida aberta anterior e o índice de DTM encontram-se na tabela 5.4. Quando aplicado o teste qui-quadrado, não se constatou uma associação estatisticamente significativa $(p=0,17)$.

Tabela 5.4 - Relação entre a mordida aberta anterior (MAA) e o grau de DTM

\begin{tabular}{c|cccc}
\hline \multicolumn{1}{r}{ DTM } & Ausente & Leve & Moderada & Total \\
\hline Ausente & $45,65 \%(21)$ & $45,65 \%(21)$ & $8,7 \%(4)$ & $100 \%(46)$ \\
Presente & $75 \%(3)$ & $0 \%$ & $25 \%(1)$ & $100 \%(4)$ \\
\hline
\end{tabular}

( ) número de indivíduos

A tabela 5.5 mostra a freqüência de pacientes com e sem mordida cruzada posterior nas diferentes intensidades de DTM. O teste qui-quadrado não detectou associação estatisticamente significante $(p=0,17)$.

Tabela 5.5 - Relação entre a mordida cruzada posterior(MCP) e o grau de DTM

\begin{tabular}{c|cccc}
\hline DTM & Ausente & Leve & Moderada & Total \\
\hline Ausente & $45,65 \%(21)$ & $45,65 \%(21)$ & $8,7 \%(4)$ & $100 \%(46)$ \\
Presente & $75 \%(3)$ & $0 \%$ & $25 \%(1)$ & $100 \%(4)$ \\
\hline
\end{tabular}

( ) número de indivíduos 
A freqüência de relação sagital obtida na amostra está descrita na tabela 5.6. O teste qui-quadrado não detectou associação significativa $(p=0,8)$.

Tabela 5.6 - Relação sagital e grau de DTM

\begin{tabular}{c|cccc}
\hline $\begin{array}{l}\text { Relação } \\
\text { Sagital }\end{array}$ & Ausente & Leve & Moderada & Total \\
\hline Classe I & $50 \%(16)$ & $40,6 \%(13)$ & $9,4 \%(3)$ & $100 \%(32)$ \\
Até $1 \frac{1}{2}$ Classe III & $42,9 \%(6)$ & $50 \%(7)$ & $7,1 \%(1)$ & $100 \%(14)$ \\
Mais de $1 / 2$ & $50 \%(2)$ & $25 \%(1)$ & $25 \%(1)$ & $100 \%(4)$ \\
Classe III & & & & \\
\hline ( ) número de indivíduos & & &
\end{tabular}

A discrepância entre as posições de relação cêntrica (RC) e máxima intercuspidação habitual (MIH) estão descritas na tabela 5.7. O teste quiquadrado não revelou associação estatisticamente significativa $(p=0,3)$.

Tabela 5.7 - Relação entre a discrepância de RC para MIH e o grau de DTM

\begin{tabular}{c|cccc}
\hline DTM & Ausente & Leve & Moderada & Total \\
DISCREPÂNCIA & & & & \\
\hline 0 a $2 \mathrm{~mm}$ & $50 \%(23)$ & $39,1 \%(18)$ & $10,9 \%(5)$ & $100 \%(46)$ \\
2 a $4 \mathrm{~mm}$ & $25 \%(1)$ & $75 \%(3)$ & $0 \%()$ & $100 \%(4)$ \\
\hline
\end{tabular}

( ) freqüência em número de indivíduos 
A freqüência de indivíduos com RC e MIH coincidentes também foi avaliada e está relatada na tabela 5.8 e figura 5.2. O teste qui-quadrado não detectou associação estatisticamente significativa $(p=0,57)$.

Tabela 5.8 - Relação presença de RC coincidente com MIH e o grau de DTM

\begin{tabular}{c|cccc}
\hline DTM & Ausente & Leve & Moderada & Total \\
\hline Coincidente & $45,2 \%(14)$ & $51,6 \%(16)$ & $3,2 \%(1)$ & $100 \%(31)$ \\
\hline Não coincidente & $52,6 \%(10)$ & $26,3 \%(5)$ & $21,1 \%(4)$ & $100 \%(19)$ \\
\hline
\end{tabular}

( ) freqüência em número de indivíduos

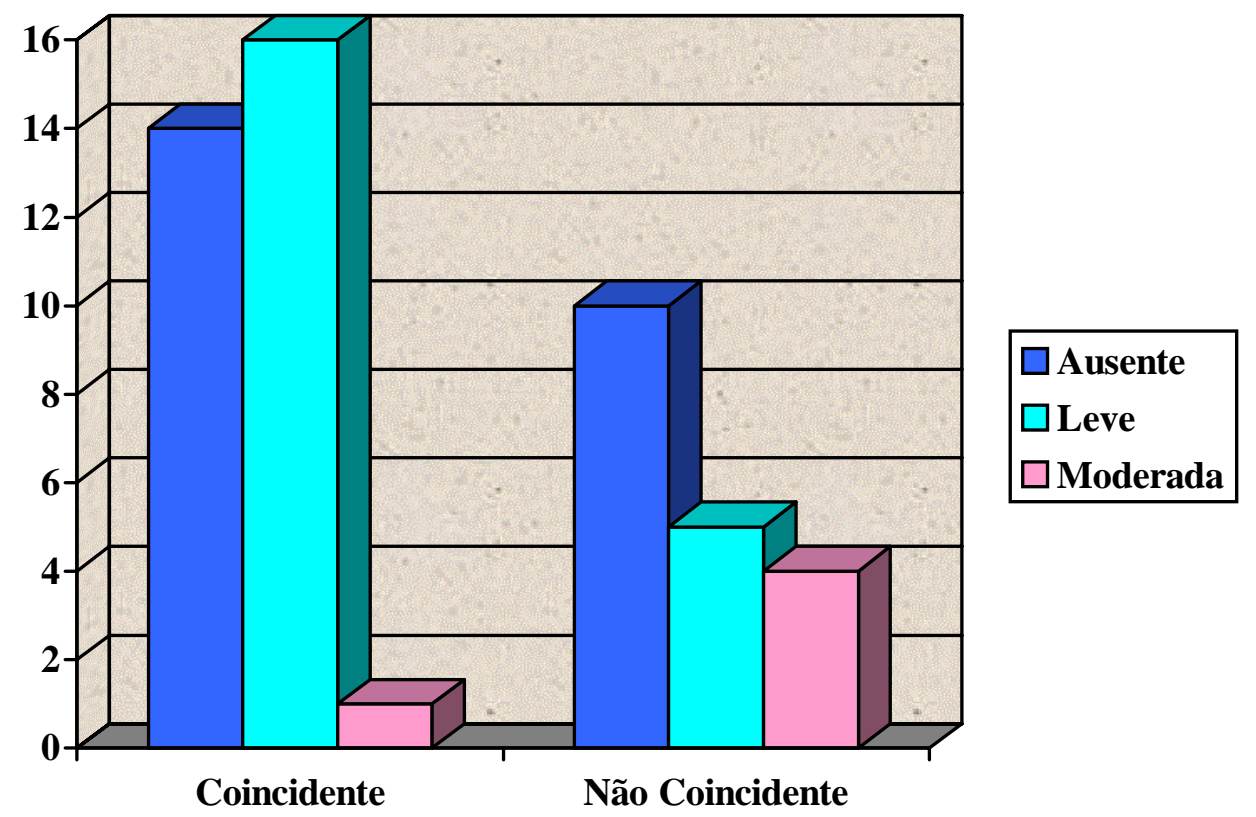

Figura 5.2 - Gráfico da relação entre a presença de RC coincidente com MIH e o grau de DTM 
Os movimentos de guia lateral direita e esquerda foram analisadas em conjunto para a comparação do índice de DTM (tabela 5.9). O teste qui-quadrado não constatou associação estatisticamente significativa entre as variáveis $(p=0,35)$.

Tabela 5.9 - Relação entre o guia lateral e o grau de DTM

\begin{tabular}{c|cccc}
\hline DTM & Ausente & Leve & Moderada & Total \\
GUIA LATERAL & & & & \\
\hline Ausente & $60 \%(9)$ & $26,6 \%(4)$ & $13,4 \%(2)$ & $100 \%(15)$ \\
Presente & $42,8 \%(15)$ & $48,6 \%(17)$ & $8,6 \%(3)$ & $100 \%(35)$ \\
\hline
\end{tabular}

( ) número de indivíduos

Na tabela 5.10 encontra-se descritas a freqüência e a porcentagem de pacientes com guia anterior, em relação ao grau de DTM. Quando aplicado o teste qui-quadrado não se observou associação estatisticamente significativa $(p=0,6)$.

Tabela 5.10 - Relação entre a guia anterior e o grau de DTM

\begin{tabular}{c|cccc}
\hline DTM & Ausente & Leve & Moderada & Total \\
GUIA ANTERIOR & & & & \\
\hline Ausente & $41,6 \%(5)$ & $41,6 \%(5)$ & $16,8 \%(2)$ & $100 \%(12)$ \\
Presente & $50 \%(19)$ & $42,1 \%(16)$ & $7,9 \%(3)$ & $100 \%(38)$ \\
\hline
\end{tabular}

( ) número de indivíduos 
As interferências em lado de não-trabalho (direito e esquerdo), que caracterizam a impossibilidade da realização de guia de desoclusão lateral, foram comparadas ao índice de Disfunção Temporomandibular (tabela 5.11 e figura 5.3) e quando os dados foram submetidos ao teste qui-quadrado, observou-se associação estatisticamente significativa entre as variáveis $(p=0,02)$.

Tabela 5.11 - Relação entre as interferências oclusais em não-trabalho e o grau de DTM $^{*}$

\begin{tabular}{c|cccc}
\hline DTM & Ausente & Leve & Moderada & Total \\
INTERFERÊNCIAS & & & & \\
\hline Ausente & $57,5 \%(23)$ & $35 \%(14)$ & $7,5 \%(3)$ & $100 \%(40)$ \\
Presente & $10 \%(1)$ & $70 \%(7)$ & $20 \%(2)$ & $100 \%(10)$ \\
\hline
\end{tabular}

( ) número de indivíduos *Estatisticamente significativo

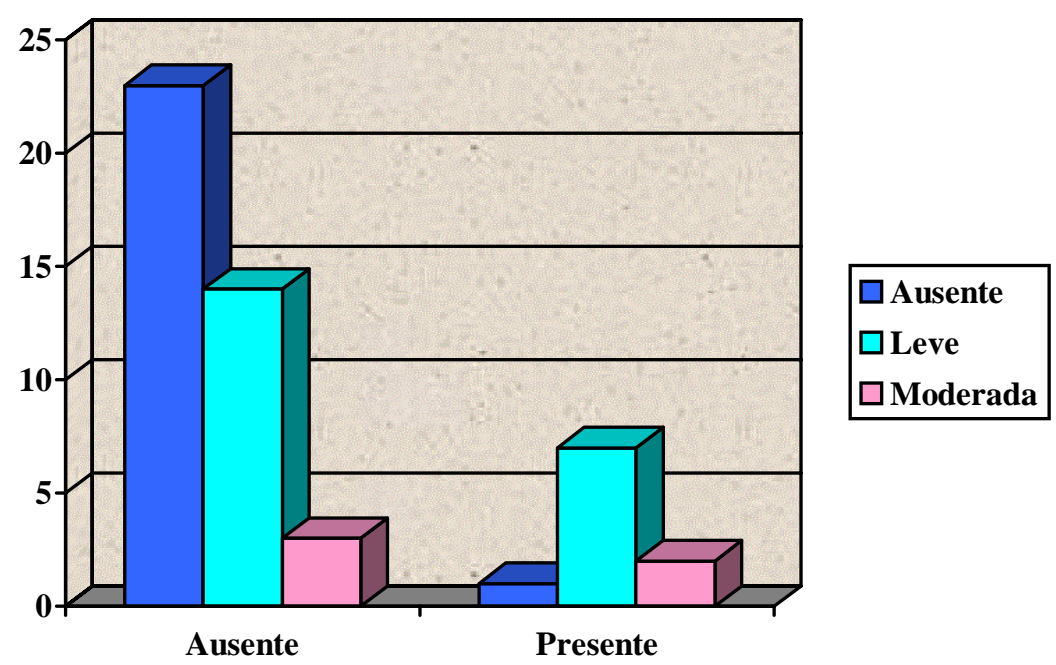

Figura 5.3 - Gráfico da relação entre os contatos oclusais em não-trabalho e o grau de $\mathrm{DTM}^{*}$ 
A freqüência dos tipos de aparelhos utilizados em relação ao índice de DTM está descrita na tabela 5.12. O teste qui-quadrado não revelou associação estatisticamente significativa $(p=0,6)$.

Tabela 5.12 - Relação entre tipo de aparelho e o grau de DTM

\begin{tabular}{c|cccc}
\hline DTM & Ausente & Leve & Moderada & Total \\
Aparelhos & $52,2 \%(12)$ & $39,1 \%(9)$ & $8,7 \%(2)$ & $\begin{array}{c}100 \% \\
(23)\end{array}$ \\
Fixo & $40 \%(6)$ & $40 \%(6)$ & $20 \%(3)$ & $\begin{array}{c}100 \% \\
(15)\end{array}$ \\
$\begin{array}{c}\text { Fixo+expansor } \\
\text { Máscara }\end{array}$ & $40 \%(2)$ & $60 \%(3)$ & $0 \%$ & $100 \%(5)$ \\
$\begin{array}{c}\text { Fixo+expansor+ } \\
\text { máscara+mentoneira }\end{array}$ & $40 \%(2)$ & $60 \%(3)$ & $0 \%$ & $100 \%(5)$ \\
$\begin{array}{c}\text { Fixo+expansor+ } \\
\text { máscara+progênico }\end{array}$ & $100 \%(2)$ & $0 \%$ & $0 \%$ & $100 \%(2)$ \\
\hline $\begin{array}{c}\text { () número de indivíduos } \\
\text { núm }\end{array}$ & & & & \\
\hline
\end{tabular}

Comparou-se a prevalência de DTM em relação ao tratamento ortodôntico sem extração, com extração no arco superior ou inferior e extração em ambos os arcos (tabela 5.13 e figura 5.4). O teste qui-quadrado não detectou associação estatisticamente significativa $(p=0,2)$. 
Tabela 5.13 - Relação entre o tipo de extração e o grau de DTM

\begin{tabular}{c|cccc}
\hline DTM & Ausente & Leve & Moderada & Total \\
\cline { 2 - 4 } Tipo de extração & & $34,4 \%(10)$ & $10,4 \%(3)$ & $100 \%(29)$ \\
Sem extração & $55,2 \%(16)$ & $0 \%$ & $100 \%(6)$ \\
Pré-molares sup. & $66,65 \%(4)$ & $33,35 \%(2)$ & $0 \%, 6 \%(2)$ & $100 \%(7)$ \\
Pré-molares inf. & $14,3 \%(1)$ & $57,1 \%(4)$ & $28 \%$ & $100 \%(8)$ \\
Pré molares sup. & $37,5 \%(3)$ & $62,5 \%(5)$ & $0 \%$ & \\
\hline
\end{tabular}

( ) número de indivíduos

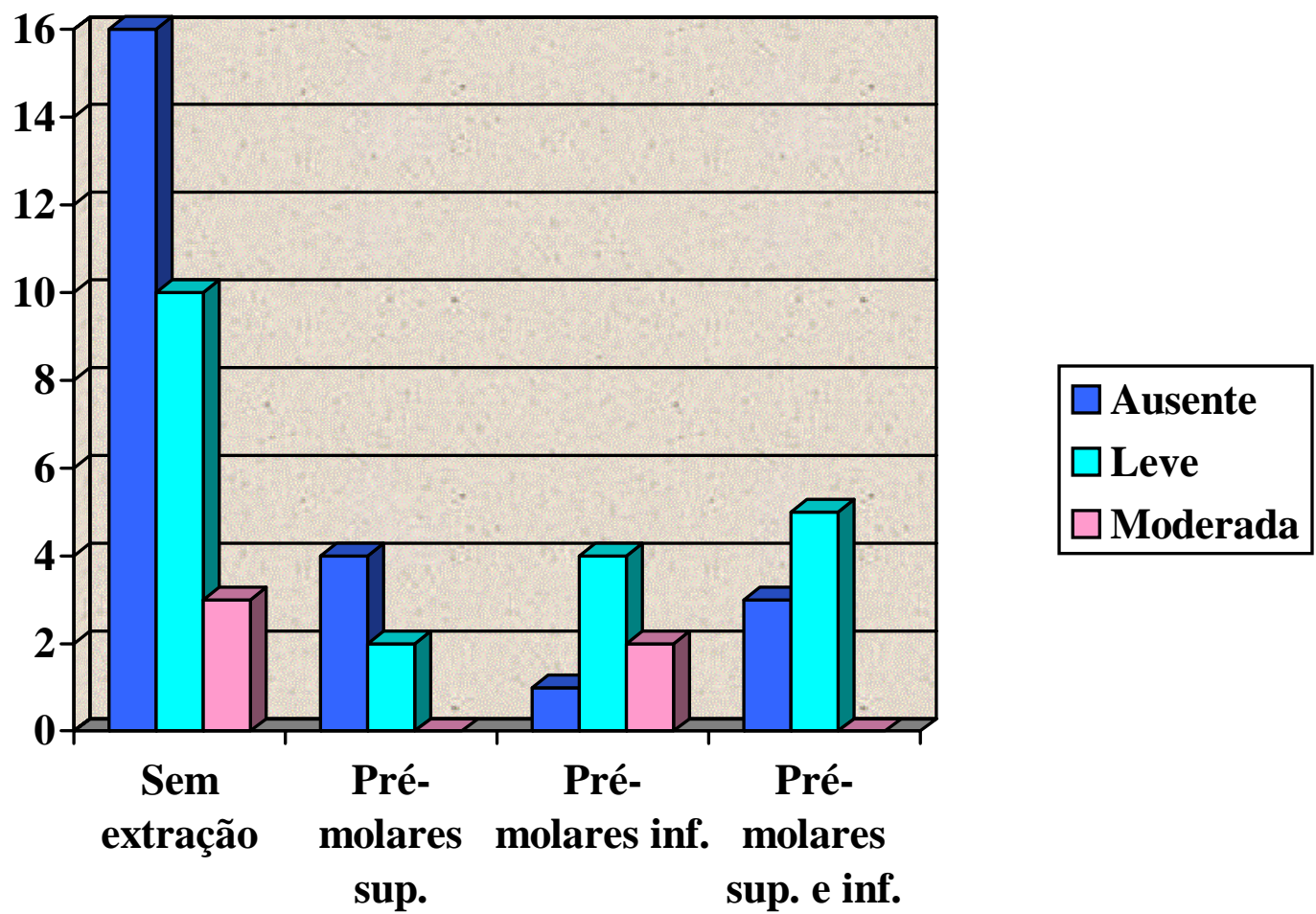

Figura 5.4 - Gráfico da relação entre o tipo de extração e o grau de DTM 
A relação entre as bases ósseas operadas, maxila, mandíbula ou ambas e o índice de DTM está descrita na tabela 5.14 e figura 5.5. Quando estes resultados foram submetidos ao teste qui-quadrado não se observou associação estatisticamente significativa $(p=0,7)$.

Tabela 5.14 - Relação entre as bases ósseas e o grau de DTM

\begin{tabular}{c|cccc}
\hline DTM & Ausente & Leve & Moderada & Total \\
\hline Maxila & $33,3 \%(1)$ & $33,3 \%(1)$ & $33,3 \%(1)$ & $100 \%(3)$ \\
Mandíbula. & $66,6 \%(2)$ & $33,3 \%(1)$ & $0 \%$ & $100 \%(3)$ \\
Maxila e & $57,9 \%(11)$ & $31,6 \%(6)$ & $10,5 \%(2)$ & $100 \%(19)$ \\
\hline \begin{tabular}{c} 
Mandíbula. \\
\hline
\end{tabular}
\end{tabular}

( ) número de indivíduos

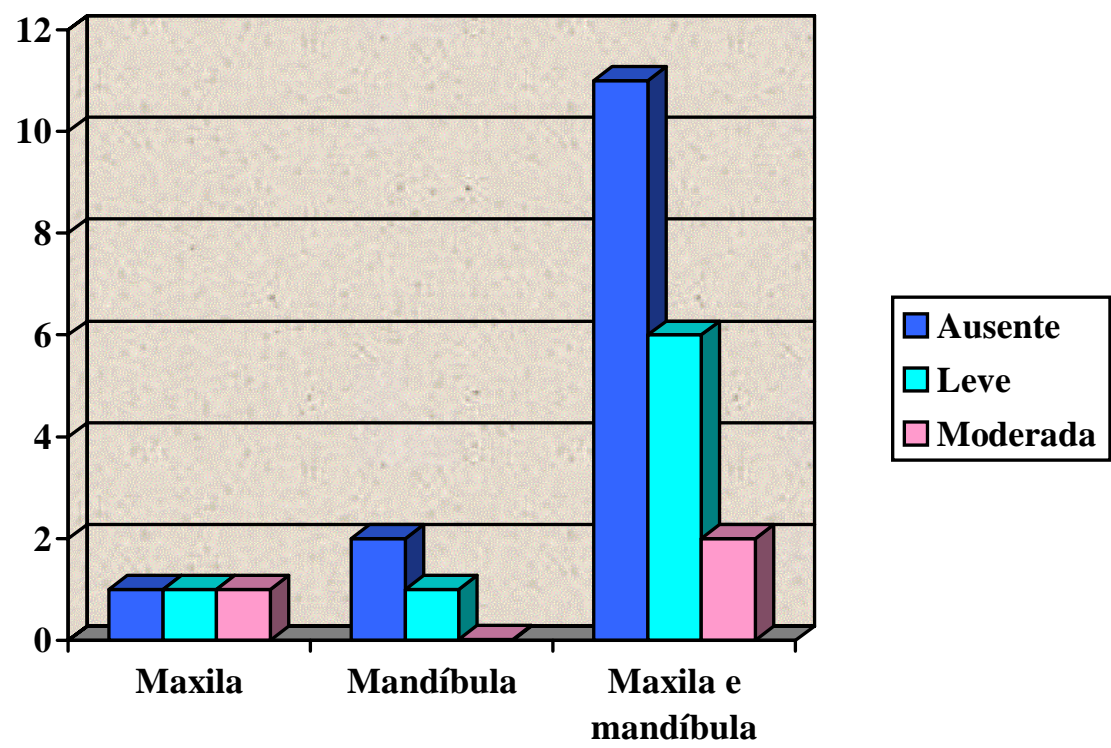

Figura 5.5 - Gráfico da relação entre as bases ósseas e o grau de DTM 
Os tipos de contenção utilizados após a cirurgia ortognática, elásticos ou fio de aço estão descritos na tabela 5.16 e figura 5.6. O teste quiquadrado não detectou associação estatisticamente significativa $(p=0,5)$

Tabela 5.15- Relação entre o tipo de contenção e o grau de DTM

\begin{tabular}{c|cccc}
\hline DTM & Ausente & Leve & Moderada & Total \\
\hline Elásticos & $64,3 \%(9)$ & $28,6 \%(4)$ & $7,1 \%(1)$ & $100 \%(14)$ \\
Fio de aço & $45,4 \%(5)$ & $36,4 \%(4)$ & $18,2 \%(2)$ & $100 \%(11)$ \\
\hline ( ) número de indivíduos
\end{tabular}

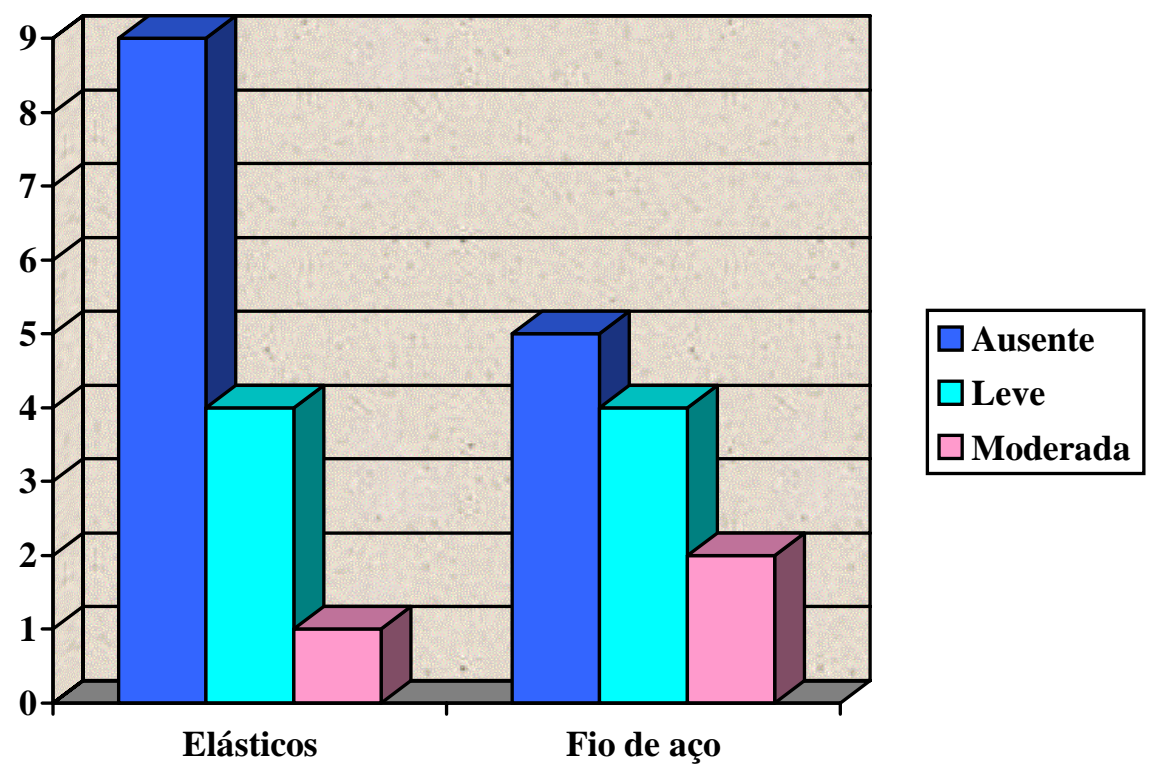

Figura 5.6 - Gráfico da relação entre o tipo de contenção e o grau de DTM 


$$
\text { DISCUSSÃO }
$$




\section{6 - DISCUSSÃO}

A etiologia das Disfunções Temporomandibulares tem sido estudada nos últimos anos e alguns fatores como oclusão e tratamento ortodôntico estão descritos na literatura como participantes de uma possível relação com as DTM $^{3,8,16,95,121 . ~}$

O estudo dos efeitos do tratamento ortodôntico sobre as DTM começou a merecer uma maior atenção, por parte da classe ortodôntica, a partir do momento em que os processos judiciais foram movidos, atribuindo ao tratamento ortodôntico, o surgimento de sinais e sintomas de DTM.

Fatores como alteração na posição condilar e ausência de uma oclusão funcional bem estabelecida, após a correção da má oclusão, têm sido citados como possível risco para o desenvolvimento da DTM. Portanto, alguns autores atribuíram ao término inadequado dos tratamentos ortodônticos, o aparecimento de sinais e sintomas de DTM em alguns pacientes.

Os tratamentos das alterações dentárias e esqueléticas, que resultam na má oclusão de Classe III, foram estudados conforme as diferentes abordagens terapêuticas, sendo elas ortodônticas e/ou cirúrgicas. A amostra foi dividida em dois grupos, um tratado ortodonticamente e o outro tratado com ortodontia seguido de cirurgia ortognática, o que possibilitou a comparação dos diferentes tratamentos com a presença e/ou severidade dos sinais e sintomas de DTM. Realizou-se ainda uma avaliação comparativa entre a oclusão e o índice de DTM. 
A execução deste trabalho se deparou com a dificuldade para a obtenção da amostra e este fato se deu, provavelmente, pela baixa prevalência da má oclusão de Classe III na população, de 3\% segundo SILVA FILHO; FREITAS; CAVASSAN $^{116}$ em um estudo realizado na cidade de Bauru. Os pacientes incluídos nesta amostra tinham concluído o tratamento ortodôntico em um período mínimo de 1 ano e este critério de inclusão foi escolhido com a finalidade de evitar a presença de dores características do período pós-operatório e esperar o período de acomodação dentária que pode ocorrer após a remoção do aparelho fixo.

\section{1 - DADOS GERAIS E PREVALÊNCIA DE DTM}

O questionário anamnésico aplicado neste trabalho foi respondido de forma auto-aplicável por todos os pacientes e os dados, expressos em porcentagem, se encontram nas tabelas 5.1 e 5.2 (p.68). O índice de DTM (ausente, leve e moderada) foi obtido pela somatória dos escores atribuídos às respostas deste questionário. A confiabilidade de $95 \%$ da classificação de DTM obtida pelo questionário anamnésico, foi demonstrada por FONSÊCA ${ }^{35}$, em 1994, e confirmada por HESSE; VAN LOON; NAEIJE ${ }^{53}$ que observaram alta correlação $(p=0,0003)$ entre as respostas do questionário e os achados clínicos. Este questionário representa uma forma simplificada de avaliação quando comparada com o exame clínico e pode ser incorporado ao exame ortodôntico inicial ${ }^{44}$, complementando a documentação ortodôntica, pois suas informações são precisas e extremamente importantes para o ortodontista. 
Os resultados nos mostram que nos 2 grupos estudados encontraram-se $48 \%$ do total da amostra sem DTM; DTM leve foi encontrada em $42 \%$ e moderada em 10\%, ao passo que a DTM severa não foi encontrada em nenhum paciente, independente do grupo. Tais valores foram obtidos de acordo com o índice proposto e modificado por outros autores $35,47,48$. Em termos de necessidade de tratamento, aceita-se que apenas os pacientes portadores de DTM severa ou moderada precisam de intervenção direta, enquanto os portadores de DTM leve precisam predominantemente de orientação e autoconhecimento ${ }^{17,35}$.

Os resultados demonstraram que o número de pacientes com algum grau de DTM $(n=26)$ foi semelhante ao de pacientes sem DTM $(n=24)$ e quando submetidos à análise estatística não se encontraram diferenças significativas. Os dados desta pesquisa não corroboram com a afirmação de que, a correção da Classe III, é responsável pela cura ou prevenção da DTM, sendo necessário para isto, uma avaliação longitudinal da amostra. Estes dados apresentaram-se semelhantes a vários trabalhos que não consideram o tratamento ortodôntico enquanto causa, cura ou prevenção das DTM 16, 32, 42, 60, 66, 75, 100, 107, 123, 124

Considerando a totalidade da amostra, observou-se que 52\% apresentaram algum grau de DTM, o que demonstrou quão comuns são os sinais e sintomas de DTM e quão negligenciados são pelos profissionais, pois além de tudo se trata de uma amostra que foi tratada da má oclusão e continua a apresentar DTM. Cabe ao ortodontista saber diagnosticar os sinais e sintomas de DTM, para esclarecer e orientar o paciente, independente da fase de tratamento em que o paciente se encontra. Devido à longa duração do tratamento ortodôntico, dois anos 
em média, a omissão do profissional, quanto a esses dados, pode proporcionar dissabores ao ortodontista, inclusive gerando ações legais causadoras de danos morais e econômicos. A porcentagem de indivíduos com DTM moderada e severa de $10,5 \%$ no estudo de WIGDOROWICZ-MAKOWEROWA ${ }^{128}$, e de $10,3 \%$ com DTM moderada na pesquisa de CONTI et al. ${ }^{17}$, coincidem aos $10 \%$ com DTM moderada encontrada neste estudo. O valor de 42\%, referente à prevalência de indivíduos com DTM leve, encontra-se próximo ao de 43,1\% em pacientes tratados ortodonticamente e $40 \%$ no grupo controle, citado por DAHL et al. ${ }^{21}$. Estes dados, demonstram uma prevalência semelhante entre populações submetidas e não, ao tratamento ortodôntico.

A média de idade da amostra geral estudada, que foi de 25,8 anos, variando de 24,7 (grupo I) a 26,9 (grupo II), está dentro da faixa etária que RUGH; SOLBERG ${ }^{104}$ consideraram ser o alvo das DTM, muito embora autores como RIEDER; MARTINOFF; WILCOX ${ }^{101}$ afirmaram que o fator idade parece não afetar a freqüência dos sinais e sintomas.

Na literatura, muitos trabalhos ${ }^{17,41,72}$ relatam maior prevalência de DTM em mulheres, entretanto, esta pesquisa não encontrou relação entre o gênero e o índice de DTM, resultados semelhantes aos de SOLBERG; WOO; HOUSTON ${ }^{118}$

Em concordância com a literatura $26,72,77,78$, os sintomas mais relatados, pela amostra deste trabalho, foram as dores de cabeça e os ruídos articulares com $48 \%$ e $40 \%$ respectivamente, no entanto, estes valores são bem mais altos que os encontrados em outras pesquisas ${ }^{16,17,118,125}$. Com respeito aos ruídos articulares, esta diferença pode ter ocorrido devido à amostra, desta 
pesquisa, apresentar idade mais avançada. Em relação às dores de cabeça, a presença de cefaléia primária pode também ter elevado o índice de respostas positivas para dor de cabeça, pois CONTI et al. ${ }^{18}$, em um estudo recente, observaram que 54\% dos portadores de DTM têm cefaléia primária. Sugere-se que nem todas as dores de cabeça relatadas pelos indivíduos desta amostra eram causadas por disfunções dos músculos faciais.

\section{2 - MOVIMENTOS MANDIBULARES}

O grau de abertura bucal representa um dado importante na análise dos problemas relacionados à ATM, pois muitas alterações que envolvem o disco articular podem levar a limitação da abertura bucal.

Os dados relacionados à abertura bucal ativa média da amostra foram de 48,5mm, variando de 48mm (grupo II) a 49,12mm (grupo I). Os valores dos grupos não foram considerados estatisticamente diferentes entre si, e isso sugere que o grau de DTM eventualmente presente, não foi capaz de provocar limitação significativa da abertura bucal, independente do tipo de tratamento realizado. Segundo SOLBERG ${ }^{117}$, a abertura bucal ativa inferior a $40 \mathrm{~mm}$ seria indicativo de alguma alteração nos componentes do sistema estomatognático. O valor médio nos indivíduos sem DTM é de $50 \mathrm{~mm}$ ou mais ${ }^{35}$, que são muito próximos dos encontrados neste trabalho.

Em 1983, GRIFFITHS ${ }^{43}$ mostrou que a média normal do movimento lateral situa-se entre 7 e $16 \mathrm{~mm}$, sendo que valores inferiores a $7 \mathrm{~mm}$ podem ser indicativos de alteração muscular e/ou articular, assim como impedimento 
mecânico (processo coronóide, estilóide). Neste trabalho, encontrou-se média de $7,32 \mathrm{~mm}$ para o movimento lateral direito e $7,88 \mathrm{~mm}$ para o esquerdo, o que os situa dentro dos padrões de normalidade em todos os grupos. O mesmo ocorreu com o movimento protrusivo, cuja média entre os pacientes foi de 5,6mm.

\section{3 - PALPAÇÃO ARTICULAR E MUSCULAR}

Durante o exame da Articulação Temporomandibular, foram detectados estalidos em $44 \%$ da amostra, distribuídos de forma semelhante entre os grupos (24\% do grupo I e $20 \%$ do grupo II). Os resultados analíticos não demonstraram associação entre presença de ruídos articulares e índice de DTM, o que evidencia que ruído na ATM não significa presença da doença. O ruído articular compatível com estalido pode indicar a presença de deslocamento de disco, uma característica presente na população com e sem DTM ${ }^{89}$.

Quando realizado o exame de palpação da ATM, 34\% $(n=17)$ de toda a amostra,a presença de sensibilidade foi considerada quando se observou pelo menos um ponto sensível nos aspectos lateral e posterior de ambos os lados. A comparação com resultados de outros trabalhos que obtiveram $3 \%^{72}, 5,3 \%{ }^{118}$, $12,9 \%{ }^{17}, 16 \%{ }^{26}$, mostra uma maior prevalência de sensibilidade nas ATM no presente estudo. Ao avaliar a presença de sensibilidade à palpação da ATM nos dois grupos, 64,7\% destes indivíduos fazia parte do grupo I e 35,3\% do grupo II, o que demonstra que os pacientes submetidos à cirurgia ortognática podem ter sido beneficiados na redução deste sinal, devido a um novo relacionamento condilar póscirúrgico. 
Durante o exame de palpação da musculatura mastigatória, ao considerar pelo menos três pontos sensíveis, obteve-se um percentual de $42 \%$ da amostra geral, que se aproxima dos 40\% encontrados por DROUKAS; LINDÉE; CARLSSON $^{26}$. No entanto o valor mais alto nesta pesquisa pode ter ocorrido devido a menor quantidade de homens na amostra, que segundo FREDRIKSSON; ALSTERGREN; KOPP ${ }^{36}$ apresentam limiar de dor à pressão maior que as mulheres Mas, a diferença nos critérios utilizados para se determinar a presença de sensibilidade, dificulta as comparações.

\section{4 - OCLUSÃO MORFOLÓGICA}

Com relação à mordida aberta anterior, apenas 4 casos (8\%) de toda a amostra estudada apresentavam este tipo de má oclusão. Segundo EGERMARK-ERIKSSON et al. ${ }^{33}$, a mordida aberta representa um fator de risco para a DTM, contudo, quando avaliada isoladamente não pode ser considerada como causa da Disfunção Temporomandibular ${ }^{95}$. Assim sendo, seria interessante e útil discutir previamente com os pacientes portadores desse tipo de relacionamento oclusal, a dificuldade de corrigí-lo e mantê-lo, principalmente em casos com envolvimento esquelético, evitando retratamentos ortodônticos sucessivos, sujeitando os dentes e ligamento periodontal às seqüelas eventualmente provocadas por esses atos. É importante salientar que o conhecimento e a discussão prévia das dificuldades do tratamento, podem evitar conflitos desagradáveis na relação paciente-profissional. 
Eventualmente, pacientes portadores de mordida aberta podem ser beneficiados pela sua redução com o uso do ajuste oclusal, como comentado por BONFANTE et $\mathrm{al}^{10}$, em 1998.

A análise da tabela 5.4 mostra que apenas 1paciente apresentava mordida aberta anterior e DTM moderada e os outros 3 tinham DTM ausente, o que caracteriza ausência de fator de risco para esta amostra. Este resultado está de acordo com os achados de PULLINGER; SELIGMAN ${ }^{95}$, ao concluírem que a mordida aberta não pode ser considerada, isoladamente como causa da DTM. Por outro lado, RIOLO; BRANDT; TENHAVE ${ }^{103}$, em 1987, demonstraram associação entre a mordida aberta e a dor muscular e articular. Acredita-se que a mordida aberta não possa ser considerada como causa dos sinais e sintomas de DTM, mas quando não tratada dificulta a mastigação. Esta má oclusão também impede a realização de guia anterior e segundo VALLE-COROTTI ${ }^{121}$ a ausência desta guia está associada à presença de DTM, portanto, a mordida aberta pode aumentar o risco de DTM. Segundo MCNAMARA; SELIGMAN; OKESON ${ }^{79}$ a mordida aberta anterior esquelética está associada a artropatias da ATM e pode ser o resultado de alterações ósseas e ligamentosas da ATM.

A mordida cruzada posterior, uni e bilateral, também foi encontrada em apenas $8 \%(n=4)$ desta amostra, sendo que destes pacientes, apenas 1 fazia parte do grupo II. Percebe-se claramente aqui os efeitos benéficos do tratamento ortodôntico na correção desse problema, que ocorrem, provavelmente, devido à uma intervenção precoce nos pacientes que não realizaram cirurgia e à estabilidade do tratamento cirúrgico nos pacientes operados. 
Levando em conta à baixa incidência da mordida cruzada posterior, não houve associação estatisticamente significativa com o grau de DTM (tabela 5.5), como citado por SELIGMAN; PULLINGER ${ }^{113}$. Quarenta e seis indivíduos da amostra apresentavam relação posterior dos arcos normal, dos quais 25 apresentavam DTM, enquanto entre os 4 que apresentavam esta relação, apenas 1 tinha DTM, o que demonstra a incompatibilidade de se correlacionar a mordida cruzada posterior, com o grau de DTM.

O overbite da amostra variou de 1,8mm (grupo I) a 2,5mm (grupo II), resultando em aproximadamente $2,2 \mathrm{~mm}$ para a amostra geral. A análise estatística não mostrou diferenças entre os grupos estudados. Este resultado demonstra que os diferentes tratamentos realizados nos grupos estudados, são capazes de proporcionar um trespasse vertical que possibilita a realização do movimento de guia anterior. Segundo VALLE-COROTTI ${ }^{121}$, a ausência de guia anterior representa um fator de risco para o desenvolvimento da DTM.

Quando correlacionado o índice de DTM aos valores de overbite (figura 5.2, p.73), não se observou associação entre eles, provavelmente por serem valores próximos ao normal, de 1 a 4mm, como comentado por PULLINGER; SELIGMAN ${ }^{95}$, inferior ao valor encontrado por LIEBERMAN et al. ${ }^{70}$, responsável pela correlação positiva entre o overbite maior ou igual a 5mm e DTM.

Os mesmos resultados e relação de significância estatística foram detectados com relação ao overjet, pois o grupo tratado ortodonticamente apresentava $1,44 \mathrm{~mm}$ de trespasse, enquanto o grupo II, tratado com cirurgia ortognática, apresentava 2,20mm. Embora os valores do trespasse horizontal sejam considerados diferentes, ambos estão próximos aos valores normais, de 1 a 3mm ${ }^{95}$. 
O valor inferior encontrado no grupo I, pode significar uma maior tendência à recidiva do tratamento ortodôntico, quando comparado ao tratamento orto-cirúrgico. Entre os 50 pacientes analisados encontrou-se uma média de $1,82 \mathrm{~mm}$ de overjet, muito próximo do normal ${ }^{95}$.

Em 1992, FONSÊCA ${ }^{35}$ encontrou valores de $2,66 \mathrm{~mm}$ para o overbite e 2,95mm para o overjet em pacientes sintomáticos com idade média de 30,2 anos, não se diferenciando dos valores encontrados em pacientes assintomáticos, como descrito por PULLINGER; SELIGMAN ${ }^{95}$. HENRIKSON; EKBERG; NILNER ${ }^{51}$ relataram que valores superiores a $6 \mathrm{~mm}$ aumentam o risco de DTM e HENRIKSON; NILNER; KUROL ${ }^{52}$ observaram que pacientes com overjet, também neste valor, apresentam mastigação deficiente. Estes dados indicam que alterações esqueléticas severas, não encontradas neste estudo, apresentam maiores chances de estarem associadas às disfunções do sistema estomatognático.

Quanto à relação sagital, os resultados demonstraram que 64\% $(n=32)$ dos pacientes apresentavam relação de Classe I, sendo que 20 destes, faziam parte do grupo II. Apenas 4 indivíduos (8\%), todos do grupo I, apresentaram relação sagital maior ou igual a Classe III. Estes valores retratam uma maior eficiência do tratamento ortodôntico associado à cirurgia ortognática na correção da Classe III, e na manutenção dos resultados obtidos pós-tratamento. Como a má oclusão de Classe III está, comumente ligada, às alterações esqueléticas, muitas vezes o tratamento mais indicado é o orto-cirúrgico, que permite uma intervenção adequada nas bases ósseas, entretanto, quando diagnosticada precocemente, pode-se intervir, durante o crescimento e desenvolvimento facial, na maxila e/ou na mandíbula, na tentativa de impedir que o paciente chegue à fase adulta com esta má 
oclusão. Vale ressaltar que mesmo no tratamento precoce, não é possível prever precisamente o potencial de crescimento de cada paciente, e em alguns casos, a intervenção preventiva não é suficiente, justificando também os resultados deficientes do grupo I em relação ao II.

Os resultados deste estudo não mostraram associação entre o índice de DTM e a má oclusão de Classe III (tabela 5.6). A ausência da participação da relação de Classe III na etiologia das DTM é compartilhada por autores como VIEIRA; PAURA ${ }^{122}$. Diferentemente, MOHLIN; INGERVALL; THILANDER ${ }^{85}$ encontraram uma relação positiva entre a má oclusão de Classe III e os sintomas de DTM, enquanto EGERMARK-ERIKSSON et al. ${ }^{33}$ verificaram que a relação de Classe III pode ser um fator de risco no desenvolvimento da DTM.

\section{5 - ASPECTOS OCLUSAIS}

Neste trabalho, encontrou-se a média geral de 16,9 contatos dentários efetivos, sendo que o grupo I apresentou uma media de 17,2 contatos e o grupo II, 16,6. Estes valores não apresentaram diferença estatística, e foram semelhantes aos valores encontrados por KORIOTH ${ }^{65}$ (14) e RIISE; ERICSSON ${ }^{102}$ (16). WÄNMAN; AGERBERG ${ }^{125}$ observaram maior risco de DTM em indivíduos com poucos contatos oclusais. Este achado revela a importância dos cuidados para uma boa finalização do tratamento ortodôntico e a estabilidade oclusal após os tratamentos realizados nesta amostra. A não associação entre o índice de DTM e o número de contatos oclusais neste trabalho deve-se provavelmente, ao resultado muito próximo do normal, evitando que este seja um fator de risco para a DTM. 
Durante anos, a discrepância entre as posições de RC e MIH sustentou a teoria oclusal de etiologia de DTM, como comentado por MCNEILL ${ }^{82}$, em 1990. Dos 50 casos analisados, 31 (62\%) apresentavam coincidência entre as posições de RC e MIH, posição conhecida por ORC ${ }^{91}$, sendo 17 para o grupo I, 14 para o grupo II. Estes achados diferem dos encontrados por JANSON; MARTINS ${ }^{58}$, onde $85 \%$ dos pacientes examinados não apresentavam esta posição ao término do tratamento, entretanto PULLINGER et al..$^{98,99}$ encontraram dois terços da amostra com RC e MIH coincidentes ou com discrepâncias de até 0,5mm.

Talvez a divergência entre os dados encontrados na literatura e os achados deste trabalho, se deva à diferentes técnicas utilizadas para se obter RC, como a confecção e uso de dispositivos como preconizado por $\mathrm{LUClA}^{74}$ (jig) ou LONG $^{73}$ (tiras de acetato). Neste estudo a RC foi obtida apenas com a manipulação unilateral. No tipo de má oclusão estudada nesta pesquisa, a Classe III, mesmo após a sua correção, dificilmente ocorre uma protrusão mandibular durante o estabelecimento da $\mathrm{MIH}$, como pode acontecer na Classe II, na tentativa do paciente mascarar uma recidiva, causando danos ao seu perfil.

A discrepância de RC para $\mathrm{MIH}$ não apresentou relação estatisticamente significante com o grau de DTM (tabela 5.7), pois dos 46 pacientes que apresentavam ORC ou distância de até $2 \mathrm{~mm}$ entre as posições, metade apresentava algum grau de DTM. Quando a distância entre as posições de RC para MIH era maior (2 a 4mm), podendo ser considerada fator de risco por MCNAMARA; SELIGMAN; OKESON ${ }^{79}$ (1995), apenas 4 pacientes a apresentavam, porém nenhum deles apresentava DTM moderada. 
O desgaste oclusal seletivo, que pode ser indicado como terapia pós-tratamento ortodôntico, tem como finalidade refinar o padrão oclusal, levando o paciente a uma ORC.

A guia lateral, foi detectada em $70 \%$ da amostra, sendo a maioria, desoclusão pelo canino. Quando considerado o lado direito, 66\% apresentavam guia pelo canino e $62 \%$ quando considerado o esquerdo. A guia por função em grupo foi encontrada em $16 \%$ da amostra para o lado direito e $14 \%$ para o esquerdo, enquanto sua ausência foi encontrada em $18 \%$ dos pacientes para o lado direito e $24 \%$ para o esquerdo.

Quando se leva em conta os grupos avaliados, encontra-se respectivamente para os lados direito e esquerdo, 56\% e $48 \%$ do grupo I com guia pelo canino e $76 \%$ para ambos os lados, no grupo II. Esses dados comprovam a eficiência do tratamento ortodôntico associado à cirurgia ortognática em estabelecer este tipo de guia, extremamente importante para o preenchimento dos princípios da oclusão ideal ${ }^{92}$ ou mutuamente protegida ${ }^{82}$. BELSER; HANNAM $^{9}$ observaram que a desoclusão pelo canino reduz a a tividade muscular durante o apertamento parafuncional, enquanto SELIGMAN; PULLINGER ${ }^{112}$ afirmaram que as guias de desoclusão influenciam os níveis de atividade muscular durante a função. Observase aqui, a importância em se proporcionar a desoclusão lateral pelo canino ao final do tratamento ortodôntico.

Os dados relativos à presença de guia lateral, ou mesmo sua ausência, foram analisados com relação à DTM e estão representados na tabela 5.9, não demonstrando relação estatística entre estes valores e de acordo com estes resultados, estão os achados de DONEGAN; CHRISTENSEN; MC KAY ${ }^{25}$, que 
relataram a impossibilidade de se determinar o potencial do paciente em desenvolver DTM, com base no tipo de guia.

Apesar dos benefícios dos tratamentos realizados com relação à obtenção de guias, vale a pena ressaltar que, 15 pacientes deixaram de ter suas oclusões protegidas pela guia de desoclusão pelo canino. Se isso não significa relação com DTM, significa possibilidades de forças oblíquas que seriam melhor dissipadas e com menor intensidade se a desoclusão ocorresse nos caninos, como discutido por D'AMICO ${ }^{20}$ desde 1958.

A guia anterior estava presente em $76 \%$ da amostra, com a mesma freqüência para os grupos separadamente. Observa-se que os benefícios da guia anterior, um dos requisitos da oclusão ideal, foi conseguida em ambos os grupos, independente do tratamento realizado. Os pacientes que não apresentavam este tipo de guia eram portadores de mordida aberta anterior, mordida cruzada anterior ou relação de topo entre os incisivos, que representam uma recidiva do tratamento da Classe III ou a finalização inadequada do caso.

Os resultados não mostraram associação entre a guia anterior e o grau de DTM (tabela 5.10) e estes achados diferem de uma pesquisa realizada por VALLE-COROTTI et al. ${ }^{121}$, que observaram uma associação positiva entre ausência de guia anterior e grau de DTM. A discordância nos resultados pode se dar ao fato de as amostras apresentarem tipos de más oclusões diferentes, pois na pesquisa atual os pacientes apresentavam má oclusão de Classe III. Embora a ausência de guia anterior não tenha se apresentado de forma relevante neste trabalho, vale lembrar que de acordo com MCNAMARA; PULLINGER; OKESON ${ }^{79}$ a ausência de guia anterior é um dos fatores de risco das DTM. 
Interferências do lado de não-trabalho, ainda encontrado na literatura como lado de balanceio, são tidas como potencialmente traumáticas e capazes de provocar danos aos componentes do sistema estomatognático ${ }^{81,82}$.

Foi observada ausência de interferências em lado de não-trabalho em $80 \%$ (40) da amostra. O grupo I apresentou maior número de pacientes com interferências, o que demonstra uma maior possibilidade em se alcançar as guias de desoclusão com o tratamento orto-cirúrgico, confirmando melhor padrão oclusal presente no grupo II.

Conforme se visualiza na tabela 5.11 e figura 5.3, a presença de interferências no lado de não-trabalho apresentou relação estatisticamente significativa com o índice de DTM. Dos 10 pacientes com interferência, 9 apresentavam algum grau de DTM, entretanto, apenas 2 com DTM severa necessitariam de algum tipo de tratamento. Esta associação entre interferências e DTM é comentada na literatura ${ }^{29,62}$, mas o mecanismo desta relação parece ainda obscuro. Entretanto não se pode afirmar que a interferência representa um fator determinante para o desenvolvimento da DTM, visto que existe neste e em outros trabalhos $^{13,76}$ pacientes com interferência e DTM ausente. Esta não associação entre as interferências e as DTM talvez se explique devido à capacidade adaptativa do sistema mastigatório à situação oclusal, como comentada por INGERVALL; CARLSSON $^{57}$ e KARLSON; CHO; CARLSSON ${ }^{59}$. Entretanto as interferências oclusais podem causar danos locais como facetas de desgaste, sobrecarga localizada em apenas um dente e ainda alterações periodontais que causam mobilidade dentária. Tais alterações podem passar despercebidas durante anos e se tornam graves em longo prazo. A presença de hábitos parafuncionais pode ser um 
dos fatores que leva o portador de interferências a desenvolver DTM ${ }^{90}$, no entanto, esta relação não foi avaliada neste trabalho.

As interferências oclusais devem ser corrigidas, durante o tratamento ortodôntico, com a alteração do torque ou coordenação dos arcos, ou mesmo ao final do tratamento com a realização de desgaste seletivo, pois a ausência deste tipo de contato representa um dos requisitos para uma oclusão ideal $^{14}$.

\section{6 - TIPO DE TRATAMENTO}

Todos os indivíduos da amostra foram tratados com aparelho fixo, mas apenas 5, pertencentes ao grupo I, foram tratados exclusivamente com este aparelho, enquanto os demais utilizaram aparelhos ortopédicos e/ou foram submetidos à cirurgia ortognática. Este resultado confirma o forte envolvimento esquelético na má oclusão de Classe III e ressalta a importância de um tratamento precoce, a fim de evitar um perfil desagradável ao paciente durante a sua juventude. Como observado neste trabalho, a expansão maxilar associada à tração reversa da maxila representa uma aliada importante neste tratamento, presente em $54 \%$ da amostra. Este protocolo de tratamento, que envolve principalmente a maxila, ocorre devido a dificuldade em se controlar o crescimento mandibular, predominante na Classe III, tornando a terapia na maxila uma opção mais segura.

O tipo de aparelho não apresentou associação significativa com o grau de DTM, como já observado em outras pesquisas ${ }^{16,21,42,106,121}$. Assim, podese afirmar que os diferentes protocolos de tratamento, para os diferentes tipos de 
Classe III (dentária ou esquelética), são eficazes na correção desta má oclusão e não estão vinculados aos fatores de risco das DTM.

Contrários aos resultados deste estudo, outros autores encontraram dados diferentes como menor prevalência de DTM em pacientes tratados ortodonticamente ${ }^{30,34}$ ou maior severidade de DTM em indivíduos com necessidade de tratamento ${ }^{60,84,93,103}$, caracterizando a ortodontia como curativa ou preventiva da DTM. HEIKINHEIMO et al. ${ }^{46}$ afirmaram que nenhum sinal ou sintoma de DTM, ou uma combinação deles, pode determinar a necessidade de tratamento ortodôntico. Outros estudos avaliaram o tratamento ortodôntico enquanto causa da DTM, entretanto não encontraram evidências a este respeito ${ }^{75,100,105,107,123,124 .}$

Para WYATT ${ }^{29}$, a relação do tratamento ortodôntico com as DTM baseia-se no aparecimento de interferências oclusais decorrentes da extração de pré-molares, causando posteriorização dos côndilos devido à retração anterior dos incisivos com conseqüente anteriorização dos discos articulares, tornando os pacientes tratados com esta técnica, mais predispostos a desenvolver DTM. Contrario a esta afirmação, este trabalho não encontrou relação entre a extração de pré-molares e o grau de DTM.

Embora a relação entre tratamento ortodôntico e DTM se apresente de modo controverso na literatura, as evidências indicam que a etiologia das Disfunções Temporomandibulares é multifatorial e não se pode associar à DTM apenas um fator de risco $2,24,26$. Outra consideração se deve ao fato de que, o tratamento ortodôntico baseia-se em efeitos dentoalveolares e o tratamento ortopédico tem efeitos esqueléticos limitados, e juntos causam pouco efeito nas ATM, caso contrário seriam responsáveis pelas disfunções articulares. As disfunções 
musculares parecem também não serem desenvolvidas por este tipo de tratamento, visto que os tecidos moles do sistema estomatognático apresentam um grande potencial de adaptação.

EGERMARK-ERIKSSON et $\mathrm{al}^{33}$ consideraram alguns tipos de má oclusão, dentre elas a Classe III, como fatores de risco no desenvolvimento das DTM, mas outros estudos demonstram que esta relação está baseada na alteração da morfologia esquelética ${ }^{39,40,64}$ e não simplesmente em problemas dentários. Uma destas alterações esqueléticas, segundo UEKI et al. ${ }^{120}$ é a assimetria, pois eles observaram maior incidência de degeneração interna da ATM em pacientes assimétricos, proveniente da diferença na morfologia das duas ATM. MUTO et al. ${ }^{87}$ comenta ainda que o ângulo goníaco aberto na Classe III, pode ser considerado fator de risco para as DTM.

Ao avaliarem os aspectos morfológicos, alguns autores ${ }^{15,} 115$ observaram que na Classe III, o côndilo assume uma posição mais para anterior que em indivíduos com oclusão normal. Este fato pode justificar a baixa prevalência de deslocamento de disco em pacientes com má oclusão esquelética de Classe III, como observado por SANROMAN; GONZÁLEZ; HOYO ${ }^{108}$. No entanto, esta posição condilar pode estar mascarada devido a um deslize para anterior da mandíbula, nos casos de falsa Classe III. Embora DAHLBERG et al. ${ }^{22}$ tenham afirmado que não existe relação entre um tipo específico de alteração craniofacial e as disfunções articulares, neste trabalho 22 pacientes apresentavam sinal de deslocamento de disco (presença de estalido) e entre eles não estavam os 4 pacientes com Classe III, sendo que 18 eram Classe I e 4 apresentavam até $1 / 2$ Classe III, confirmando a baixa prevalência de deslocamento de disco na má oclusão de Classe III. 
O envolvimento esquelético na Classe III é o grande responsável pela necessidade do tratamento ortodôntico associado à cirurgia, que pode envolver a maxila, a mandíbula ou ambas as bases. A intervenção em ambas as bases foi realizada em $76 \%$ da amostra, o que demonstra a participação da maxila nesta má oclusão.

Os efeitos positivos da cirurgia ortognática, em relação às DTM, são citados na literatura ${ }^{64,88}$. Neste trabalho os grupos se comportaram de forma semelhante em relação ao índice de DTM, não se observando vantagens no grupo cirúrgico, mas esta afirmação estaria melhor embasada se fosse realizada uma comparação com um grupo de indivíduos não tratados, ou se o estudo fosse longitudinal.

A relação entre as bases ósseas envolvidas nas cirurgias e o índice de DTM não apresentou associação estatística significativa neste trabalho, no entanto, $60 \%$ do grupo I apresentavam algum grau de DTM enquanto no grupo II a freqüência era de $48 \%$. Mesmo pequena, esta diferença pode ter ocorrido devido aos benefícios promovidos pela cirurgia, como comentado anteriormente. SANROMÁN et al. ${ }^{109}$ observaram que as alterações ocorridas nas ATM após a cirurgia eram transitórias e não acarretavam problemas à longo prazo. A técnica utilizada na cirurgia também parece influenciar na presença de sinais de DTM $\operatorname{articular}^{55}$.

Com base no tipo de contenção utilizada, elástico ou fio de aço, após a cirurgia ortognática, pôde-se determinar a fixação óssea, pois os pacientes submetidos à fixação óssea com fios de aço, necessitam de contenção também com este material, enquanto os pacientes que recebem fixação com mini-placas usam 
contenção com elásticos intermaxilares ${ }^{5}$. Quanto ao tipo de contenção utilizada após a cirurgia ortognática, os pacientes estavam divididos de modo semelhante, $56 \%$ com elásticos e $44 \%$ com fio de aço.

O tipo de contenção utilizada não apresentou relação com a DTM. Este dado permite sugerir que, com base nesta amostra, o tipo de fixação óssea, com fios de aço ou com mini-placas, não influencia no índice de DTM. Por outro lado FIENERMAN; PIECUCH ${ }^{34}$ uma diminuição de sinais e sintomas de DTM em indivíduos que receberam fixação com mini-lacas e parafusos.

\section{7- CONSIDERAÇÕES GERAIS}

A realização deste estudo analisou os diferentes tipos de tratamento para má oclusão de Classe III e os comparou com a presença de DTM. Os dois grupos estudados não se comportaram significativamente diferentes, o que permite a afirmação de que os tratamentos não influenciaram na determinação dos graus de DTM.

A avaliação da amostra permitiu ainda, uma comparação da qualidade oclusal dos 2 grupos. Embora, não se tenha obtido diferenças estatísticas, os dados demonstraram melhor padrão oclusal no grupo tratado com cirurgia ortognática. Estes resultados indicaram que o tratamento orto-cirúgico foi mais efetivo ou mais estável que o tratamento ortodôntico, o que provavelmente se deve ao fato deste tratamento não depender das alterações que ocorrem na face durante o pico de crescimento. Mesmo havendo alterações decorrentes de um suave 
crescimento na idade adulta, este parece não ser comprometedor quanto à estabilidade da oclusão após o tratamento orto-cirúrgico.

Os trabalhos que como este, visaram estudar os fatores etiológicos das DTM, encontraram dificuldade em determiná-los, provavelmente devido à etiologia multifatorial ${ }^{84,85}$ destas disfunções, onde se deve enfatizar a relevância dos fatores psicoemocionais ${ }^{4}$ no desenvolvimento das DTM. Com isto, fatores isolados não são aceitos como responsáveis pelas DTM. Ainda que a dificuldade de esclarecer a etiologia das DTM seja real, a oclusão parece estar sempre acompanhando tais especulações.

Os resultados deste trabalho que mostraram associação entre a presença de interferências em lado de não-trabalho e o índice de DTM e, como observado em outras pesquisas, pode ser considerado um fator de risco para a DTM. Com base nesta amostra e em outras de diferentes estudos, a presença desse tipo de contato se apresenta com bastante freqüência ao final do tratamento ortodôntico. Várias pesquisas demonstraram que a interferência está presente em indivíduos sem DTM e por isso não deve ser considerada, isoladamente, como causa das DTM.

Assim o ortodontista não deve se preocupar apenas com o desenvolvimento de DTM, mas principalmente em promover uma oclusão mais próxima do ideal, independente do tratamento realizado. Para isto, o profissional deve estar apto não só a avaliar e promover uma boa oclusão estática, mas também a proporcionar uma oclusão funcional correta, buscando assim uma oclusão ideal.

Este trabalho teve como base a utilização de um questionário anamnésico que, de maneira simplificada, indica a presença e a severidade dos 
sintomas de DTM. Este questionário representa um indicador importante para o ortodontista que talvez não seja apto a tratar Disfunção Temporomandibular, mas deve estar sempre capacitado ao menos a diagnosticá-la. 


$$
\text { CONCLUSÕES }
$$




\section{7 - CONCLUSÕES}

Em vista da metodologia utilizada e dos resultados obtidos, pôde-se concluir que:

- 60\% dos pacientes submetidos à tratamento ortodôntico da má oclusão de Classe III apresentava DTM, sendo que nenhum paciente foi portador de DTM severa;

- 44\% dos pacientes submetidos à Cirurgia Ortognática no tratamento da má oclusão de Classe III apresentava DTM, sendo que nenhum paciente foi portador de DTM severa;

- Não houve diferença estatisticamente significativa na prevalência de DTM entre os grupos estudados;

- Encontrou-se associação significativa entre a presença de interferências em lado de não-trabalho e o índice de DTM. 
ANEXOS 
Data: I I

Grupo:

$\mathrm{N}^{0}$ do arquivo:

UNIVERSIDADE DE SÃO PAULO

FACULDADE DE ODONTOLOGIA DE BAURU

Nome: Data nascimento:

Endereço: Bairro:

Cidade: Estado: CEP: Fone res:

Nome do responsável:

Endereço de trabalho: Fone:

Telefone para recados:

Idade:

sexo:

\section{ANAMNESE}

1. Você sente dificuldade de abrir a boca?

2. Você sente dificuldade de movimentar sua mandíbula para os lados?

3. Você sente desconforto ou dor muscular quando mastiga?

4. Você sente dores de cabeça com freqüência ?

5. Você sente dores no pescoço e/ou ombros ?

6. Você sente dores de ouvido ou próximo a ele ?

7. Você percebe algum ruído na ATM ?

8. Você considera sua mordida "normal" ?

9. Você usa apenas um lado de sua boca para mastigar?

10. Você sente dores na face ao acordar?

11. Você se considera uma pessoa tensa?

12. O tratamento ortodôntico melhorou, piorou ou não Modificou os seus sintomas?

13. Você apresenta algum dos seguintes hábitos?

$\square$ Ranger dentes

Apertar dentes

Roer unhas

Morder objetos
SIM

NÃO

ÀS VEZES 


\section{EXAME CLÍNICO}

1. AVALIAÇÃO DA ATM:

a) Movimentação

\section{DOR}

ABERTURA MÁXIMA

(incluindo trespasse)

LATERALIDADE DIREITA

LATERALIDADE ESQUERDA

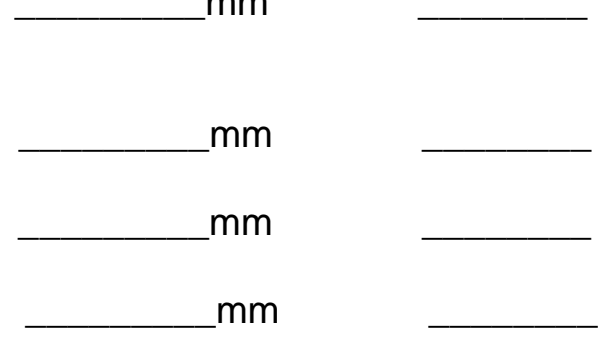

PROTRUSÃO

$\mathrm{mm}$

ABERTURA: $\square$ Simétrica
$\square$ Desvio
$\square$ Deflexão

$\square$ Direita

Esquerda

$\square$ Direita

Esquerda

b) Ruídos articulares

ABERTURA

ESTALIDO

Direito

Esquerdo
FECHAMENTO

Direito $\square$ Esquerdo
CREPITAÇÃO
Direito
Esquerdo
HIPERMOBILIDADE
Direito
Esquerdo

c) Palpação da ATM:

\begin{tabular}{|c|c|c|}
\hline & Direita & Esquerda \\
\hline Aspecto lateral & & \\
\hline Aspecto posterior & & \\
\hline
\end{tabular}

\section{EXAME MUSCULAR:}

\section{Temporal}

DIREITO

ESQUERDO

Anterior

Médio

Posterior
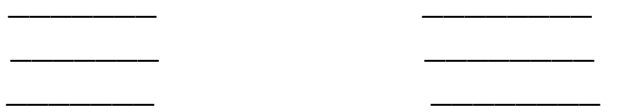
DIREITO ESQUERDO

Masseter superficial

Origem

Médio

Posterior

Masseter profundo

Esternocleidomastoideo

Trapézio (superior)

3. AVALIAÇÃO DENTAL E OCLUSAL:

$\mathbf{X}=$ Ausente/extraído $\quad \mathbf{F}=$ Faceta de desgaste $\quad \mathbf{E}=$ Em erupção

\begin{tabular}{l|l|l|l|l|l|l|l|l|l|l|l|l|l|l|l}
18 & 17 & 16 & 15 & 14 & 13 & 12 & 11 & 21 & 22 & 23 & 24 & 25 & 26 & 27 & 28 \\
\hline 48 & 47 & 46 & 45 & 44 & 43 & 42 & 41 & 31 & 32 & 33 & 34 & 35 & 36 & 37 & 38
\end{tabular}

\begin{tabular}{l|l|l|l|l|l|l|l|l|l}
55 & 54 & 53 & 52 & 51 & 61 & 62 & 63 & 64 & 65 \\
\hline 85 & 84 & 83 & 82 & 81 & 71 & 72 & 73 & 74 & 75
\end{tabular}

NÚMERO DE DENTES AUSENTES: $\square 0-4 \quad \square 4-10 \quad \square+10$

TRESPASSE VERTICAL: $\mathrm{mm}$

TRESPASSE HORIZONTAL: $\mathrm{mm}$

Mordida aberta anterior

RELAÇÃO SAGITAL Classe I

Mordida cruzada unilateral

Até $1 / 2$ Classe III

Mordida cruzada bilateral

Classe III

TIPO DE APARELHO:

Fixo

Fixo + outro aparelho:

RELAÇÕES MAXILOMANDIBULARES: 
$\square \mathrm{RC}=\mathrm{MIH}$

$\mathrm{RC} \neq \mathrm{MIH}$

Discrepância vertical:
$0-2 \mathrm{~mm}$
$2-4 \mathrm{~mm}$
$4 \mathrm{~mm}$

GUIA LATERAL DIREITA

GUIA LATERAL ESQUERDA

Ausente

Ausente

Guia canino

Guia canino

$\square$ Função em grupo

Função em grupo

GUIA ANTERIOR

$\square$ Presente

Ausente

INTERFERÊNCIAS EM NÃO-TRABALHO DIREITO

$\square$ Não

$\square \operatorname{Sim}$

Com guia

Sem guia

INTERFERÊNCIAS EM NÃO-TRABALHO ESQUERDO

$\square$ Não

$\square \operatorname{Sim}$

$\square$ Com guia

Sem guia

NÚMERO DE CONTATOS EM MIH:

TÉRMINO DO TRATAMENTO HÁ meses

$\begin{array}{llll}\text { EXTRAÇÃO DE PRÉ-MOLARES } & \square \text { Sim } \quad \square \quad \text { Superior } \square \text { Não } \\ & \square \quad \text { Inferior } \\ \text { BASES ÓSSEAS ENVOLVIDAS NA CIRURGIA } \quad \square \quad \text { Maxila } \square \text { Mandíbula } \square \text { Ambas }\end{array}$

TIPO DE CONTENÇÃO $\square$ Elásticos $\quad \square$ Fio de aço

ANO QUE REALIZOU A CIRURGIA 


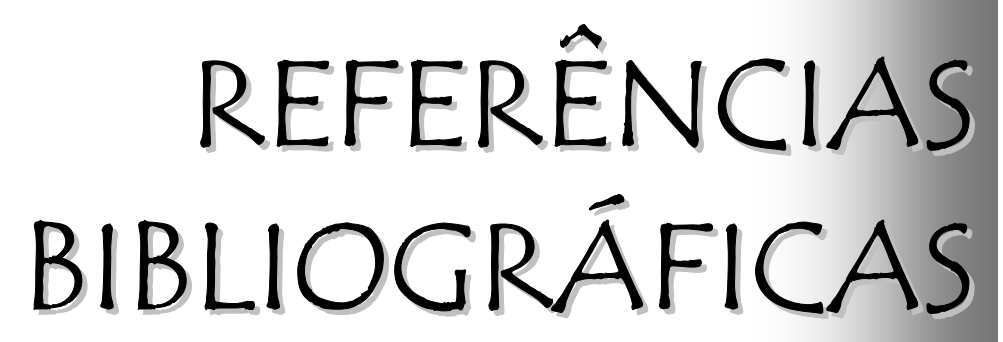




\section{REFERÊNCIAS BIBLIOGRÁFICAS**}

1. AGERBERG, G.; CARLSSON, G.E. Functional disorders of the masticatory system. I - Distribuition of symptoms according to age and Sex as judged from investigation by questionaire. Acta odont. scand., v.30, n.6, p.597613, 1972.

2. AGERBERG, G.; CARLSSON, G.E. Functional disorders of the masticatory system. II - Symptoms inrelation impaired mobility of the mandible as judged from investigation by questionaire. Acta odont. scand., v.31, n.6, p.335-47, 1973.

3. AGERBERG, G.; SANDSTRÖM, R. Frequency of occlusal interferences: a clinical study in teenagers and young adults. J. prosth. Dent., v.59, n.2, p.212-7, Feb. 1988.

4. ALENCAR JÚNIOR, F.G.P. Fatores psicológicos nas disfunções craniomandibulares: estudo da relação entre graus de disfunção e escalas de ansiedade traço-estado. Bauru, 1997. 179p. Tese (Doutorado) - Faculdade de Odontologia de Bauru, Universidade de São Paulo.

5. ARAÚJO, A. Cirurgia Ortognática. 1999

6. ARNOLD, J.P. Traumatic occlusion. Int. J. Orthodont., n.13, p.24-7, 1927.

\footnotetext{
* Normas recomendadas para o uso no âmbito da Universidade de São Paulo, com base no documento "Referências Bibliográficas: exemplos", emanados do Conselho Supervisor do Sistema Integrado de Bibliotecas da USP, em reunião de 20 de setembro de 1990.
} 
7. BELL, W. E. Clinical management of temporomandibular disorders classification, diagnosis, manegement. Chicago, Year Book Medical, 1982.

8. BELL, Y.L. et al. Effect of artificial occlusal interferences depends on previous experience of temporomandibular disorders. Acta odont. scand., v.60, n.1, p.219-22, Aug. 2002.

9. BELSER, U.C.; HANNAM, A.C. The influence of altered working-side occlusal guidence on masticatory muscles and relates jaw movement. $\mathbf{J}$. prosth. Dent., v.53, n.3, p.406-13, Mar. 1985.

10. BONFANTE, G. et al. Redução da mordida aberta anterior através de desgaste seletivo. Rev. Odonto Pope, v.2, n.3, p.399-404, ,jul./set. 1998.

11. BUSH, F.M.; Malocclusion, masticatory muscle, and temporomandibular joint tenderness. J. dent. Res., v.64, n.2, p.129-33, Feb. 1985.

12. CARLSON, C.R., et. al. Psychological an physiological parameters of masticatory muscle pain. Pain, v.76, p.297-307, 1998.

13. CLARK, J.R. et al. Sixty-eight years of experimental occlusal interference studies: what have we learned? J. prosth. Dent., v.82, n.6, p.704-13, Dec. 1999.

14. CLARK, J.R. et al. Functional occlusion: I a review. J. Orthodont., v.28, n.1, p.76-81, Mar. 2001. 
15. COHLMIA, J.T. et al Tomographic assessment of temporomandibular joints in patients with malocclusion. Angle Orthodont., v.66, n.1, p.27-35, 1996.

16. CONTI, A. et al. Relationship between signs and symptoms of temporomandibular disorders and orthodontic treatment: a crosssectional study. Angle Orthodont., v.73, n.4, p.411-7, Aug. 2003.

17. CONTI, P.C.R., et al. A cross-sectional study of prevalence and etiology of signs and symptoms of temporomandibular disorders in high school and university students. J. Orofac. pain., v.10, n.3, p.254-62,1996.

18. CONTI, P.C.R., et al. Avaliação da prevalência das dores de cabeça primárias e seu relacionamento com sintomas de desordens temporomandibulares no campus da USP, na cidade de Bauru/SP. R. Dental Press Ortodon. Ortop Facial, v.8, n.2, p.49-56, mar./abr. 2003.

19. COSTEN, J.B. A syndrome of ear and sinus symptoms dependent upon disturbed functions of TMJ. Ann. Otol. (St. Louis), v.43, n.1, p.1-15, Mar. 1934.

20. D'AMICO, A. Canine teeth - normal function relation of natural teeth of man. J. Calif. Dent Ass., v. 26, p.127-42, 1958.

21. DAHL, B.L. et al. Signs and symptoms of craniomandibular disorders in two groups of 19-year-old individuals, one treated orthodontically and other nor. Acta odont. scand., v.46, n.2, p.89-93, Mar. 1988. 
22. DAHLBERG, G. et al. Disk displacement and temporomandibular joint symptoms in orthognathic surgery patients. Oral Surg., v.79, p.273-7, 1995.

23. DAWSON, P.E. Temporomandibular joint pain-dysfunction can be solved. J. prosth. Dent., v.29, n.3, p.100-12, Oct. 1973.

24. DE BOEVER, J.O.; ADRIAENS, P.A. Occlusal relationship in patients with pain-dysfunction symptoms in temporomandibular joints. J. oral Rehab., v.10, n.1, p.1-7, Jan. 1983.

25. DONEGAN, S.J.; CHRISTENSEN,L.V.; MC KAY,D.C. Canine tooth guidance and temporomandibular joint sounds in non-patients and patients. J. oral Rehab., v.23, n.12, p.799-804, Dec. 1996.

26. DROUKAS, B.; LINDEE, C.; CARLSSON, G.E. Relationship between occlusal factors and signs and symptoms of mandibular dysfunction. Acta odont. Scand., v.42, n.5, p.277-83, Oct.1984.

27. DWORKIN, S.F.; LE RESCHE, L. Research diagnostic criteria for temporomandibular disorders: review, criteria, examinations and specifications, critique. J. craniomandibular. dis. fac. oral pain, v.6, n.4, p.301-6, 1992.

28. DWORKIN, S.F. et al. Epidemiology of signs and symptoms in temporomandibular disorders: clinical in cases and controls. J. Amer. dent. Ass., v.120, n.3, p.273-81, Mar. 1990.

29. EGERMARK-ERIKSSON, I.; RÖNNERMAN, A. Temporomandibular disorders in the active phase of orthodontic treatment. J. oral Rehab., v.22, n.8, p.613-8, Aug. 1995. 
30. EGERMARK-ERIKSSON, I.; THILANDER, B. Craniomandibular disorders with special reference to orthodontic treatment: an evaluation from childhood to adulthood. Amer. J. Orthodont. Dentofac. Orthop. v.101, n.1, p.28-34, Jan. 1992.

31. EGERMARK-ERIKSSON, I.; CARLSSON, G.E.; MAGNUSSON, T. A longTerm epidemiolgic study of the relationship between occlusal factors and mandibular dysfunction in children and adolescents. J. dent. Res., v.66, n.1, p.67-71, Jan. 1987.

32. EGERMARK-ERIKSSON, I.; MAGNUSSON, T.; CARLSSON, G.E. A 20year follow-up of signs and symptoms of temporomandibular disorders and malocclusions in subjects with and without orthodontic treatment in childhood. Angle Orthodont., v.73, n.2, p.109-15, April, 2003.

33. EGERMARK-ERIKSSON, l.; et al. A longitudinal study on malocclusion in relation to signs and symptoms of cranio-mandibular disorders in children and adolescents. Europ. J. Orthodont., v.12, n.4, p. 399-407, Nov. 1990.

34. FIENERMAN, D.M.; PIECUCH, J.F. Long-term effects of orthognathic surgery on the temporomandibular joint: comparison of rigid and nonrigid fixation methods. Int. J. oral Maxillofac. Surg., v.24, n.4, p.268-72, Aug. 1995.

35. FONSÊCA, D.M. Disfunção craniomandibular (DCM) - elaboração de índice anamnésico. Bauru, 1992. 116p. Dissertação (Mestrado) Faculdade de Odontologia de Bauru, Universidade de São Paulo. 
36. FREDRIKSSON, L.; ALSTERGREN, P.; KOPP, S. Absolute and relative facial pressure-pain threshold in healthy individuals. J. Orofac. pain, v.14, n.2, p.98-104, 2000.

37. FUJII, T. The relationship between the occlusal interference side and the symptomatic side in the temporomandibular disorders. J. oral. Rehab., v.30, n.3, p.295-300, Mar. 2003

38. GEERING, A.H. Occlusal interferences and functional disturbances of masticatory system. J. clin. Periodont., v.1, n.2, p.112-9, 1974.

39. GIDARAKOU, I.K. et al. Comparison of skeletal and dental morphology in asymptomatic volunteers and symptomatic patients with bilateral disk displacement with reduction. Angle Orthodont., v.72, n.6, p.541-6, Dec. 2002.

40. GIDARAKOU, I.K. et al. Comparison of skeletal and dental morphology in asymptomatic volunteers and symptomatic patients with unilateral disk displacement without reduction. Angle Orthodont., v.73, n.2, p.121-7, April. 2003.

41. GOSS, A.N. The myofascial pain dysfunction syndrome. I. A etiology and diagnosis. N.Z.dent.J., v.70, p.192-8, July 1974.

42. GREENE, C.S. Orthodontics and temporomandibular disorders. Dent. Clin. N. Amer., v.32, n.3, p.529-38, July 1988.

43. GRIFFITHS, R.H. Report of the president's conference on examination, diagnosis and manegement of temporomandibular disorders. J. Amer. dent. Ass., v.107, n.6, p.932-6, Dec. 1983. 
44. HANS, M.G. et al. A comparison of clinical examination, history, andmagnetic resonance imaging for identiying orthodontic patients with temporomandibular joint disorders. Amer. J. Orthodont. Dentofac. Orthop. v.101, n.1, p.54-9, Jan.1992.

45. HARAGUCHI, S.; TAKADA, K.; YASUDA, Y. Facial asymmetry in subjects with skeletal class III deformity. Angle Orthodont., v.72, n.1, p.28-35, Feb. 2002.

46. HEIKINHEIMO, K. et al. A longitudinal study of occlusal interferences and signs of craniomandibular disorder at the ages of 12 and 15 years. Europ. J. Orthodont., v.12, n.2, p.190-7, May 1990.

47. HELKIMO, M. Studies on function and dysfunction of the masticatory system. I - an epidemiological investigation of symptoms of dysfunction in lapps in north of Finland. Proc. Fin. dent. Soc., v.70, n.4, p.37-49, Apr. 1974.

48. HELKIMO, M. Studies on function and dysfunction of the masticatory system. II - Index for anamnesic and clinical dysfunction and occlusal state. Sven Tandlak Tidskr., v.67, n.2, p.101-21, Mar. 1974.

49. HELKIMO, M. Studies on function and dysfunction of the masticatory system. III - Analyses of anamnesic and clinical recordings of dysfunction with the aid of indices. Sven Tandlak Tidskr., v.67, n.3, p.165-81, May 1974. 
50. HELKIMO, M. Studies on function and dysfunction of the masticatory system. IV - age and Sex distribuition of symptoms of dysfunction of the masticatory system in lapps in the north of Finland. Acta odont. scand., v.32, n.4, p.255-67, 1974.

51. HENRIKSSON, T.; EKBERG, E.C.; NILNER, M. Symptoms and signs of temporomandibular disorders in girls with normal occlusion and class II malocclusion. Acta odont. scand., v.55, n.4, p.229- 35, Aug. 1997.

52. HENRIKSSON, T.; NILNER, M.; KUROL, J. Symptoms and signs of temporomandibular disorders before, during and after orthodontic treatment. Swed. dent. J., v.26, n.5-6, p.193-207, 1999.

53. HESSE, J.R.; VAN LOON, L.A.J.; NAEIJE, M. Subjective pain report and the outcome of several orthopedic tests in craniomandibular disorder patients with recent pain complaints. J.oral Rehab., v.24, p.483-9, 1997.

54. HOPPENREIJS, T.J.M. et. al. Long-term evaluation of patients with progressive condylar resorption following orthognathic surgery. Int. J. oral Maxillofac. Surg., v.28, n.6, p.411-8, Dec. 1999

55. HU, J.; WANG, D.; ZOU, S. Effects of mandibular setback on the temporomandibular joint: a comparison of oblique and sagittal splint ramus ostectomy. J. oral Maxillofac. Surg., v. 58, n.4, p.375-81, Apr. 2000.

56. HWANG, H.S.; BEHRENTS, R.G. The effect of orthodontic treatment on centric discrepancy. J. Cranio Practice. , v.14, n.2, p.132-7, Apr. 1996. 
57. INGERVALL, B.; CARLSSON, G.E. Masticatory muscle activity before and elimination of balancing side occlusal interference. J. oral Rehab., v.9, n.3, p.183-92, May 1982.

58. JANSON, G.R.P.; MARTINS, D.R. Análise funcional e ajuste oclusal em ortodontia: estudo clínico. Ortodontia, v.23, n.1, p.4-15. 1990.

59. KARLSON, S.; CHO, S.A.; CARLSSON, G.E. Changes in mandibular masticatory movements after insertion of nonworking-side interference. J. craniomandibular Disord., v.13, n.4, p.177-83, Mar. 1992.

60. KEB, K.; BAKOPULOS, K.; WITT, E. TMJ function with and without orthodontic treatment. Europ. J. Orthodont. v.13, n.3, p.192-6, June 1991.

61. KEELING, S.D. et al. Risk factors associated with temporomandibular joint in children 6 to 12 years of age. Amer. J. Orthodont. Dentofac. Orthop., v.105, n.3, p.279-87, Mar. 1994.

62. KIM, M.; GRABER, T.M.; VIANA, M.A. Orthodontics and temporomandibular disorder: a meta-analysis. Amer. J. Orthodont. Dentofac. Orthop., v.121, n.5, p.438-46, May, 2002.

63. KIRVESKARI, P.; ALANEN, P.; JÄMSA, T. Association between craniomandibular disorders and occlusal interferences. J. prosth. Dent., v.62, n.1, p.66-9, July 1989.

64. KOBAYASHI, T. et al. Temporomandibular joint symptoms and disc displacement in patients with mandibular prognathism. Br. J. oral Maxillofac. Surg., v.37, n.6, p.455-8, Dec. 1999. 
65. KORIOTH, T.W.P. Number and location of occlusal contacts in intercuspal position. J. prosth. Dent., v.64, p.206-10, 1990.

66. KREMNAK, C.R. et al. Orthodontic risk factors for temporomandibular disorders (TMD). II. Amer. J. Orthodont. Dentofac. Orthop. v.101, n.1, p.21-7, Jan. 1992.

67. KVINNSLAND, S.; KVINNSLAND, I.; KRISTIANSEN, A.B. Effect of experimental traumatic occlusion in blood flow in the temporomandibular joint of the rat. Acta odont. scand., v.51, n.5, p.293-8, Oct. 1993.

68. LASKIN, D.M. Etiology of the pain-dysfunction syndrome. J. Amer. dent. Ass., v.79, n.6, p.147-53, July 1969.

69. LASKIN, D.M.; RYAN, W.A.; GREENE, C.S. Incidence of temporomandibular symptoms in patients with major skeletal malocclusions: a survey of oral and maxilofacial surgery training programs. Oral Surg. Oral Med. Oral Pathol., v. 61, n.6, June, 1986

70. LIEBERMAN, M.A. et al. Mandibular dysfunction in 10-18 year old school children as related to morphological malocclusion. J. oral Rehab., v.13, n.3, p.209-14, May/June 1985.

71. LIPP, M.J. Temporomandibular symptoms and occlusion: a review of the literature e the concept. N. Y. St. dent. J., p.58-66, Nov. 1990.

72. LIST, T. et al. TMD in children and adolescents: prevalence of pain, gender differences, and perceived treatment need. J. Orofac. pain, v.13, n.1, p.9-20, 1999. 
73. LONG, J.H. Locating centric relation with a leaf gauge. J. prosth. Dent., v.29, p. 608-10, 1973.

74. LUCIA, V.O. Centric relation: theory and practice. J. prosth. Dent., v.10, p.849-56, 1960.

75. LUTHER, F.; MORTH,M.S. Orthodontics and the temporomandibular joint: where are we now? Part 2. Functional occlusion, malocclusion, and TMD. Angle Orthodont., v.68, n.4, p.305-18, Aug. 1998.

76. MAGNUSSON, T.; ENBON, L. Signs and symptoms of mandibular dysfunction after introduction of experimental balancing-side interferences. Acta odont. scand., v.42, p.129-35, 1984.

77. MAGNUSSON, T.; CARLSSON,G.E.; EGERMARK-ERIKSSON,I. Changes in clinical signs of craniomandibular disorders from the age of 15 to 25 years. J. Orofac. pain, v.8, n.2, p.207-15, Spring 1994.

78. MAGNUSSON, T.; EGERMARK-ERIKSSON, I.; CARLSSON, G.E. Fiveyear longitudinal study of signs and symptoms of mandibular dysfunction in adolescents. J. craniomandibular pratc., v.4, n.4, p.339-43, Oct. 1986.

79. MCNAMARA, J.A.; SELIGMAN, D.A.; OKESSON, J.P. Occlusion, orthodontic treatment, and temporomandibular disorders: a review. J. Orofac. pain., v.9, n.1, p.73-90, Winter 1995.

80. MCNEILL, C. Ciência e prática da oclusão. São Paulo, Quintessence, 2000. 
81. MCNEILL, C. Craniomandibular (TMJ) disorders - the state of the art. J. prosth. Dent., v.44, p.434, 1980.

82. MCNEILL, C. Craniomandibular disorders - guidelines for evaluation, diagnosis, and management $I$ The American Academy of Craniomandibular disorders. Chicago, Quintessence, 1990.

83. MENDONÇA NETO, T. Avaliação da magnitude das interferências oclusais e sua relação com os sinais clínicos de trauma oclusal e sinais e sintomas de desordens temporomandibulares. Bauru 2003. 96p. Dissertação (Mestrado) - Faculdade de Odontologia de Bauru, Universidade de São Paulo.

84. MOHLIN, B. Prevalence of mandibular dysfunction and relation between malocclusion and mandibular dysfunction in a group of women in Sweden. Europ. J. Orthodont., v.4, p.115-23, 1983.

85. MOHLIN, B.; INGERVALL, B.; THILANDER, B. Relation between malocclusion and mandibular dysfunction in Swedish men. Europ. J. Orthodont., v.2, n.4, p.229-38, 1980.

86. MOLIN,C. et al. Frequency of symptoms of mandibular dysfunction in young swedish men. J. oral Rehab., v.3, n.1, p.9-18, Jan. 1976.

87. MUTO, T. et al. Relationship between disc displacement and morphologic features of skeletal Class III malocclusion. Int. J. Adult Orthod. Orthognat. Surg., v.13, n.2, p.145-51, 1998. 
88. NAGAMINE, T.; KOBAYASHI, T.; NAKAJIMA, T.; HANADA, K. The effects of surgical-orthodontic correction of skeletal class III malocclusion on mandibular movement. J. oral Maxillofac. Surg., v.51, n.4, p.385-9, Apr. 1993.

89. NEBBE, B.; MAJOR, P.W. Prevalence of TMJ disc displacement in a preorthodontic adolescent sample. Angle Orthodont., v.70, n.6, p.454-63, Dec. 2000.

90. NILNER, M. Relationships between oral parafunctions and functional disturbances and diseases of the stomatognathic system among 15 - to - 18 year olds. Acta odont. scand.,v.41, p.197-201, 1983.

91. OKESON, J.P. Management of temporomandibular disorders and occlusion. 4.ed. St Louis, Mosby, 1998.

92. OKESON, J.P. Orofacial Pain. Guidelines for assessment, diagnosis and management. Quintessence Publishing Co., 1996.

93. OLSSON, M.; LINDQVIST,B. Mandibular function before orthodontic treatment. Europ. J. Orthodont., v.14, n.1, p.61-8, Feb. 1992.

94. PANULA, K. et al. Effects of orthognathic surgery on temporomandibular joint dysfunction. Int. J. oral Maxillofac. Surg., v.29, p.183-7, 2000.

95. PULLINGER, A.G.; SELIGMAN,D.A. Overbite and overjet characteristics of refined diagnostic groups of temporomandibular disorder patients. Amer. J. Orthodont. Dentofac. Orthop., v.100, n.5, p.401-15,1991. 
96. PULLINGER, A.G.; SELIGMAN,D.A. Quantification and validation of predictive values of occlusal variables in temporomandibular disorders using a multifactorial analysis. J. prosth. Dent., v.83, n.1, p.66-75, Jan. 2000.

97. PULLINGER. A.D.; SELIGMAN, D.A; SOLBERG. W.K. Temporomandibular disorders. part I: functional status, dentomorphologic features, and sex differences in a no patients population. J. prosth. Dent., v.59, n.2, p.22835, Feb. 1988.

98. PULLINGER. A.D.; SELIGMAN, D.A; SOLBERG. W.K. Temporomandibular disorders. part II: occlusal factors associated with temporomandibular joint tenderness and dysfunction. J. prosth. Dent., v.59, n.3, p.363-7, Mar. 1988.

99. PULLINGER, A.G. et al. Relationship of mandibular condilar position to dental occlusion factors in an asymptomatic population. Amer. J. Orthodont. Dentofac. Orthop., v.91, n.3, p.200-6, Mar. 1987.

100. RENDELL, J.K.; NORTON, L.A.; GAY, T. Orthodontic treatment and temporomandibular joint disorders. Amer. J. Orthodont. Dentofac. Orthop., v.101, n.1, p.84-7, Jan. 1992.

101. RIEDER, C.E.; MARTINOFF, J.T.; WILCOX, S.A. The prevalence of mandibular dysfunction. Part I: Sex and age distribution of related signs and symtoms. J. prosth. Dent., v.50, n.1, p.81-8, July 1983.

102. RIISE, C.; ERICSSON, S.G. A clinical study of occlusal tooth contacts in the intercuspal position at light and hard pressure in adults. J. oral Reab., v.10, n.6, p.473-80, Nov. 1983. 
103. RIOLO, M.L.; BRANDT, D.; TENHAVE, T.R. Associations between occlusal characteristics and signs and symptoms of TMJ dysfunction in children and young adults. Amer. J. Orthodont. Dentofac. Orthop., v.92, n.6, p.467-77, Dec. 1987.

104. RUGH, J.D.; SOLBERG, W.K. Oral health status in the United States: temporomandibular disorders. J. dent. Educ., v.49, n.6, p.398-405, June 1985.

105. SADOWSKY, C. The risk of orthodontic treatment for producing temporomandibular mandibular disorders: a literature overview. Amer. J. Orthodont. Dentofac. Orthop., v.101, n.1, p.79-83, Jan. 1992.

106. SADOWSKY, C.; BEGOLE, E.A. Long-term status of temporomandibular joint function and functional occlusion after orthodontic treatment. Amer. J. Orthodont. Dentofac. Orthop., v.78, n.2, p.201-12, Aug. 1980.

107. SADOWSKY, D.; POLSON, A.M. Temporomandibular disorders and functional occlusion after orthodontic treatment: results of two long-term studies. Amer. J. Orthodont. Dentofac. Orthop., v.86,n.5, p.386-90, Nov.1984.

108. SANROMÁN, J.F.; GONZÁLEZ, J.M.G.; HOYO, J.A. Relationship between condilar position, dentofacial deformity and temporomandibular joint dysfunction: an mri and ct prospective study. J. Maxillofac. Surg., v26, p.35-42, 1997.

109. SANROMÁN, J.F. et al. Morphometric and morphological changes in the temporomandibular joint after orthognathic surgery: a magnetic resonance imaging and computed tomography prospective study. $\mathbf{J}$. Maxillofac. Surg., v.25, p.139-48, 1997. 
110. SANTOS SILVA, R.S. Determinação do intervalo de pressão necessário para estimular resposta dolorosa em pacientes com DTM de origem miogênica. Bauru - 2003. 126p. Dissertação (Mestrado) - Faculdade de Odontologia de Bauru, Universidade de São Paulo.

111. SCHWARTZ, L. Pain associated with the temporomandibular joint. J. Amer. dent. Ass., v.51, n.10, p.394-401, Oct. 1955.

112. SELIGMAN, D.A.; PULLINGER, A.G. The role of functional occlusal relationship in temporomandibular disorders: a review. J. craniomandibular dis. fac. oral pain., v.5, n.4, p.265-79, 1991.

113. SELIGMAN, D.A.; PULLINGER, A.G. The role of intercuspal occlusal relationship in temporomandibular disorders: a review. J. craniomandibular dis. fac. oral pain., v.5, n.2, p.96-106, 1991.

114. SELIGMAN, D.A.; PULLINGER, A.G.; SOLBERG, W.K. Temporomandibular disorders. Part III: occlusal and articular factors associated with muscle tenderness. J. prosth. Dent., v.59, n.4, p.483-9, Apr. 1988.

115. SEREN, E. et al. An evaluation of the condilar position of the temporomandibular joint by computerized tomography in Class III malocclusion: a preliminary study. Amer. J. Orthodont. Dentofac. Orthop., v.105, n.5, p.483-8, May 1994.

116. SILVA FILHO, O.G.; FREITAS, S.F.; CAVASSAN, A.O. Prevalência de oclusão normal e má oclusão em escolares da cidade de Bauru (São Paulo) parte I: relação sagital. Rev. Odont. Bauru, v.4, n.2, p.130-7, abr./jun. 1990. 
117. SOLBERG, W.K. TMD - physical test in diagnosis. Brit. Dent. J., v.160, n.4, p.273-7, Apr. 1986.

118. SOLBERG, W.K.; WOO, M.W.; HOUSTON, J.B. Prevalence of mandibular dysfunction in young adults. J. Amer. dent. Assoc., v.98, n.1, p.25-34, Jan. 1979.

119. UEKI, K. et al Temporomandibular joint morphology and disc position in skeletal class III patients. J. Maxillofac. Surg., v. 28, n.6, p.362-8, Dec. 2000.

120. UEKI, K.; et al. Condylar and temporomandibular joint disc positions after mandibular osteotomy for prognathism. J. oral Maxillofac Surg., v.60, n.12, p.1424-32, Dec. 2002.

121. VALLE-COROTTI, K.M. et al. Estudo comparativo da oclusão e da sua relação com as Disfunções Temporomandibulares (DTM) em jovens com e sem tratamento ortodôntico Rev. Dental Press Ortodon. Ortop. Facial, v.8, n.6, p.61-71, nov./dez. 2003.

122. VIEIRA, M.M.; PAURA, A.C. A disfunção da articulação temporomandibular na oclusão normal e na mal-oclusão dentária. Ortodontia, v.32, n.1, p.18-28, jan./abr. 1999.

123. VLACHOS, C.C. Occlusal principles in orthodontics. Dent. Clin. N. Amer. v.39, n.2, p.363-78, Apr. 1995.

124. WADHWA, L.; UTREJA, A.; TEWARI, A. A study of clinical signs and symptoms of temporomandibular dysfunction in subjects with normal occlusion, untreated, and treated malocclusions. Amer. J. Orthodont. Dentofac. Orthop., v.103, n.2, p.54-61, Jan. 1993. 
125. WÄNMAN, A.; AGERBERG, G. Etiology of craniomandibular disorders: evaluation of some occlusal and psychosocial factors in 19-year-olds. J. craniomandibular dis. fac. oral pain, v.5, n.1, p.35-44, 1990.

126. WATANABE, E.K. et al. The relationship between signs and symptoms of temporomandibular disorders and bilateral occlusal contact patterns during lateral excursions. J. oral Rehab., v.25,n.6, p.409-15, Jun. 1998.

127. WESTLING, L. Occlusal interferences in retruded contact position and temporomandibular joint sounds. J. oral Rehab., v.22, n.8, p.601-6, Aug. 1995.

128. WIGDOROWICZ-MAKOWEROWA, N. et al. Epidemiologic studies on prevalence and etiology of functional disturbances of the masticatory system. J. prosth. Dent., v.41, n.1, p.76-82, Jan. 1979.

129. WYATT, W.E. Preventing adverse effects on the temporomandibular joint through orthodontic treatment. Amer. J. Orthodont. Dentofac. Orthop., v.91, n.6, p.493-9, June 1987. 
ABSTRACT 


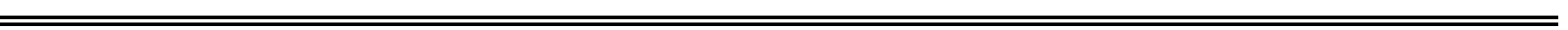

\begin{abstract}
The aim of this study was to evaluate the prevalence of Temporomandibular Disorders (TMD) in individuals after Class III orthodontic treatment. The sample consisted of 50 individuals divided into two groups, according to the type of treatment (orthodontic or orthodontic with orthognathic surgery). The presence of signs and symptoms of TMD were evaluated by an anamnestic questionnaire and a clinical examination, including TMJ and muscle palpation, active mandibular range of motion, joint noises and occlusal examination. Based on the anamnestic questionnaire, $42 \%$ was considered as having mild TMD, while $10 \%$ had moderate TMD. The presence and severity of TMD did not show any relationship with the type of orthodontic treatment. A positive association, by qui square test $(p<0,05)$ was found between TMD and nonworking side contacts. Based on that, it was concluded that Class III orthodontic treatment is not associated with the presence of signs and symptoms of TMD.
\end{abstract}

